UNIVERSIDADE DE SÃO PAULO
HOSPITAL DE REABILITAÇÃO DE ANOMALIAS CRANIOFACIAIS

KARINA COSTA BROSCO MENDES

Percepção da fala, linguagem oral e qualidade de vida em indivíduos com síndromes genéticas usuários de implante coclear 
KARINA COSTA BROSCO MENDES

\title{
Percepção da fala, linguagem oral e qualidade de vida em indivíduos com síndromes genéticas usuários de implante coclear
}

\begin{abstract}
Tese apresentada ao Hospital de Reabilitação de Anomalias Craniofaciais da Universidade de São para obtenção do título de Doutor em Ciências da Reabilitação, na área de concentração Fissuras Orofaciais e Anomalias Relacionadas.
\end{abstract}

Orientadora: Profa. Dra. Ana Paula Fukushiro Coorientadora: Profa. Dra. Kátia de Freitas Alvarenga 


\section{Mendes, Karina Costa Brosco}

Percepção da fala, linguagem oral e qualidade de vida em indivíduos com síndromes genéticas usuários de implante coclear / Karina Costa Brosco Mendes. -- Bauru, 2020.

134 p. : il. ; $31 \mathrm{~cm}$.

Tese (doutorado) -- Hospital de Reabilitação de Anomalias Craniofaciais, Universidade de São Paulo, 2020.

Orientadora: Profa. Dra. Ana Paula Fukushiro

Coorientadora: Profa. Dra. Kátia de Freitas Alvarenga

Autorizo, exclusivamente para fins acadêmicos e científicos, a reprodução total ou parcial desta tese, por processos fotocopiadores e outros meios eletrônicos.

Karina Costa Brosco Mendes

Data:

Comitê de Ética do HRAC-USP

CAAE: 02881918.6.0000.5441

Data: $29 / 11 / 2018$ 
ERRATA 
FOLHA DE APROVAÇÃO 


\section{DEDICATÓRIA}

Dedico este trabalho a Dra. Maria Cecília Bevilacqua (in memoriam) uma pessoa muito especial, que sempre foi e sempre será minha inspiração e referência na audiologia.

Ela que me fez conhecer a fonoaudiologia, amar e dedicar à audiologia. Sempre aconselhou-me e apoiou-me em todas as situações e escolhas, orientou-me, guiou-me e incentivou-me a chegar até aqui, fazendo-me acreditar que seria capaz!

Com sua força, carisma, inteligência, dedicação e amor tornou-se meu maior exemplo de vida!

Muito Obrigada!

Saudades eternas.... 


\section{AGRADECIMENTOS ESPECIAIS}

Agradeço imensamente à minha família querida e abençoada. Presente de Deus na minha vida! Razão de minhas conquistas, força, perseverança e do meu viver!!

Agradeço aos meus três filhos: Gabriela, Guilherme e Bruno pela paciência, amor, abdicação e colaboração durante essa trajetória!! Vocês alimentam minha alma, me dão força e esperança.

Ao meu esposo Geraldo agradeço pelo companheirismo constante, compreensão, amor incondicional, cuidado diário, paciência e principalmente incentivo.

À minha rainha e mãe Maria Costa, meu exemplo de vida! Obrigada por sua grande colaboração neste trabalho, por sempre estar ao meu lado, me fazer acreditar que sou forte e capaz de tudo superar! 


\section{AGRADECIMENTOS}

À minha orientadora Profa. Dra. Ana Paula Fukushiro, muito obrigada pela oportunidade de crescimento profissional e pessoal, pela total confiança, paciência, apoio em todos os momentos, principalmente nos mais difíceis, motivando e colaborando comigo durante toda minha trajetória na pós-graduação.

À Profa. Dra. Kátia de Freitas Alvarenga agradeço por compartilhar sua vasta experiência na área da audiologia, disponibilidade e colaboração no meu crescimento pessoal e profissional.

Ao Prof. Dr. Luiz Fernando Manzone Lourençone agradeço pelo apoio, compreensão e colaboração neste trabalho e em minha caminhada profissional.

À Dra. Jerusa Roberta Massola de Oliveira meus agradecimentos pela amizade, incansável dedicação, imenso apoio e ensinamentos durante toda a minha jornada neste trabalho. Minha eterna gratidão!

Aos profissionais, colegas de trabalho da SIC do HRAC-USP meus agradecimentos pelo companheirismo, apoio, motivação e colaboração neste trabalho.

À Dra. Flávia M. R. Neves Cintra muito obrigada pela atenção e colaboração na análise estatística.

À coordenação, professores e profissionais do setor de PósGraduação do HRAC-USP meus agradecimentos pela dedicação, colaboração e apoio durante toda minha trajetória da pós-graduação. 
"Quando não podemos mais mudar uma situação, somos desafiados a mudar a nós mesmos."

Viktor Frankl

"A mente que se abre a uma nova ideia, jamais voltará ao seu tamanho original."

Albert Einstein 


\section{RESUMO}

Introdução: É consenso entre os pesquisadores que o implante coclear (IC) traz como benefícios o desenvolvimento da percepção da fala e linguagem oral para indivíduos com deficiência auditiva, propiciando melhor qualidade de vida a essa população, todavia na literatura existem poucos estudos que revelam o impacto do IC para indivíduos que apresentam síndrome genética associada à deficiência auditiva. Assim, é necessário o desenvolvimento de novos estudos para proporcionar maior detalhamento e melhor entendimento do impacto da utilização desse dispositivo nesta população específica. Objetivo: Caracterizar o desenvolvimento da percepção da fala e da linguagem oral de indivíduos com síndromes genéticas usuários de IC, verificar o impacto desse dispositivo na qualidade de vida, na perspectiva do indivíduo adulto e da família das crianças, bem como analisar a correlação entre a idade na cirurgia e o tempo de uso do dispositivo com a percepção da fala e linguagem oral, de acordo com a síndrome genética. Metodologia: Delineamento com estudo longitudinal com dados retrospectivos quanto à análise da percepção da fala e linguagem oral, por meio dos testes GASP, categorias de audição e de linguagem. Estudo transversal prospectivo quanto à análise da qualidade de vida, por meio dos questionários Children with cochlear implants: parental perspectives (CCIPP) e Nijmegen Cochlear Implantation Questionnaire (NCIQ). Casuística de 30 indivíduos, distribuídos entre 9 síndromes genéticas com deficiência auditiva bilateral sensorioneural de grau severo a profundo, sendo 22 do sexo masculino e 8 do sexo feminino, com várias faixas etárias, usuários de IC unilateral e bilateral. Resultados: Houve variabilidade de resultados de percepção da fala e linguagem oral, principalmente na presença de limitações sensoriais e cognitivas, conforme as características de cada síndrome. A idade na cirurgia do IC, após a manifestação da deficiência auditiva, para a maioria dos participantes foi precoce, bem como o tempo de uso do dispositivo satisfatório. Para a síndrome de Waardenburg não houve diferença significante entre a idade na cirurgia do IC e as variáveis percepção da fala e linguagem oral, mas observou-se significância entre a idade e o tempo de uso do IC. Quanto aos resultados da avaliação na qualidade de vida, a influência do IC apresentou impacto variável, porém eficaz, com destaque para os domínios de relação social, autonomia/autoconfiança e funcionalidade, no CCIPP, e nos subdomínios percepção básica de sons, percepção avançada dos sons, produção de fala e autoestima, no NCIQ. Conclusão: $O$ desenvolvimento da percepção da fala e da linguagem oral dos indivíduos com síndromes genéticas, usuários de IC, mostraram-se satisfatórios para os casos que não apresentavam limitações motoras, sensoriais e cognitivas. Especificamente para indivíduos com síndrome de Waardenburg, a idade na cirurgia do IC não interferiu nas variáveis percepção da fala e linguagem oral, mas o tempo de uso foi determinante. Nas demais síndromes constatou-se variabilidade na percepção da fala, linguagem oral, idade na cirurgia do IC e tempo de uso do dispositivo nos indivíduos com deficiência auditiva de ocorrência peri e pós-lingual. O IC é considerado um método eficaz de habilitação/reabilitação auditiva e foi capaz de proporcionar melhor qualidade de vida aos usuários com síndromes genéticas.

Palavras-chave: Perda auditiva. Genética. Implante coclear. Percepção da fala. Qualidade de vida. 


\section{ABSTRACT \\ Speech perception, oral language and quality of life in individuals with genetic syndromes using cochlear implant}

Introduction: Is consensus among researchers that cochlear implant bring benefits to the development of speech perception and oral language for individuals with hearing impairment, providing a better quality of life for this population, however in the literature there are few studies that reveal the impact of cochlear implant for individuals with genetic syndrome associated with hearing loss. Thus, it is necessary to develop new studies to provide greater detail and better understanding of the impact of using this device on this specific population. Objective: To characterize the development of speech perception and oral language of individuals with genetic syndromes who use cochlear implant to verify the impact of this device on quality of life, from the perspective of the adult individual and the children's family, as well as to analyze the correlation between the age at surgery and time of use of the device with the perception of speech and oral language, according to the genetic syndrome. Methodology: Design with a longitudinal study with retrospective data regarding the analysis of speech perception and oral language through the GASP tests, hearing categories and language. Prospective cross-sectional study regarding the analysis of quality of life, using the Children with cochlear implants: parental perspectives (CCIPP) and Nijmegen Cochlear Implantation Questionnaire (NCIQ) questionnaires. Casuistic of 30 individuals, distributed among 9 genetic syndromes with severe to profound bilateral sensorineural hearing loss, 22 males and 8 females, with various age groups, users of unilateral and bilateral cochlear implant. Results: There was variability in the results of speech perception and oral language, especially in the presence of sensory and cognitive limitations, according to the characteristics of each syndrome. The age at cochlear implant surgery, after the hearing loss manifestation, for most participants was early, as well as the time of use of the device was satisfactory. For Waardenburg's syndrome, there was no significant difference between age at cochlear implant surgery and the variables speech perception and oral language, but there was a significant difference between age and the time of cochlear implant use. Regarding the results of the assessment on quality of life, the cochlear implant influence had a variable, but effective impact, with emphasis on the domains of social relationship, autonomy/selfconfidence and functionality, in the CCIPP, and in the subdomains basic perception of sounds, advanced perception of sounds, speech production and self-esteem, at NCIQ. Conclusion: The development of speech perception and oral language of individuals with genetic syndromes, users of cochlear implant, proved to be satisfactory for cases that did not have motor, sensory and cognitive limitations. Specifically for individuals with Waardenburg syndrome, the age at cochlear implant surgery did not affect the speech perception and oral language variables, but the time of use was decisive. In the other syndromes, there was variability in speech perception, oral language, age at cochlear implant surgery and time of use of the device in individuals with peri- and post-lingual hearing loss. The cochlear implant is considered an effective method of auditory habilitation/rehabilitation and was able to provide a better quality of life to users with genetic syndromes.

Keywords: Hearing loss. Genetics. Cochlear implant. Speech perception. Quality of life. 


\section{LISTA DE FIGURAS}

Figura 1 - Dados quanto a idade na cirurgia de implante coclear (em anos) e o tempo de uso do dispositivo (em anos) nos 13 participantes com síndrome de Waardenburg

Figura 2 - Dados quanto ao teste de percepção da fala nos participantes com síndrome de Waardenburg - Protocolo GASP

Figura 3 - Dados quanto ao teste de percepção da fala nos participantes com síndrome de Waardenburg - Protocolo Delgado

Figura 4 - Dados quanto ao teste de percepção da fala nos participantes com síndrome de Waardenburg - Protocolo Sentenças do Dia a Dia (situações silêncio e ruído) 64

Figura 5 - Dados quanto à idade na cirurgia do implante coclear (em anos) e o tempo de uso do dispositivo (em anos) nos participantes com síndrome de Usher

Figura 6 - Dados quanto ao teste de percepção da fala nos participantes com síndrome de Usher - Protocolo Delgado e GASP 66

Figura 7 - Dados quanto ao teste de percepção da fala nos participantes com síndrome de Usher - Protocolo Sentenças do dia a dia (situações silêncio e ruído).

Figura 8 - Dados quanto à comparação das categorias de audição entre os participantes com síndromes de Waardenburg e Usher 68

Figura 9 - Dados quanto à comparação das categorias de linguagem entre os participantes com as síndromes de Waardenburg $(n=13)$ e Usher $(n=6)$

Figura 10 - Dados quanto à percepção da qualidade de vida na perspectiva dos pais de crianças com síndrome genética usuárias de implante coclear, por meio dos domínios do questionário $\operatorname{CCIPP}(n=21)$.

Figura 11 - Dados quanto à da percepção da qualidade de vida na perspectiva dos indivíduos adultos com síndrome genética usuárias de implante coclear, por meio dos subdomínios do questionário $\mathrm{NCIQ}(\mathrm{n}=9)$ 


\section{LISTA DE QUADROS}

Quadro 1-Acompanhamento dos retornos de pacientes implantados no HRAC-USP

Quadro 2 - Descrição das categorias de audição de acordo com o proposto por Geers (1994)

Quadro 3 - Descrição das categorias de linguagem propostas por Bevilacqua, Delgado e Moret (1996) 53

Quadro 4 - Descrição de dados sociodemográficos e as variáveis estudadas em participantes com síndrome genética usuários de implante coclear 60

Quadro 5 - Informações adicionais dos participantes com síndrome genética usuários de implante coclear 61

Quadro 6 - Dados quanto à percepção da fala e linguagem oral atual dos três participantes pós-linguais com síndrome de Usher

Quadro 7 - Dados quanto à percepção da fala e linguagem oral atual dos participantes com deficiência auditiva pré-lingual com outras síndromes genéticas .70

Quadro 8 - Dados quanto à percepção da fala e linguagem oral atual dos participantes peri e pós-linguais com outras síndromes genéticas 


\section{LISTA DE TABELAS}

Tabela 1 - Correlação entre a idade na cirurgia de implante coclear com percepção da fala e linguagem oral atual nos participantes com síndrome de Waardenburg....

Tabela 2 - Correlação entre tempo de uso do dispositivo com a percepção da fala e linguagem oral atual nos participantes com síndrome de Waardenburg 


\section{LISTA DE ABREVIATURAS E SIGLAS}
AASI Aparelho de Amplificação Sonora Individual
CCIPP Children with cochlear implants: parental perspectives
CEP Comitê de Ética em Pesquisa
dB Decibel
dBNA Nível de audição
dBNPS Nível de pressão sonora
DNPM Desenvolvimento neuropsicomotor
FM Frequência Modulada
FOB Faculdade de Odontologia de Bauru
GASP Procedimento para Avaliação de Crianças Deficientes Auditivas
HRAC Hospital de Reabilitação de Anomalias Craniofaciais
IC Implante Coclear
IT-MAIS Infant-Toddler: Meaningful Auditory Integration Scale
Libras Língua Brasileira de Sinais
MUSS Meaningful Use of Speech Scale
NCIQ Nijmegen Cochlear Implantation Questionnaire
PANS Perda auditiva não sindrômica
PAS Perda auditiva sindrômica
S/R Sinal/Ruído
SIC Seção de Implante Coclear
SIH Serviço de Informática Hospitalar
SU Síndrome de Usher
SUS Sistema Único de Saúde
SW Síndrome de Waardenburg
USP Universidade de São Paulo 


\section{SUMÁRIO}

1 INTRODUÇÃO

2 REVISÃO DE LITERATURA

2.1 IMPLANTE COCLEAR, PERCEPÇÃO DA FALA E LINGUAGEM

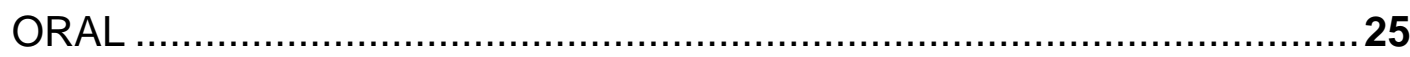

2.2 IMPLANTE COCLEAR NAS SÍNDROMES GENÉTICAS .......................27

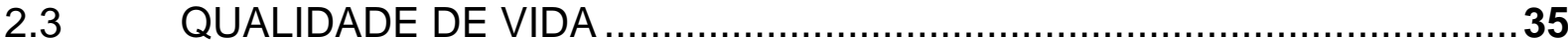

3 OBJETIVOS

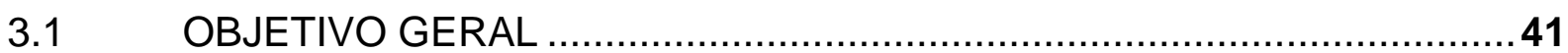

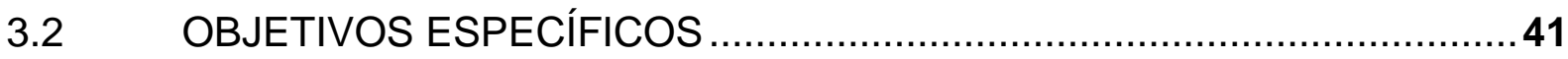

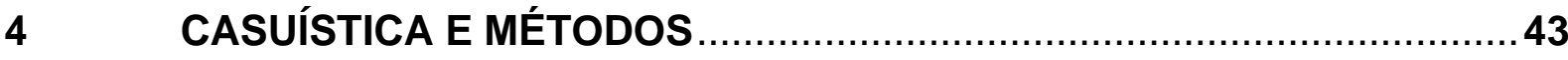

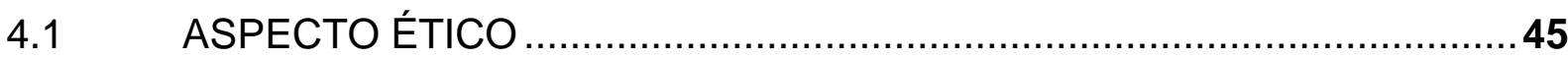

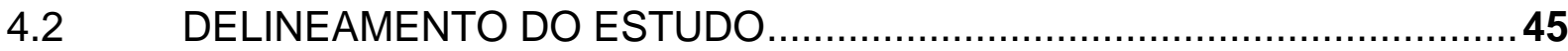

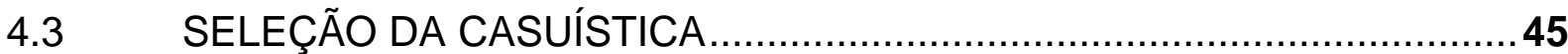

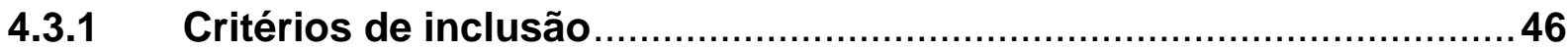

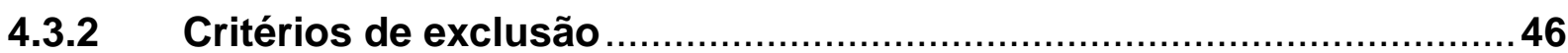

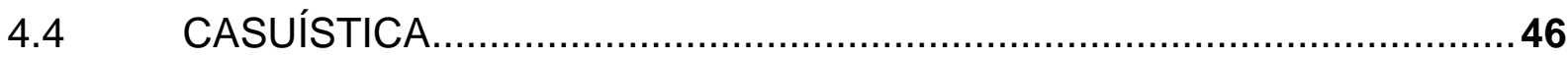

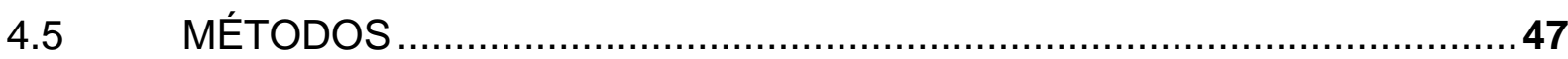

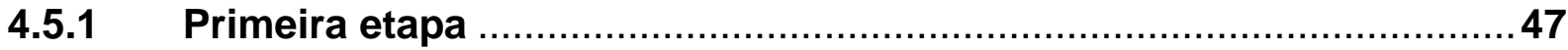

4.5.1.1 Dados da audição da criança com deficiência auditiva.............................48

4.5.1.2 Dados da audição do indivíduo adulto com deficiência auditiva ................51

4.5.1.3 Dados de linguagem oral na criança deficiente auditiva .........................53

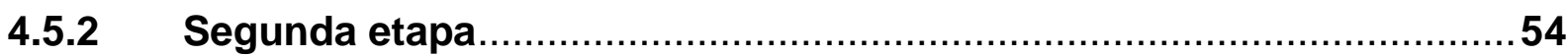

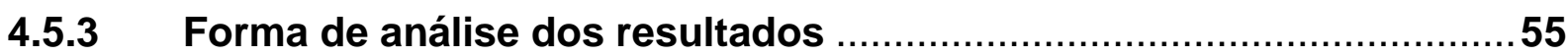

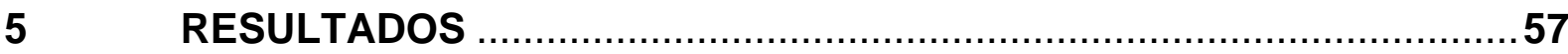

5.1 RESULTADOS REFERENTE A PERCEPÇÃO DA FALA E LINGUAGEM ORAL ATUAL DOS INDIVÍDUOS COM SÍNDROMES GENÉTICAS USUÁRIOS DE IMPLANTE COCLEAR.

5.2 RESULTADOS REFERENTE A QUALIDADE DE VIDA DOS INDIVÍDUOS COM SÍNDROMES GENÉTICAS USUÁRIOS DE

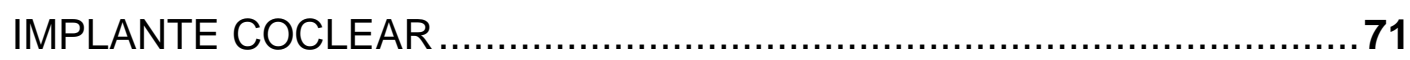

6 DISCUSSÃO 


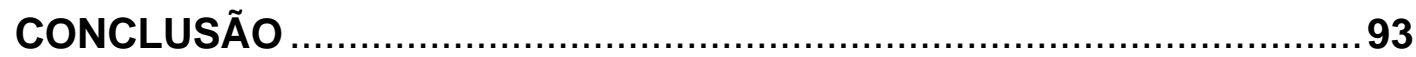

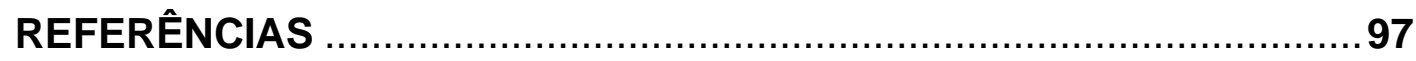

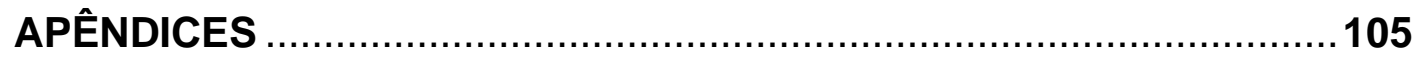

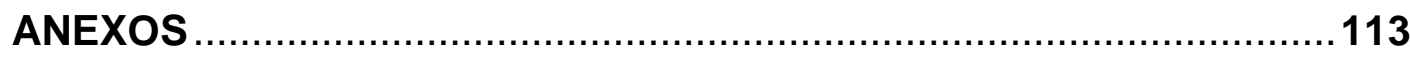


1 INTRQDUÇÃ 



\section{INTRODUÇÃO}

A audição é um dos sentidos fundamentais para a aquisição, desenvolvimento da linguagem oral e seu comprometimento pode trazer consequências, limitações e desajustes na vida do indivíduo. Segundo Coelho et al. (2009) e Martins et al. (2012), dentre as consequências de uma perda auditiva estão as limitações sociais, emocionais, intelectuais, educacionais e de linguagem, com transtornos na comunicação relacionados à fala e voz.

Segundo Godinho, Keogh e Eavey (2003), quando a perda auditiva congênita ocorre como um sistema isolado, esta é referida como perda auditiva não sindrômica (PANS), sendo responsável por $70 \%$ das perdas auditivas genéticas. Quando está associada a outros sintomas, é referida como perda auditiva sindrômica (PAS). Assim, cerca de $30 \%$ das perdas auditivas genéticas podem estar associadas a uma síndrome e, aproximadamente, 400 síndromes estão associadas à deficiência auditiva. À semelhança da PANS, a perda auditiva em pacientes sindrômicos pode ser considerada condutiva, mista ou sensorioneural.

Para auxiliar o processo terapêutico de indivíduos com síndromes associadas à perda auditiva tem-se o Implante Coclear (IC), o qual é um dispositivo eletrônico implantado cirurgicamente na cóclea, sendo indicado em indivíduos que apresentam perdas auditivas de grau severo e/ou profundo, incapazes de se beneficiarem com 0 aparelho de amplificação sonora individual (AASI). Esse dispositivo tem se mostrado um método efetivo na reabilitação dessa população (BENTO et al., 2004; BEVILACQUA; MORET; COSTA, 2011; FORTUNATOTAVARES et al., 2012; BARNARD et al., 2015). No Brasil, o IC tornou-se acessível aos serviços públicos de saúde por meio da Portaria ํo 1.278, de 20 de outubro de 1999, hoje substituída pela oㅡ 2.776, de 18 de dezembro de 2014. Esta Portaria incorporou a indicação e realização cirúrgica dessas próteses nos centros de saúde auditiva credenciados e habilitados pelo Sistema Único de Saúde (SUS), permitindo o acesso a toda população.

Apesar de ser considerado uma das opções de tratamento para crianças deficientes auditivas sensorioneurais pré-linguais, o IC não se trata simplesmente de um procedimento cirúrgico após o qual a criança pode ser conduzida, exclusivamente, por seu próprio dispositivo eletrônico (DOWELL; COWAN, 1997; O'NEILL et al., 2002). 
De acordo com Moret (2002), a indicação do IC em crianças se constitui em um processo multifatorial que ocorre basicamente em três fases distintas: na avaliação pré-cirúrgica; no ato cirúrgico e no acompanhamento, sendo neste último incluído o monitoramento do dispositivo, ou seja, verificação de seu funcionamento, programação adequada e a (re)habilitação contínua. Essas fases são formadas por aspectos que se interagem, como a idade da criança na ativação, tempo de surdez, cognição da criança e tempo de uso do dispositivo. Além disso, a participação da família, terapia fonoaudiológica especializada e potencial cognitivo da criança para a aprendizagem também devem ser destacados (ROBBINS; GREEN; BOLLARD, 2000; GEERS, 2002; BEVILACQUA; COSTA; AMANTINI, 2005). Para Magalhães et al. (2013), os resultados com o IC dependem de vários fatores que conduzem a um bom prognóstico, como o diagnóstico e intervenção precoce, reabilitação sistemática, permeabilidade familiar e tipo de comunicação, bem como outros fatores relacionados à perda auditiva, incluindo etiologia, período de surdez e presença de outras deficiências associadas a um quadro de síndrome genética.

Neste cenário, surgem alguns questionamentos como: Será que os sinais e sintomas adicionais à perda auditiva sensorioneural, que os pacientes com síndrome genética apresentam, dificultam obter os benefícios que a tecnologia do IC proporciona? Os benefícios obtidos com o IC trariam melhor qualidade de vida aos indivíduos com deficiência auditiva associada a uma síndrome genética?

Na literatura há escassez de resultados do IC em indivíduos portadores de síndromes genéticas, sendo que alguns estudos relatam sucesso limitado, na dependência das características associadas à síndrome e à idade em que foi realizado o IC. Neste sentido, o objeto de pesquisa do presente estudo visou a caracterização do desenvolvimento da percepção da fala ${ }^{1}$, da linguagem oral em indivíduos com síndromes genéticas usuários de IC, bem como, o impacto desse dispositivo na qualidade de vida, a fim de auxiliar na reabilitação de sua comunicação oral, além de contribuir para o avanço dos estudos nesta área.

A hipótese desta pesquisa concentrou-se na concepção de que o uso do IC pode ter influência na percepção da fala, linguagem oral, como também, na

\footnotetext{
1 Os termos percepção auditiva da fala e percepção da fala são encontrados na literatura científica, porém, padronizou-se para este estudo o termo percepção da fala.
} 
qualidade de vida para indivíduos que apresentam deficiência auditiva no quadro de síndrome genética.

Conhecendo-se os benefícios da atuação da fonoaudiologia integrada à genética, no processo de diagnóstico e intervenção dos distúrbios da comunicação associados às síndromes genéticas, espera-se colaborar na melhor caracterização e elaboração de programas de reabilitação específicos para essa população. 

2 REVISÃa DE LITERATURA 



\section{REVISÃO DE LITERATURA}

Inicialmente com 0 intuito de pesquisar na literatura nacional e internacional, foi realizado uma revisão sistematizada sobre o assunto a ser estudado, seguindo quatro etapas: identificação; seleção; elegibilidade e inclusão de acordo com o recomendado pelo Preferred Reporting Items for Systematic Reviews and MetaAnalyses (PRISMA) (LIBERATI et al., 2009), como apresentado no Apêndice A. No texto a seguir, encontram-se os estudos que subsidiaram as discussões dos resultados obtidos.

\subsection{IMPLANTE COCLEAR, PERCEPÇÃO DA FALA E LINGUAGEM ORAL}

Os benefícios proporcionados pelo IC são evidentes e sedimentados na literatura nacional e internacional, principalmente referente às habilidades de percepção da fala e da linguagem oral.

A literatura científica, no geral, concorda que o IC gera um impacto positivo na vida de seus usuários, principalmente nos aspectos referentes à comunicação, embora exista uma grande variabilidade de resultados (GEERS; BRENNER; DAVIDSON, 2003; RAY et al., 2006; WILSON; DORMAN, 2008).

O desenvolvimento das habilidades auditivas e da linguagem oral é demonstrado de forma variável entre as crianças usuárias de IC, onde nem todas alcançam os resultados esperados nos primeiros anos de uso do dispositivo. Autores como Costa, Bevilacqua e Tabanez (2006) destacaram que a privação auditiva quando surge antes da aquisição da linguagem restringe e compromete 0 desenvolvimento da linguagem oral, o desenvolvimento global e a qualidade de vida. Referiram que a realização do IC não se trata apenas de um procedimento cirúrgico, onde o usuário será conduzido apenas pelo seu dispositivo, e que existem variáveis que influenciam no seu desempenho.

As variáveis como tempo de uso diário do IC, habilidades cognitivas, qualidade da linguagem ofertada pelos pais e o acompanhamento periódico do dispositivo podem afetar o desenvolvimento da linguagem oral das crianças (DUNN et al., 2014). 
Moret, Bevilacqua e Costa (2007), em um estudo com 60 crianças portadoras de perda auditiva na fase pré-lingual usuárias de IC, descreveram 0 desempenho auditivo e de linguagem das mesmas e citaram alguns aspectos que influenciaram na evolução das Categorias de Audição e de Linguagem como: idade da criança na implantação; tempo de privação sensorial; tempo de uso do IC; grau de permeabilidade da família no processo terapêutico; o tipo de IC e a estratégia de codificação da fala utilizada.

Siagh (2018) descreveu seis fatores que influenciaram no desenvolvimento da percepção auditiva da fala de crianças usuárias de IC com no mínimo cinco anos de uso do dispositivo, e que não desenvolveram a habilidade de reconhecimento auditivo em conjunto aberto, sendo: fatores relacionados aos eletrodos; problemas com o mapeamento; interrupção do uso do IC; uso assistemático do dispositivo; faltas no acompanhamento pós-operatório; fatores relacionados a terapia fonoaudiológica e ao neurodesenvolvimento.

De acordo com Barnard et al. (2015) e Kirk e Hugins (2016), o resultado mais significante do IC é o reconhecimento auditivo, pois ele fornece as bases para o desenvolvimento das habilidades para a produção da fala, linguagem e alfabetização. Desta forma, avaliar a percepção da fala é fundamental para descrever o desempenho dos usuários de IC. Estudos sobre o desempenho de crianças aquém do esperado são restritos, e a determinação para um parâmetro de atraso é complexo.

A idade no implante é um aspecto que desperta interesse e é muito discutido entre os pesquisadores, pois a maioria das pesquisas apontaram que crianças que receberam o IC precocemente apresentaram melhores resultados no desenvolvimento das habilidades auditivas e de linguagem, alcançando uma melhor inteligibilidade de fala (NIPARKO et al., 2010; BEVILACQUA et al., 2014).

Além da importância da implantação precoce, os autores Colletti et al. (2011); Geers e Sedey (2011); Harris et al. (2013) reforçaram que o desenvolvimento cognitivo desempenha um papel importante no processo da aquisição da linguagem e que as habilidades cognitivas (memórias de curto prazo e memória de trabalho) interferem diretamente nos resultados de percepção da fala e da linguagem oral de crianças implantadas. 
A participação da família no processo de habilitação e reabilitação auditiva é fortemente discutida na literatura devido a sua importância. $\mathrm{O}$ ambiente e a família desempenham um papel fundamental no desenvolvimento das habilidades de linguagem das crianças implantadas durante o período sensível de desenvolvimento (SZAGUN; STUMPER, 2012).

A participação da família durante o processo terapêutico da criança com IC, que valorize a estimulação da audição e da linguagem oral foram enfatizados pelos autores Moog e Geers (2010), que igualmente ressaltaram o ingresso precoce no meio acadêmico, proporcionando um impacto positivo para o desenvolvimento da linguagem.

Black, Hickson e Black (2012) referiram em seus estudos que mesmo que uma criança implantada não alcance o desempenho desejado, ele pode ser considerado de sucesso, dependendo do prognóstico determinado pela análise dos fatores que o influenciam.

\subsection{IMPLANTE COCLEAR NAS SÍNDROMES GENÉTICAS}

Em estudo com a análise de 13 indivíduos diagnosticados com a síndrome de Usher (SU), em média aos 10 anos de idade, Loundon et al. (2003) verificaram melhora significante na percepção da fala em conjunto fechado, com evolução para reconhecimento de palavras em conjunto aberto após dois anos de uso do IC. Referente à produção da fala, os autores descreveram variação na evolução, desde nenhuma produção a produção de frases complexas entre os grupos estudados e a linguagem oral progrediu em todos os casos. Com o estudo, os autores afirmaram que os resultados do IC são indiscutíveis em crianças mais novas, estão ligados à precocidade do implante e que um diagnóstico precoce da SU contribui para a otimização da terapia fonoaudiológica.

O resultado do $\mathrm{IC}$ em crianças pré-linguais referente à linguagem receptiva e à inteligibilidade da fala é variável, e pode ser influenciado por diversos fatores que incluem a idade na cirurgia do IC, o ambiente educacional e provavelmente a etiologia (RAJPUT; BROWN; BAMIOU, 2003). Os autores confirmaram este posicionamento ao realizarem um estudo retrospectivo em 106 crianças com o objetivo de verificar a existência de relação entre a etiologia da perda auditiva, a melhora na inteligibilidade 
da fala e os escores de linguagem receptiva após o IC, ao considerar o sexo, a idade na cirurgia e o ambiente educacional. A etiologia da perda auditiva foi classificada como hereditária-sindrômica, hereditária-não sindrômica, intrauterina adquirida, adquirida-perinatal, adquirida-outra e desconhecida. Ao analisar especificamente 0 grupo com etiologia hereditária-sindrômica, formado por 16 crianças, sendo seis com Usher, duas com Jervell e Lange-Nielsen, uma com Goldenhar, duas com CHARGE e cinco com Waardenburg, que tiveram os escores de fala e de linguagem avaliados retrospectivamente em intervalos anuais (de 1 a 5 anos após o IC) observaram que estes apresentaram escores significativamente menores que o grupo não sindrômico. Referiram que crianças com problemas visuais, neurológicos e outras deficiências tendem a ter piores resultados de linguagem receptiva e inteligibilidade da fala do que crianças sem essas alterações. Adicionalmente, os autores observaram que os escores de inteligibilidade da fala foram significativamente melhores em crianças que estavam em um ambiente educacional oral. Destacaram que após o IC, a linguagem é produto de uma interação complexa entre fatores "internos", que podem estar relacionados à causa da perda auditiva e/ou à patologia associada, assim como, de fatores "externos" não diretamente relacionados à perda auditiva, a idade na cirurgia ou ao ambiente educacional.

Pennings et al. (2006) realizaram um estudo incluindo 14 indivíduos com diagnóstico de Usher tipo 1 com o objetivo de avaliar o desempenho audiológico e 0 benefício do IC por meio do nível de audição equivalente, das mudanças na qualidade de vida observadas no Inventário de Benefícios de Glasgow e do inventário de benefícios para crianças - Glasgow Children's Benefit Inventory. A idade na cirurgia do IC variou de três anos e meio a 30,4 anos de idade (média de idade: 10 anos). Os resultados demonstraram que a melhora no desempenho audiológico ocorreu em relação ao número de meses após o uso do $\mathrm{IC}$, que na maioria dos indivíduos com SU tipo I, o IC é benéfico quando realizado dentro da primeira e mesmo da segunda década de vida. Os questionários correlacionaram-se claramente com o desempenho audiológico em pacientes implantados com SU. Similar aos estudos precedentes, este evidenciou que o IC realizado precocemente conduz ao melhor desempenho audiológico e enfatizou também que os indivíduos com SU em uma idade mais jovem dificilmente experimentam problemas visuais e que, portanto, provavelmente usam seu córtex visual de forma semelhante que os sujeitos com visão normalmente fazem. 
Resultados de linguagem em crianças com IC, deficiência adicionais e de desenvolvimento, foram relatados em um estudo feito por Meinzen-Derr et al. (2010) com 20 indivíduos avaliados quanto à linguagem (receptiva e expressiva), somados a informações sobre estratégias de comunicação, escola, terapia e informação dos pais. A idade na identificação da perda auditiva, idade na cirurgia do IC e tipos de incapacidades também foram coletados. Os autores referiram que estudos sobre crianças com atraso cognitivo relataram ganhos mensuráveis pós-implante referente à percepção da fala, reconhecimento de palavras ou sentenças, embora o progresso seja frequentemente mais lento do que em crianças com IC sem o atraso. Informaram, ainda, que não se deve esperar que o progresso da linguagem entre crianças com desenvolvimento cognitivo mais baixo seja equivalente ao de crianças com desenvolvimento típico, e que a variação nas habilidades de linguagem entre crianças com atraso cognitivo tem se mostrado altamente correlacionada com a habilidade cognitiva geral ou específica. Destacaram que as medidas de qualidade de vida são considerações importantes para esse tipo de população onde nem todos conseguem atingir os objetivos de comunicação auditivo-oral. Um passo crítico é determinar melhor como as terapias e intervenções devem ser adaptadas para suprir as necessidades de aprendizagem dessas crianças.

Kontorinis et al. (2011) realizaram um estudo retrospectivo com 25 indivíduos com a síndrome de Waardenburg (SW) submetidos ao IC. Todos eram usuários efetivos de seus dispositivos e foram observadas dificuldades em seis pacientes (24\%) durante a reabilitação pós-implante como: distúrbios de concentração; aceitação; problemática do IC e cooperação limitada com os pedagogos. Os autores relataram que, considerando a inteligência normal nestes pacientes, esperava-se que os receptores de IC nessa síndrome tivessem um bom desempenho. Referiram que em um grupo de cinco pacientes, baixos escores de percepção da fala monossilábica (25\% e 40\%) foram observados, sendo dois em conjunto aberto. Do total, 18 apresentaram bom desempenho com o IC, sendo que nove alcançaram pontuações monossilábicas superiores a $80 \%$, apontando um excelente desempenho auditivo. Referiram que embora esses casos representassem exceção no desempenho satisfatório pós-implante alcançado, um resultado de audição menos favorável pode ser esperado em uma minoria de pacientes com SW. 
Analisando a mesma síndrome, Amirsalari et al. (2012) descreveram crianças com SW e perda auditiva de severa a profunda pré-lingual com IC para avaliar a correlação entre a síndrome e os resultados de fala, comparando-as a um grupo controle de crianças com perda auditiva sensorioneural, sem evidências de características dismórficas, anatômicas, comportamentais e de distúrbios de desenvolvimento. As concepções auditivas e de fala foram avaliadas por meio de categorias de escalas de percepção auditiva e testes de classificação de inteligibilidade de fala. A percepção auditiva e habilidades de fala foram avaliadas antes e 12 meses após o implante ter sido ativado e os resultados foram comparados entre os dois grupos. Trezentas e trinta e seis crianças foram inicialmente avaliadas, com seis casos de diagnóstico de SW. Observou-se significativa melhora nos escores das categorias de escalas de percepção auditiva e inteligibilidade da fala no acompanhamento de 12 meses após o IC, não havendo diferença significativa no resultado auditivo. No entanto, a diferença no resultado da fala foi significante entre SW e casos com perda auditiva pura. Ainda assim, concluíram que a presença da SW não é uma contraindicação para 0 IC, e que o dispositivo pode apoiar o desenvolvimento e facilitar as habilidades de comunicação da maioria das crianças com diversas deficiências.

Com resultados semelhantes quanto aos benefícios do IC, Pietola et al. (2012) estudaram crianças com SU, e verificaram que o benefício do dispositivo parece ser indiscutível, com a melhora do desempenho auditivo e da qualidade de vida, em indivíduos com SU tipo 1, quando implantados em idade mais precoce. Avaliaram, ainda, 19 indivíduos com SU tipo 3, com faixa etária de 19 a 47 anos e tempo de uso do dispositivo de 4 a 6 anos. As habilidades de percepção da fala foram comparadas em três diferentes intervalos de tempo para avaliar as mudanças no reconhecimento da fala que ocorreram ao longo do tempo. O Inventário de Benefícios de Glasgow e o Inventário de Estado de Saúde de Glasgow) foram utilizados para avaliar os efeitos dos problemas visuais e auditivos sobre a qualidade de vida dos pacientes. Os resultados mostraram que os pacientes com SU tipo 3 se beneficiaram com o IC, com reconhecimento da fala que variou de $33 \%$ a $52 \%$. A discriminação da fala, audição, bem como a idade no implante e a alteração na capacidade auditiva, variaram significativamente após o implante. Referente a qualidade de vida, os indivíduos com SU tipo 3 se beneficiaram do IC tanto quanto os pacientes implantados 
sem déficits visuais. O escore total dos questionários foi positivo, significando que os pacientes acreditaram que seu estado de saúde após a intervenção é melhor.

Ainda com relação à SU, Jatana et al. (2013) estudaram consecutivamente 26 indivíduos com a síndrome e uso de IC. O estudo abrangeu idade no diagnóstico e na cirurgia do IC, achados diagnósticos, nível de desempenho de fala e método de comunicação do último acompanhamento audiológico do IC. A idade média na cirurgia do implante foi de três anos e três meses. O implante foi bilateral em $46,2 \%$ dos pacientes e o tempo médio para o último acompanhamento foi de sete anos. Os testes de percepção de fala se diferenciaram e foram administrados com base na idade e nas habilidades de linguagem dos indivíduos e foram categorizadas com base no nível mais alto de desempenho obtido, no qual 92,3\% das crianças foram capazes de alcançar o nível de percepção da fala em conjunto aberto sobre os testes adequados à idade, e a modalidade de comunicação foi oral ou principalmente oral em $69,2 \%$ das crianças, no último acompanhamento.

O estudo acima também referiu que as mudanças que contribuíram para melhores resultados incluíam: ênfase em atingir uma idade mais jovem no IC; critérios audiológicos de candidatura mais amplos; implementação de programas universais de triagem auditiva neonatal; melhor tecnologia de implante; implementação de programas de intervenção precoce, incluindo serviços de habilitação auditiva; maior acesso a programas de reabilitação oral e implante bilateral. A reabilitação oral demonstrou ser um importante fator contribuinte para melhorar a percepção da fala, linguagem oral e os resultados de alfabetização de crianças implantadas. Para diminuir o impacto devastador de um distúrbio sensorial duplo, os autores enfatizaram que o desenvolvimento das habilidades auditivas e da linguagem oral é de grande importância para as crianças com SU e que o implante bilateral precoce, juntamente com uma reabilitação auditivo-oral, provavelmente permitirá que crianças com SU obtenham comunicação oral sem depender da linguagem de sinais.

Em análise retrospectiva de Bacciu et al. (2015), que objetivou avaliar o desempenho do IC em longo prazo, foram analisados 12 pacientes com diagnóstico de síndrome de Cogan, que receberam o IC. A presente síndrome tem como características alterações oculares, surdez e vertigem. A percepção da fala foi avaliada por meio de testes de reconhecimento com palavras e frases do cotidiano e os resultados foram coletados por três intervalos de tempos específicos: antes da 
cirurgia do IC; aos 12 meses pós-implante e após o mínimo de 5 anos de acompanhamento. A idade na cirurgia variou de 16 a 52 anos. Nos resultados, a média do reconhecimento de palavras em conjunto aberto pós-operatório (após 12 meses) para os 12 pacientes foi de $91,4 \%$ e a pontuação média de reconhecimento de sentenças foi de 93,1\%. Na avaliação pós-operatória de 5 anos, os escores médios de reconhecimento de palavras e sentenças foram de $94 \%$ e $96,3 \%$, respectivamente. Os bons resultados são explicados pelos autores provavelmente pelo fato de que todos os indivíduos eram jovens surdos progressivos, pós-linguais, que usaram próteses auditivas antes do implante, além da privação auditiva ter sido relativamente breve em todos os casos. Demonstraram que indivíduos com a síndrome tiveram benefícios significativos de reconhecimento da fala em conjunto aberto, a partir do IC, e permaneceram estáveis em longo prazo.

Van Nierop et al. (2016b) analisaram a percepção da fala de 14 crianças com SW, submetidas ao IC com idade igual ou inferior a 2 anos, sendo 06 delas com deficiências adicionais. Por meio de listas de palavras compostas por consoantevogal-consoante foneticamente balanceadas e a avaliação da linguagem utilizando The Reynell Developmental Language Scales, o grupo de crianças com SW foi comparado a um grupo de referência de crianças jovens surdas sem deficiências adicionais. As crianças com SW apresentaram a pontuação média de fonemas de $91 \%$ com uma diferença não significativa no escore de fonema de $2 \%$ com o grupo de referência. $O$ fator incapacidade adicional teve influência negativa significativa no escore de fonema, resultando em uma diferença de $25 \%$. As crianças com SW sem deficiências adicionais tiveram um escore médio de 0,87 que está dentro de um desvio de pontuação em crianças normalmente desenvolvidas com audição normal e as crianças com incapacidades adicionais alcançaram resultados variáveis e significativamente menores, tanto na percepção auditiva quanto no desenvolvimento da linguagem. Embora o adequado aconselhamento sobre deficiências adicionais concomitante à síndrome seja relevante, o IC foi considerado pelos autores como um bom método de reabilitação para crianças com SW e indicou desempenhos comparáveis na percepção da fala a longo prazo e na compreensão da linguagem entre as crianças implantadas com e sem a SW.

Em outro estudo dos mesmos autores (VAN NIEROP et al., 2016a), verificou-se o benefício do IC em 28 indivíduos com a síndrome de Pendred (21 
crianças e 7 adultos), que tem como característica a deficiência auditiva, o bócio e defeito da organização do iodo. A média de idade na cirurgia do IC nas crianças foi de seis anos de idade e nos adultos de 34 anos. Os escores no pós-operatório foram verificados em 12 meses para adultos, 36 meses para crianças e comparados com um grupo de referência com deficiência auditiva de causa desconhecida. Os escores médios dos fonemas das crianças foram de $91 \%$ e dos adultos $78 \%$. A qualidade de vida com o IC foi verificada por meio do Nijmegen Cochlear Implantation Questionnaire (NCIQ) e uma melhora significativa pós-implante foi encontrada em quatro dos seis subdomínios do questionário, a saber, percepção sonora básica, percepção sonora avançada, produção de fala e limitações de atividade. Os dois subdomínios não significativos foram autoestima e interação social. O estudo demonstrou, mais uma vez, que o IC proporcionou benefícios referente à percepção da fala e à qualidade de vida.

Quintana Mirabal et al. (2016) analisaram o resultado do IC em 42 indivíduos com perda auditiva severa a profunda, sendo 15 com SW e 27 com deficiência auditiva de causa genética não sindrômica, em um estudo descritivo transversal, por meio da percepção de vocábulos, dissílabos, audiometria tonal em campo livre e categorias de rendimento auditivo. Não foram encontradas diferenças significativas nos tempos médios entre o nascimento e o diagnóstico; diagnóstico e cirurgia, e entre o nascimento e o check-up evolutivo nos dois grupos estudados. No entanto, houve diferenças entre a idade no implante e o check-up evolutivo. Os resultados mostraram uma melhora na percepção dos sons para os dois grupos implantados e os autores concluíram que o IC é uma alternativa terapêutica válida para deficiência auditiva nas condições, mas o número de pacientes foi insuficiente para demonstrar significância estatística nas diferenças observadas no estudo.

Um estudo retrospectivo com 31 crianças com síndrome CHARGE e comprometimento auditivo associado, sendo $15 \mathrm{com}$ perda auditiva profunda foi realizado por Trevisi et al. (2016). Destes, sete realizaram o IC, dois foram candidatos e o restante foi acompanhado com AASI. O objetivo foi avaliar as características audiológicas em longo prazo e os resultados da reabilitação auditiva, utilizando respostas auditivas do tronco encefálico, audiometria condicionada de reforço visual, emissões otoacústicas por produto de distorção, timpanometria, estudo dos reflexos estapedianos e a eletrococleografia (em alguns casos), além de percentual e 
habilidades de linguagem expressiva aos 6, 12 e mais de 36 meses após a adaptação de AASI ou IC. Em três casos ocorria agenesia de nervo vestibulococlear, enquanto outros hipoplasia. A maioria das crianças apresentou algum atraso no desenvolvimento das habilidades cognitivas e motoras. A percepção de fala e os resultados de linguagem expressiva após reabilitação auditiva indicaram que não foram homogêneos, devido principalmente às diferentes deficiências associadas, como atraso de desenvolvimento, atraso intelectual e deficiência visual, mas a maioria demonstrou melhora nas respostas. Demonstraram melhora lenta, mas consistente, em suas habilidades perceptivas, obtendo discriminação verbal após um ano ou mais de uso. A compreensão de fala em conjunto aberto ocorreu em um caso e a linguagem oral foi severamente prejudicada na maioria dos casos, mesmo após longo período de acompanhamento, sugerindo a necessidade de formas alternativas de comunicação, somados à presença de prejuízos neuropsicológicos que devem ser considerados no planejamento reabilitativo personalizado.

Ainda em estudo com a síndrome CHARGE, Young et al. (2017) analisaram 12 crianças com a síndrome, que receberam o IC. Verificou-se as habilidades auditivas categorizadas em quatro níveis: achados de imagem do osso temporal; complicações; tempo para o surgimento da percepção da fala e o modo de comunicação expressiva. O estudo demonstrou que a percepção da fala melhorou com o IC em comparação ao pré-operatório em $83 \%$ das crianças, quatro crianças melhoraram para o nível auditivo 2 (detecção melhorada), três obtiveram o nível 3 (percepção em conjunto fechado), três apresentaram nível 4 (percepção de fala em conjunto aberto), duas crianças tiveram melhora mínima ou limitada. Os autores reforçaram que as habilidades auditivas podem se desenvolver lentamente em crianças com esta síndrome que recebem o IC, a maioria pode conseguir, no mínimo, melhor detecção de sons ou adquirir alguma habilidade de percepção da fala.

O resultado e a eficácia do IC foram avaliados por Alzhrani et al. (2018) em 25 crianças com deficiência auditiva, sendo 13 com síndromes genéticas Waardenburg $(n=2)$, Usher $(n=9)$ e Dandy-Walker $(n=2)$ e 12 do grupo controle, pareando-se idade no IC e uso do dispositivo, comparando-se as habilidades auditivas, a inteligibilidade de fala, os limiares tonais e o modo de comunicação. A média de idade na cirurgia dos participantes foi de 63 meses. Após o IC, todos realizaram efetivamente terapia de reabilitação por 3 anos. Os nove indivíduos com 
SU apresentaram excelentes resultados, com pontuação máxima na inteligibilidade da fala e categorias de escalas de percepção auditiva. Um dos dois sujeitos com SW teve um resultado positivo com uma pontuação alta de categorias de escalas de percepção auditiva e inteligibilidade da fala, posteriormente, ingressou em uma escola regular e o outro sujeito não apresentou melhora satisfatória, talvez por ter sido implantado tardiamente, após os 6 anos de idade. Na síndrome Dandy-Walker, apenas um indivíduo foi implantado e embora apresentasse um limiar auditivo de 20 dBNA pós-implante, os escores categorias de escalas de percepção auditiva e inteligibilidade da fala foram muito baixos e o paciente se comunicava por linguagem de sinais. As pontuações comparativamente baixas são justificadas pelos autores, provavelmente, pelo seu comparecimento irregular no programa de acompanhamento. $\mathrm{O}$ estudo concluiu que indivíduos com síndromes genéticas que recebem o IC podem alcançar níveis semelhantes de percepção auditiva e inteligibilidade de fala como seus pares sem síndrome e a presença desta não deve contra indicar o IC, pois tem impacto positivo na percepção sensorial desses indivíduos, assim como no seu estilo de vida. Os autores acreditam que a detecção e a intervenção precoces são a chave para o bom desempenho alcançado pelas crianças com síndromes e que a colaboração dos pais é importante para se obter excelentes resultados com o IC.

\subsection{QUALIDADE DE VIDA}

Qualidade de vida é um conceito dinâmico que sofre influência de diversas variáveis, tais como, condições sociais, ambiente, trabalho, saúde, entre outras. Portanto, é esperado que ao longo do tempo se modifique (PEREIRA; TEIXEIRA; SANTOS, 2012). Considerando o envolvimento de vários fatores, a avaliação desse aspecto só é possível por medidas subjetivas com questionários que abordam aspectos da funcionalidade, definindo um estado normal para certa idade, além de função social e seu desvio, ou morbidade (MINAYO; HARTS; BUSS, 2000).

Os benefícios obtidos com o uso do IC, vão além do desenvolvimento da audição, da linguagem oral, e tem motivado os pesquisadores a utilizar medidas de qualidade de vida. Warner-Czyz et al. (2011) afirmaram que o impacto do IC em crianças e adolescentes com deficiência auditiva severa ou profunda se estende para 
além de bons resultados na percepção e produção da fala, bem como no desenvolvimento da linguagem, englobam assuntos relacionados à saúde física e mental, ou seja, qualidade de vida. Os questionários específicos para sujeitos com IC, envolvendo aspectos como audição e conforto em ambientes, tempo de uso do IC, limitações em atividades, sentimento de frustração e constrangimento devem ser acrescidos para proporcionar o maior número de informações possíveis (benefícios clínicos) e permitir correlações entre essas informações (benefícios científicos).

Para O'Neill et al. (2004), a aplicação de questionários nos pais da população infantil usuária de IC permite checar as características de qualidade de vida da criança, dos pais, dos familiares e da interação entre todos eles.

Os pais são importantes críticos do processo de evolução da intervenção terapêutica de seus filhos. A satisfação dos pais é um marcador do desenvolvimento de seus filhos e demonstra que o uso do IC atinge ou supera as expectativas de intervenção (NIKOLOPOULOS et al., 2001; INCESULU; VURAL; ERKAM, 2003).

A utilização de instrumentos específicos para a avaliação da qualidade de vida em crianças usuárias de IC, permite a mensuração do impacto da deficiência auditiva e do uso do dispositivo, além dos limites das habilidades auditivas e de linguagem oral obtidas pelas medidas clínicas tradicionais. Tais resultados podem auxiliar no processo de intervenção, no processo da reabilitação de crianças com variabilidade de resultados pós-implante e no direcionamento de condutas profissionais (FORTUNATO-TAVARES et al., 2012). Concomitantemente, Geers (2004) e Thai-Van et al. (2010) referiram, em seus estudos, que conjuntamente a estimulação auditiva precoce, as medidas adequadas de habilitação com terapia fonoaudiológica baseada na abordagem aurioral e apoio familiar desempenham papel determinante no contato com os sons, no processo de aquisição e desenvolvimento da linguagem oral e na inserção e participação da criança em diversos ambientes. Isso resulta em melhora na autoconfiança, bem-estar, felicidade, autonomia, escolarização, socialização e qualidade de vida dessas crianças.

Ainda assim, poucos são os estudos disponíveis voltados à qualidade de vida principalmente em crianças nas situações naturais do cotidiano, no que se refere a funcionalidade da comunicação, as interações com 0 meio social, suas necessidades e desejos (MORET; BEVILACQUA; COSTA, 2007; MORETTIN et al., 2013). 
O efeito positivo na qualidade de vida das crianças e de suas famílias foi descrito em estudo de Almeida et al. (2015), no qual todos os domínios referentes à criança apresentaram melhoria de qualidade de vida após ativação do dispositivo. Os pais apresentaram maior satisfação em relação aos domínios autoconfiança e relações sociais, sugerindo que a audibilidade, proporcionada pelo $\mathrm{IC}$, associada à evolução das habilidades auditivas e linguísticas, trouxeram uma aceitação e postura positiva da criança com relação à suas competências e habilidades nas situações de comunicação e, consequentemente, a ampliação de suas relações sociais (com familiares e não familiares).

Em estudo realizado por Silva (2017), sobre a qualidade de vida de crianças implantadas por meio do instrumento Children with cochlear implants: parental perspectives (CCIPP), foi constatado que os benefícios do IC impactaram na diminuição da necessidade de suporte da família à criança, que o domínio social apresentou o impacto mais significativo, seguido dos domínios da comunicação, do funcionamento geral, da autoconfiança, da educação, do bem-estar e felicidade e dos efeitos do IC sobre a família.

No estudo em que o instrumento Nijmegen Cochlear Implantation Questionnaire (NCIQ) foi desenvolvido, Hinderink, Krabbe e Van Den Broek (2000) referiram aumento importante em suas pontuações, nos seis domínios. Melhora na qualidade de vida não somente para o domínio físico, mas também para o psicológico e social. A melhora mais significativa foi observada nos subdomínios da percepção básica e avançada dos sons pertencentes ao domínio físico, não havendo correlação positiva entre a pontuação dos seis domínios.

Da mesma forma, Sousa (2017) demonstrou em seu estudo referente a qualidade de vida em adultos usuários de IC, efeitos positivos para os diferentes aspectos e destacou que o domínio mais bem pontuado por meio do questionário $\mathrm{NCIQ}$ foi o social, seguido pelos domínios psicológicos e físicos. Destacou que as variáveis gênero, idade, tempo de IC, nível de instrução e condição de estimulação não influenciaram nos aspectos da qualidade de vida. 

3 口BJETIVDS 



\section{OBJETIVOS}

\subsection{OBJETIVO GERAL}

Caracterizar o desenvolvimento da percepção da fala e da linguagem oral de indivíduos com síndromes genéticas usuários de IC, assim como, verificar o impacto na qualidade de vida na perspectiva do indivíduo adulto ou da família das crianças.

\subsection{OBJETIVOS ESPECÍFICOS}

- Analisar a correlação entre a idade na cirurgia com a percepção da fala atual e linguagem oral atual, de acordo com a síndrome genética.

- Analisar a correlação entre o tempo de uso do dispositivo com a percepção da fala atual e linguagem oral atual, de acordo com a síndrome genética. 

4 CAsUÍSTICA E MÉTODOS 



\section{CASUÍSTICA E MÉTODOS}

\subsection{ASPECTO ÉTICO}

Esta pesquisa foi desenvolvida na Seção de Implante Coclear (SIC) do Hospital de Reabilitação de Anomalias Craniofaciais (HRAC) da Universidade de São Paulo (USP), após aprovação do Comitê de Ética em Pesquisa (CEP) em Seres Humanos da Instituição, CAAE: 02881918.6.0000.5441, parecer no 3.046.495 (Anexo A), contemplando a Resolução 466/2012, com anuência dos participantes, dos pais ou responsáveis pelas crianças (Apêndices $B$ e $C$ ).

\subsection{DELINEAMENTO DO ESTUDO}

O delineamento da pesquisa ocorreu em duas etapas realizadas. A primeira etapa tratou-se de um estudo longitudinal retrospectivo com dados levantados mediante a análise dos prontuários médicos com a casuística definida por conveniência. A segunda etapa, um estudo transversal prospectivo com aplicação de questionários compatíveis com a população estudada.

\subsection{SELEÇÃO DA CASUÍSTICA}

Previamente, realizou-se um levantamento no Serviço de Informática Hospitalar (SIH) do HRAC-USP para averiguar o número de indivíduos adultos e crianças que apresentavam síndrome genética associada à deficiência auditiva, submetidos à cirurgia de IC no período de maio de 1991 até setembro de 2018, na SIC-HRAC-USP. Após o levantamento realizou-se a análise dos dados dos prontuários para verificar se atendiam aos critérios de elegibilidade descritos a seguir. 


\subsubsection{Critérios de inclusão}

a) Estar regularmente matriculado na SIC-HRAC-USP;

b) apresentar diagnóstico associado ao quadro de deficiência auditiva de acometimento bilateral do tipo sensorioneural de grau severo à profundo, de acordo com World Health Organization (c2018);

c) ter realizado uso ininterrupto do IC por mais de 2/3 meses no primeiro ano;

d) apresentar bom funcionamento dos componentes internos e externos do IC durante a realização das avaliações audiológicas.

\subsubsection{Critérios de exclusão}

a) Ausentar-se do acompanhamento das rotinas do IC nos primeiros 2 anos de uso;

b) não realizar uso do IC ou utilizá-lo de forma assistemática;

c) dados de exames inexistentes ou insuficientes no prontuário médico.

\subsection{CASUÍSTICA}

A casuística foi composta por 30 indivíduos que contemplaram os critérios de elegibilidade sendo portadores de síndrome genética, diagnosticados com deficiência auditiva de acometimento bilateral do tipo sensorioneural de grau severo a profundo, de ocorrência pré, peri e pós-linguais. Esses indivíduos pertenciam ao sexo masculino $(n=22)$ e ao sexo feminino $(n=8)$, com várias faixas etárias, usuários de IC (uni e/ou bilateral). Especificamente nos casos de implante unilateral, alguns utilizavam AASI na orelha contralateral. 


\subsection{MÉTODOS}

\subsubsection{Primeira etapa}

A SIC possui prontuário padronizado para que possa servir como material de investigação e protocolo clínico determinado de avaliação e indicação do IC para indivíduos com deficiência auditiva, assim como para o acompanhamento dos usuários do IC. Deste modo, todos os dados foram coletados dos prontuários da SIC.

Para o manuseio dos dados dos prontuários, a autorização estava prevista no documento Termo de Consentimento Livre e Esclarecido, o qual foi assinado pelos participantes adultos, pelos pais ou responsáveis das crianças titulares do prontuário médico. Neste documento, o participante adulto, os pais ou responsáveis autorizaram o uso dos dados coletados e analisados para fins de estudos científicos. Os pesquisadores envolvidos nessa pesquisa também assinaram 0 Termo de Compromisso de Manuseio de Informações requisitado pelo CEP do HRAC-USP, se comprometendo a cumprir os termos legais conforme preconizam os Documentos Internacionais, a Resolução 466/12 do Conselho Nacional de Saúde do Ministério da Saúde.

De acordo com o protocolo da SIC-HRAC-USP, o acompanhamento para os retornos presenciais dos usuários após a ativação do IC ocorre como demonstrado no Quadro 1.

Quadro 1 - Acompanhamento dos retornos de pacientes implantados no HRAC-USP

\begin{tabular}{|c|c|c|}
\hline Retorno & $\begin{array}{c}\text { Tempo de uso do implante coclear } \\
\text { (meses) - criança }\end{array}$ & $\begin{array}{c}\text { Tempo de uso do implante coclear } \\
\text { (meses) - adulto }\end{array}$ \\
\hline & Ativação & Ativação \\
\hline 1 & 3 & 3 \\
\hline 2 & 6 & 6 \\
\hline 3 & 12 & 12 \\
\hline 4 & 18 & 24 \\
\hline 5 & 24 & 36 \\
\hline 6 & 36 & Bianual \\
\hline 7 & Bianual & - \\
\hline
\end{tabular}

Fonte: Elaborado pela autora. 
Desta forma, a análise dos dados dos prontuários médicos dos participantes considerou os atendimentos de acompanhamento nas etapas pré e póscirúrgica, desde o diagnóstico audiológico, primeiro momento após ativação até o último atendimento realizado na data da coleta da pesquisa em fevereiro de 2020. Por este motivo, o período de uso do dispositivo foi variável para cada usuário.

Foram analisados os dados dos resultados da percepção da fala e da linguagem oral obtidos por meio de procedimentos que compunham o protocolo de acompanhamento da SIC-HRAC-USP.

\subsubsection{Dados da audição da criança com deficiência auditiva}

Para classificar a categoria da audição que a criança se encontrava foi considerado seu desempenho nos testes de percepção da fala aplicados de acordo com a idade: Procedimento para Avaliação de Crianças Deficientes Auditivas Profundas GASP (BEVILACQUA; TECH, 1996); Lista de palavras como procedimento de avaliação da percepção da fala (DELGADO; BEVILACQUA, 1999) e Lista de Sentença do Dia a Dia da língua portuguesa (OLIVEIRA, 1992). As habilidades auditivas também foram analisadas por meio dos dados da Infant-Toddler: Meaningful Auditory Integration Scale - IT-MAIS/MAIS (CASTIQUINI; BEVILACQUA, 2000) e das Categorias de Audição (GEERS, 1994).

\section{- Procedimento para Avaliação de Crianças Deficientes Auditivas Profundas (GASP)}

Proposto por Bevilacqua e Tech (1996), neste procedimento são utilizadas as provas 1, 3, 4, 5 e 6, de acordo com o desempenho apresentado pela criança. A prova 1 avalia a detecção dos sons do Ling; a prova 3 avalia discriminação de vogais; prova 4 avalia a discriminação de extensão da vogal/a/; prova 5 verifica a habilidade de reconhecimento com a apresentação de 12 palavras, e finalmente a prova 6 avalia a habilidade de compreensão de dez sentenças. Em todas as provas, os acertos são contabilizados e convertidos em porcentagem, sendo o máximo $100 \%$. 


\section{- Lista de palavras como procedimento de avaliação da percepção da} fala

Procedimento proposto por Delgado e Bevilacqua (1999), para crianças deficientes auditivas com idade entre 5 a 10 anos. O estímulo de fala analisado constitui-se de 20 palavras dissílabas, com estrutura silábica cvcv (consoante - vogal consoante - vogal). Essas palavras são curtas e permitem a análise do padrão silábico consoante-vogal (cv), predominantemente na língua portuguesa. O procedimento é realizado em campo livre, pelo audiômetro, na intensidade de 70 dBNA. A lista de palavras é apresentada apenas uma vez, e sem o uso de frases introdutórias antes das palavras. As crianças são orientadas a repetirem as palavras sem fazer uso da leitura orofacial. As emissões das crianças são transcritas foneticamente pelo avaliador, sendo possível registrar os resultados e realizar 0 escore de reconhecimento de fonemas e palavras.

- Teste de reconhecimento de sentenças proposto por Oliveira (1992)

Este teste propõe a utilização de três listas de sentenças do cotidiano, apresentadas:

a) situação no silêncio: uma lista gravada com 20 sentenças afirmativas da língua portuguesa é apresentada no silêncio, em cabina acústica, por meio do audiômetro, na intensidade fixa de $60 \mathrm{~dB}$ a $0^{\circ}$ azimute. As 20 sentenças contêm de três a sete vocábulos fonológicos (palavraschave) em cada sentença, totalizando 100 palavras-chave em cada lista, apresentadas sem repetição. O escore é calculado somando-se o número de acertos das palavras-chave, sendo considerado escore máximo de 100\%;

b) situação no ruído: segue a mesma técnica do Reconhecimento de sentenças no silêncio, porém, a lista é gravada contendo 20 sentenças apresentadas junto ao ruído competitivo (ruído de festa "cocktail party"), na relação sinal/ruído de $+10 \mathrm{~dB}(\mathrm{~S} / \mathrm{R}+10 \mathrm{~dB})$ na mesma caixa acústica a $0^{\circ}$ azimute.

As sentenças do dia a dia são apresentadas em campo, a $0^{\circ}$ azimute, na intensidade fixa de 60 dBNA (70 dBNPS), com o participante a $60 \mathrm{~cm}$ do alto-falante, no silêncio e com ruído competitivo do tipo ruído de festa, apresentados na mesma 
caixa acústica que as sentenças, a 50 dBNA (60 dBNPS), de modo a ser obtida a relação sinal/ruído de $+10 \mathrm{~dB}$. A relação $S / R$ de $+10 \mathrm{~dB}$ foi definida a partir de estudo anterior realizado com pessoas com deficiência auditiva pós-lingual usuárias de IC que verificou que o escore sentenças foi alcançado na relação $S / R$ de $+10 \mathrm{~dB}$ (NASCIMENTO; BEVILACQUA, 2005). O avaliador explica cada etapa da avaliação, dando exemplos à viva voz para o participante e solicita que ele repita as sentenças. Cada lista é precedida pela apresentação de três sentenças para adaptação às condições de avaliação, cuja porcentagem de acerto não é computada.

As listas usadas para a avaliação da percepção da fala por meio do teste de reconhecimento de sentenças no silêncio e no ruído foram gravadas em estúdio, com locução masculina profissional, pela Cia. de Audio-Digital Mastering de São Paulo. A gravação foi produzida pelo Curso de Fonoaudiologia da Faculdade de Odontologia de Bauru da Universidade de São Paulo (FOB-USP), que disponibilizou o material de fala gravado em formato de arquivo MP3 para ser armazenado em computadores. O ruído competitivo, tipo ruído de festa, inclui energia sonora da fala e dos sons ambientais.

$\mathrm{Na}$ avaliação da percepção da fala, as sentenças e o ruído são apresentados por meio de um computador, no qual o material de fala e o ruído competitivo estão armazenados e acoplado a um audiômetro Madsen Astera Otometrics. O audiômetro está conectado a um amplificador em campo livre e a duas caixas acústicas. A avaliação da percepção da fala é realizada em cabina acústica de $2 \mathrm{~m} \times 2 \mathrm{~m}$, sendo que esse ambiente de teste é disponível na rotina ambulatorial da SIC-HRAC-USP e, submetido à calibração dos equipamentos semestralmente.

Para atribuir a categoria de audição que cada criança do estudo se encontrava foi considerado seu desempenho nos testes de percepção da fala aplicados de acordo com a faixa etária e a pontuação da escala IT-MAIS/MAIS (CASTIQUINI; BEVILACQUA, 2000), de acordo com as sete categorias propostas por Geers (1994), descritas no Quadro 2. 
Quadro 2 - Descrição das categorias de audição de acordo com o proposto por Geers (1994)

\begin{tabular}{|c|l|}
\hline Categoria & \multicolumn{1}{c|}{ Descrição } \\
\hline $\mathbf{0}$ & $\begin{array}{l}\text { Não detecta a fala - a criança não detecta a fala em situação de } \\
\text { conversação normal (limiar de detecção de fala acima de 65 dB). }\end{array}$ \\
\hline $\mathbf{1}$ & Detecção - a criança detecta a presença do sinal de fala. \\
\hline $\mathbf{2}$ & $\begin{array}{l}\text { Padrão de percepção - a criança diferencia palavras pelos traços supra } \\
\text { segmentares (duração, tonicidade, etc.). }\end{array}$ \\
\hline $\mathbf{3}$ & $\begin{array}{l}\text { Iniciando a identificação - a criança diferencia palavras em conjunto fechado } \\
\text { com base na informação fonética. }\end{array}$ \\
\hline $\mathbf{4}$ & $\begin{array}{l}\text { Identificação de palavras por meio do reconhecimento da vogal - a criança } \\
\text { distingue palavras em conjunto fechado que diferem primordialmente no } \\
\text { som da vogal. }\end{array}$ \\
\hline $\mathbf{5}$ & $\begin{array}{l}\text { Identificação de palavras por meio do reconhecimento da consoante - a } \\
\text { criança distingue palavras em conjunto fechado que tem o mesmo som da } \\
\text { vogal, mas com diferentes consoantes. }\end{array}$ \\
\hline $\mathbf{6}$ & $\begin{array}{l}\text { Reconhecimento de palavras em conjunto aberto - a criança é capaz de } \\
\text { ouvir palavras fora do contexto, extrair bastante informação fonêmica, } \\
\text { reconhecendo a palavra exclusivamente por meio da audição. }\end{array}$ \\
\hline
\end{tabular}

Fonte: GEERS, 1994.

\subsubsection{Dados da audição do indivíduo adulto com deficiência auditiva}

- Procedimento de avaliação da percepção da fala para adultos deficientes auditivos profundos

Adaptado do GASP, proposto por Bevilacqua e Tech (1996), no qual são utilizadas as provas de 1 a 5 , de acordo com o desempenho do indivíduo. A prova 1 avalia a detecção dos sons do Ling, prova 2 a discriminação do nome, prova 3 a discriminação da questão/afirmação, prova 4 a identificação da extensão vocabular, prova 5 a identificação da extensão das sentenças e a prova 6 a identificação das sentenças. Em todas as provas, os acertos são contabilizados e convertidos em porcentagem, sendo o máximo 100\%.

\section{- Reconhecimento de sentenças proposto por Oliveira (1992)}

Este teste propõe a utilização de três listas de sentenças do cotidiano, apresentadas: 
a) situação no silêncio: uma lista gravada com 20 sentenças afirmativas da língua portuguesa apresentada no silêncio, em cabina acústica, por meio de audiômetro, na intensidade fixa de $60 \mathrm{~dB}$ a $0^{\circ}$ azimute. As 20 sentenças contêm de três a sete vocábulos fonológicos (palavraschave) em cada sentença, totalizando 100 palavras-chave em cada lista, apresentadas sem repetição. O escore é calculado somando-se o número de acertos das palavras-chave, sendo considerado escore máximo de 100\%;

b) situação no ruído: segue a mesma técnica do Reconhecimento de sentenças no silêncio, porém, a lista é gravada contendo 20 sentenças apresentadas junto ao ruído competitivo (ruído de festa "cocktail party"), na relação sinal/ruído de $+10 \mathrm{~dB}(\mathrm{~S} / \mathrm{R}+10 \mathrm{~dB})$ na mesma caixa acústica a $0^{\circ}$ azimute.

As sentenças do dia a dia são apresentadas em campo, a $0^{\circ}$ azimute, na intensidade fixa de 60 dBNA (70 dBNPS), com o participante a $60 \mathrm{~cm}$ do alto-falante, no silêncio e com ruído competitivo do tipo ruído de festa, apresentados na mesma caixa acústica que as sentenças, a 50 dBNA (60 dBNPS), de modo a ser obtida a relação sinal/ruído de $+10 \mathrm{~dB}$. A relação $S / R$ de $+10 \mathrm{~dB}$ foi definida a partir de estudo anterior realizado com pessoas com deficiência auditiva pós-lingual usuárias de IC que verificou que o escore sentenças foi alcançado na relação $S / R$ de $+10 \mathrm{~dB}$ (NASCIMENTO; BEVILACQUA, 2005). O avaliador explica cada etapa da avaliação, dando exemplos à viva voz para o participante e solicita que ele repita as sentenças. Cada lista é precedida pela apresentação de três sentenças para adaptação às condições de avaliação, cuja porcentagem de acerto não é computada.

As listas usadas para a avaliação da percepção da fala por meio do teste de reconhecimento de sentenças no silêncio e no ruído foram gravadas em estúdio, com locução masculina profissional, pela Cia. de Audio-Digital Mastering de São Paulo. A gravação foi produzida pelo Curso de Fonoaudiologia da Faculdade de Odontologia de Bauru da Universidade de São Paulo (FOB-USP), que disponibilizou o material de fala gravado em formato de arquivo MP3 para ser armazenado em computadores. O ruído competitivo, tipo ruído de festa, inclui energia sonora da fala e dos sons ambientais. 
$\mathrm{Na}$ avaliação da percepção da fala, as sentenças e o ruído são apresentados por meio de um computador, no qual o material de fala e o ruído competitivo estão armazenados e acoplado a um audiômetro Madsen Astera Otometrics. O audiômetro está conectado a um amplificador em campo livre e a duas caixas acústicas. A avaliação da percepção da fala é realizada em cabina acústica de $2 \mathrm{~m} \times 2 \mathrm{~m}$, sendo que esse ambiente de teste é disponível na rotina ambulatorial da SIC-HRAC-USP e, submetido à calibração dos equipamentos semestralmente.

\subsubsection{Dados de linguagem oral na criança deficiente auditiva}

Para a análise das habilidades da fala (linguagem oral) das crianças deste estudo utilizou-se o questionário Meaningful Use of Speech Scale (MUSS) e as categorias de linguagem proposta por Bevilacqua, Delgado e Moret (1996). procedimento MUSS é uma ferramenta utilizada para analisar o progresso das habilidades de linguagem falada da criança. Foi elaborada por Robbins e Osberger (1991) e adaptado para o português brasileiro por Nascimento (1997). Consiste em uma entrevista estruturada com os pais com o objetivo de avaliar o uso da fala das crianças em situações cotidianas.

A classificação das habilidades de linguagem oral foi realizada com base nas cinco categorias que classificam o desenvolvimento da linguagem da criança proposta por Bevilacqua, Delgado e Moret (1996) e está descrita no Quadro 3.

Quadro 3 - Descrição das categorias de linguagem propostas por Bevilacqua, Delgado e Moret (1996)

\begin{tabular}{|c|l|}
\hline Categoria & \multicolumn{1}{c|}{ Descrição } \\
\hline 1 & A criança não fala e pode apresentar vocalizações indiferenciadas. \\
\hline 2 & Emissão de palavras isoladas: a criança fala apenas palavras isoladas. \\
\hline 3 & Emissão de frases simples: a criança constrói frases de duas ou três palavras. \\
\hline 4 & $\begin{array}{l}\text { Emissão de frases complexas: a criança constrói frase de quatro ou cinco } \\
\text { palavras, e inicia o uso de elementos conectivos. }\end{array}$ \\
\hline 5 & $\begin{array}{l}\text { Fluência: a criança constrói frases de mais de cinco palavras, usando } \\
\text { elementos conectivos, conjugando verbos, usando plurais, etc. É uma criança } \\
\text { fluente na linguagem oral. }\end{array}$ \\
\hline
\end{tabular}

Fonte: BEVILACQUA; DELGADO; MORET, 1996. 


\subsubsection{Segunda etapa}

Nesta etapa foi avaliado o impacto do uso do IC na qualidade de vida na perspectiva dos indivíduos adultos, dos pais ou responsáveis pelas crianças por meio de questionários.

Para os participantes adultos foi utilizado o questionário $\mathrm{NCIQ}$, desenvolvido por Hinderink, Krabbe e Van Den Broek (2000), traduzido e adaptado culturalmente para o Português Brasileiro por Santos, Couto e Martinho-Carvalho (2017) e para os pais ou responsáveis pelas crianças foi utilizado o questionário CCIPP desenvolvido por Archbold et al. (2002), traduzido, adaptado e validado para o Português Brasileiro por Fortunato-Tavares et al. (2012) (Anexos B e C). Os questionários foram aplicados no atendimento de acompanhamento da rotina do programa de IC.

O questionário CCIPP aplicado com os pais e/ou responsável da criança, contém 74 questões fornecidas com respostas de múltipla escolha em uma escala de cinco pontos de Likert: concordo plenamente (codificado como 5); concordo (= 4); não concordo nem discordo $(=3)$; discordo $(=2)$ e discordo totalmente $(=1)$. Das declarações contidas neste questionário, 46 são redigidas de forma positiva e 28 de forma negativa, divididas em 10 domínios voltados à criança e à família.

As perguntas contemplam os seguintes domínios: comunicação (5 itens); funcionamento geral (5 itens); autoconfiança (4 itens); bem-estar e felicidade (5 itens); relações sociais (8 itens); educação (8 itens); processo de implante (16 itens); efeitos do implante (6 itens); decisão do implante (10 itens) e apoio à criança (7 itens). Quanto maior a pontuação, mais positivo é o ponto de vista dos pais.

O questionário foi aplicado em uma sala silenciosa da SIC-HRAC-USP, na qual o CCIPP foi entregue aos pais e/ou responsável e dadas as orientações sobre o preenchimento. Os pais e/ou responsáveis responderam ao questionário sem a interferência do profissional. O tempo de preenchimento variou de acordo com a necessidade de cada participante, não ultrapassando 40 minutos.

As respostas foram pontuadas em uma escala de cinco pontos de Likert, conforme mencionado anteriormente. As respostas obtidas e registradas na folha foram transferidas para o banco de dados do software Parent Questionnaire Manager- Parents 
Views and Experiences Questionnaire Data Entry (ParQ120.exe.,version 1.02:ISVR Software, Copyright 2003), elaborado pela equipe da Ear Foundation e disponível para download pelos links: http://resource.isvr.soton.ac.uk/audiology/Software/ ou http://resource.isvr.soton.ac.uk/audiology/Software/ParQ120.htm.

O software codifica as questões com pontuação inversa ao questionário, ou seja, para a marcação "concordo plenamente" a pontuação corresponde a 1 ponto, "concordo" = 2 pontos, "não concordo nem discordo" = 3 pontos, "discordo" = 4 pontos e "discordo plenamente" = 5 pontos. A partir da soma dos pontos é atribuído a cada uma das declarações um valor percentual, e ao fim da análise transformado em um gráfico com a média percentual de respostas por domínio para cada participante. Quanto mais positivo o valor, maior é a relação entre a qualidade de vida e o uso do IC na perspectiva dos pais e/ou responsáveis. Quanto mais negativo o valor, menor a relação entre o uso do dispositivo e a qualidade de vida.

O questionário NCIQ é composto por 60 questões divididas em três domínios gerais, com seus respectivos subdomínios: físico (percepção básica do som, percepção avançada do som e produção de fala); psicológico (autoestima) e social (limitações em atividades e interação social), com 10 itens em cada subdomínio. Cada questão possui cinco alternativas de resposta, sendo que nas 55 primeiras questões as possíveis respostas são: 1 = nunca; 2 = às vezes; $3=$ regularmente; $4=$ geralmente e $5=$ sempre. As cinco questões finais possuem as respostas: $1=$ não; 2 = insatisfatório; 3= satisfatório; 4= bom e 5= muito bem. Há também, para todas as questões, uma sexta categoria de resposta, caso o item não seja considerado pertinente às condições do indivíduo (não aplicável). No mínimo, sete dos dez itens devem ser preenchidos para concluir um subdomínio específico. A pontuação para cada resposta em subdomínio é atribuída da seguinte forma: $(1=0 ; 2=25 ; 3=50 ; 4=75$ e $5=100)$. Depois de finalizada a soma de todos os itens de um subdomínio, divide-se o valor total pelo número de respostas completas.

\subsubsection{Forma de análise dos resultados}

Com relação ao tratamento estatístico foi utilizada na apresentação e análise dos dados obtidos, atribuídos à caracterização do desenvolvimento da percepção da fala e da linguagem oral atual de indivíduos com síndromes genéticas 
usuários de IC, a estatística descritiva das variáveis de estudo. Tais variáveis foram apresentadas em quadros, tabelas e gráficos com valores absolutos e em porcentagem.

Para representar o conjunto de dados sobre a verificação do impacto do IC na qualidade de vida na perspectiva do indivíduo adulto ou da família das crianças foi elaborado o diagrama de caixa (Box Plot), utilizando as referências de valores mínimos e máximos, primeiro e terceiro quartil, média e mediana e outliers.

A análise inferencial foi utilizada para a correlação entre a idade na cirurgia e o tempo de uso do IC, com as variáveis percepção da fala e linguagem oral, empregando o teste estatístico de Correlação de Spearman Rank Order Correlation, considerando-se o nível de significância $p \leq 0,05$. 
5 RESULTADDS 



\section{RESULTADOS}

Para melhor visualização, os resultados foram separados quanto à percepção da fala atual, linguagem oral atual e quanto à qualidade de vida dos indivíduos analisados. Para as síndromes de Waardenburg e Usher, os resultados foram, ainda, analisados separadamente em função da casuística.

\subsection{RESULTADOS REFERENTE A PERCEPÇÃO DA FALA E LINGUAGEM ORAL ATUAL DOS INDIVÍDUOS COM SÍNDROMES GENÉTICAS USUÁRIOS DE IMPLANTE COCLEAR}

O Quadro 4 disponibiliza a descrição sociodemográfica quanto à idade, sexo, síndrome genética, e as variáveis estudadas: idade na cirurgia do IC; tempo de uso do dispositivo; percepção da fala e linguagem oral atual, para cada indivíduo estudado. As informações adicionais referentes à deficiência auditiva pré, peri ou póslingual, desenvolvimento neuropsicomotor (DNPM), IC unilateral ou bilateral, assiduidade na fonoterapia e o tipo de ensino estão apresentadas no Quadro 5. 
Quadro 4 - Descrição de dados sociodemográficos e as variáveis estudadas em participantes com síndrome genética usuários de implante coclear

\begin{tabular}{|c|c|c|c|}
\hline \multirow[b]{2}{*}{ Participante } & \multicolumn{3}{|c|}{ Dados sócio demográficos } \\
\hline & Idade & Sexo & Síndrome \\
\hline 1 & $16 a 8 m$ & $\mathrm{M}$ & Cardiofacial Cayler \\
\hline 2 & $9 \mathrm{a} 6 \mathrm{~m}$ & $\mathrm{M}$ & Charcot Marie Tooth \\
\hline 3 & $7 a 3 m$ & $\mathrm{M}$ & Donai-Barrow \\
\hline 4 & $5 \mathrm{a} 10 \mathrm{~m}$ & $\mathrm{M}$ & Down \\
\hline 5 & 19a 1m & $\mathrm{M}$ & Down \\
\hline 6 & $30 \mathrm{a} 1 \mathrm{~m}$ & $\mathrm{~F}$ & Kaern Sayre \\
\hline 7 & $3 a 9 m$ & $\mathrm{~F}$ & Patau \\
\hline 8 & $16 a 2 m$ & $\mathrm{M}$ & Usher \\
\hline 9 & $13 \mathrm{a} 10 \mathrm{~m}$ & $\mathrm{M}$ & Usher \\
\hline 10 & $26 a$ & $\mathrm{~F}$ & Usher \\
\hline 11 & $14 a 4 m$ & $\mathrm{M}$ & Usher \\
\hline 12 & $25 a 4 m$ & $\mathrm{M}$ & Usher \\
\hline 13 & $36 a 9 m$ & $\mathrm{M}$ & Usher \\
\hline 14 & $60 a$ & $\mathrm{M}$ & Usher \\
\hline 15 & $13 a$ & $\mathrm{M}$ & Usher \\
\hline 16 & $41 \mathrm{a}$ & $\mathrm{M}$ & Usher \\
\hline 17 & $12 a$ & $\mathrm{M}$ & Waardenburg \\
\hline 18 & $17 \mathrm{a} 2 \mathrm{~m}$ & $\mathrm{M}$ & Waardenburg \\
\hline 19 & $5 \mathrm{a} 1 \mathrm{~m}$ & $\mathrm{M}$ & Waardenburg \\
\hline 20 & $3 a 5 m$ & $\mathrm{M}$ & Waardenburg \\
\hline 21 & $17 \mathrm{a} 2 \mathrm{~m}$ & $\mathrm{M}$ & Waardenburg \\
\hline 22 & $5 a 8 m$ & $\mathrm{M}$ & Waardenburg \\
\hline 23 & 16a $2 \mathrm{~m}$ & $\mathrm{~F}$ & Waardenburg \\
\hline 24 & $25 a 7 m$ & $\mathrm{M}$ & Waardenburg \\
\hline 25 & $4 a 2 m$ & $\mathrm{M}$ & Waardenburg \\
\hline 26 & $13 a 10 \mathrm{~m}$ & $\mathrm{~F}$ & Waardenburg \\
\hline 27 & $8 \mathrm{a} 10 \mathrm{~m}$ & $\mathrm{~F}$ & Waardenburg \\
\hline 28 & $11 \mathrm{a} 4 \mathrm{~m}$ & $\mathrm{~F}$ & Waardenburg \\
\hline 29 & $1 \mathrm{a} 4 \mathrm{~m}$ & $\mathrm{M}$ & Waardenburg \\
\hline 30 & $12 \mathrm{a} 8 \mathrm{~m}$ & $\mathrm{~F}$ & X-Frágil \\
\hline
\end{tabular}

\section{Variáveis estudadas}

\begin{tabular}{|c|c|c|c|}
\hline $\begin{array}{c}\text { Idade na cirurgia } \\
\text { do IC }\end{array}$ & $\begin{array}{c}\text { Tempo de uso } \\
\text { do IC }\end{array}$ & $\begin{array}{l}\text { Percepção da } \\
\text { fala atual }\end{array}$ & $\begin{array}{c}\text { Linguagem oral } \\
\text { atual }\end{array}$ \\
\hline $6 a 10 \mathrm{~m}$ & $9 \mathrm{a} 9 \mathrm{~m}$ & Conjunto fechado & Não fluente \\
\hline $4 a 8 m$ & $4 a 8 m$ & Conjunto aberto & Não fluente \\
\hline $3 a$ & $4 \mathrm{a} 1 \mathrm{~m}$ & Conjunto fechado & Não fluente \\
\hline $2 \mathrm{a} 1 \mathrm{~m}$ & $3 a 6 m$ & Conjunto fechado & Não fluente \\
\hline $18 \mathrm{a} 2 \mathrm{~m}$ & $1 a$ & Conjunto fechado & Não fluente \\
\hline $25 a 7 m$ & $4 a 6 m$ & Conjunto aberto & Fluente \\
\hline $2 \mathrm{a} 2 \mathrm{~m}$ & $1 \mathrm{a} 6 \mathrm{~m}$ & Conjunto fechado & Não fluente \\
\hline 1a $5 \mathrm{~m}$ & $15 a$ & Conjunto aberto & Fluente \\
\hline 2a 9m & $11 a$ & Conjunto aberto & Fluente \\
\hline $2 \mathrm{a} 4 \mathrm{~m}$ & $14 a$ & Conjunto aberto & Fluente \\
\hline 1a $10 \mathrm{~m}$ & $12 \mathrm{a} 4 \mathrm{~m}$ & Conjunto aberto & Fluente \\
\hline $3 a 8 m$ & $21 \mathrm{a} 6 \mathrm{~m}$ & Conjunto aberto & Fluente \\
\hline $13 a 5 m$ & $23 a 2 m$ & Conjunto aberto & Fluente \\
\hline $58 \mathrm{a} 10 \mathrm{~m}$ & $1 \mathrm{a}$ & Conjunto aberto & Fluente \\
\hline $11 \mathrm{a} 8 \mathrm{~m}$ & $1 \mathrm{a} 4 \mathrm{~m}$ & Conjunto aberto & Não fluente \\
\hline $24 a 2 m$ & $16 a 6 m$ & Conjunto fechado & Não fluente \\
\hline $10 \mathrm{~m}$ & $11 a$ & Conjunto aberto & Não fluente \\
\hline $2 a 6 m$ & $14 a 6 m$ & Conjunto aberto & Não fluente \\
\hline $11 \mathrm{~m}$ & $4 a$ & Conjunto fechado & Não fluente \\
\hline $2 \mathrm{a} 10 \mathrm{~m}$ & $1 \mathrm{a} 6 \mathrm{~m}$ & Conjunto fechado & Não fluente \\
\hline $1 \mathrm{a}$ & $16 a$ & Conjunto aberto & Fluente \\
\hline 1a $2 m$ & $4 a 3 m$ & Conjunto aberto & Fluente \\
\hline $3 a 4 m$ & $12 \mathrm{a} 8 \mathrm{~m}$ & Conjunto aberto & Fluente \\
\hline $3 a 8 m$ & 21a $9 \mathrm{~m}$ & Conjunto aberto & Fluente \\
\hline $3 a 7 m$ & $4 m$ & Conjunto fechado & Não fluente \\
\hline 3a $10 \mathrm{~m}$ & $9 \mathrm{a} 10 \mathrm{~m}$ & Conjunto aberto & Não fluente \\
\hline $5 a$ & $3 a 8 m$ & Conjunto aberto & Não fluente \\
\hline $3 a 3 m$ & $7 \mathrm{a} 11 \mathrm{~m}$ & Conjunto aberto & Fluente \\
\hline $1 \mathrm{a} 1 \mathrm{~m}$ & $3 m$ & Conjunto fechado & Não fluente \\
\hline $2 a 2 m$ & $10 \mathrm{a} 4 \mathrm{~m}$ & Conjunto aberto & Não fluente \\
\hline
\end{tabular}

Fonte: Elaborado pela autora.

$\mathbf{a}=$ anos; $\mathbf{m}=$ meses; $\mathbf{F}=$ feminino; $\mathbf{M}=$ masculino; $\mathbf{I C}=$ implante coclear. 
Quadro 5 - Informações adicionais dos participantes com síndrome genética usuários de implante coclear

\begin{tabular}{|c|c|c|c|c|c|c|}
\hline Participante & Síndrome & $\begin{array}{c}\text { DA } \\
\text { (fase) }\end{array}$ & DNPM & $\begin{array}{l}\text { IC } \\
\text { U/B }\end{array}$ & Fonoterapia & $\begin{array}{l}\text { Tipo de } \\
\text { ensino }\end{array}$ \\
\hline 1 & Cardiofacial Cayler & Pré & AT & $U$ & Sim & Regular/Libras \\
\hline 2 & Charcot Marie Tooth & Pré & $\mathrm{NL}$ & $U$ & Sim & Regular \\
\hline 3 & Donai-Barrow & Pré & AT & $U$ & Sim & Regular \\
\hline 4 & Down & Pré & AT & $U$ & Sim & Especial \\
\hline 5 & Down & Peri & AT & U & Sim & Especial \\
\hline 6 & Kaern Sayre & Pós & $\mathrm{NL}$ & $U$ & Sim & Regular \\
\hline 7 & Patau & Pré & AT & $U$ & Sim & Especial \\
\hline 8 & Usher & Pré & $\mathrm{NL}$ & $\mathrm{B}$ & Sim & Regular \\
\hline 9 & Usher & Pré & $\mathrm{NL}$ & $B$ & Sim & Regular \\
\hline 10 & Usher & Pré & $\mathrm{NL}$ & U & Sim & Regular \\
\hline 11 & Usher & Pré & $\mathrm{NL}$ & $B$ & Sim & Regular \\
\hline 12 & Usher & Pré & $\mathrm{NL}$ & B & Sim & Regular \\
\hline 13 & Usher & Pós & $\mathrm{NL}$ & $B$ & Sim & Regular \\
\hline 14 & Usher & Pós & $\mathrm{NL}$ & $U$ & Sim & Regular \\
\hline 15 & Usher & Pós & $\mathrm{NL}$ & U & Sim & Regular \\
\hline 16 & Usher & Pré & $\mathrm{NL}$ & $U$ & Sim & Regular \\
\hline 17 & Waardenburg & Pré & $\mathrm{NL}$ & $U$ & Sim & Regular/Libras \\
\hline 18 & Waardenburg & Pré & $\mathrm{NL}$ & $U$ & Sim & Especial \\
\hline 19 & Waardenburg & Pré & $\mathrm{NL}$ & B & Sim & Regular \\
\hline 20 & Waardenburg & Pré & $\mathrm{NL}$ & U & Sim & Regular \\
\hline 21 & Waardenburg & Pré & $\mathrm{NL}$ & $U$ & Sim & Regular \\
\hline 22 & Waardenburg & Pré & $\mathrm{NL}$ & $B$ & Sim & Regular \\
\hline 23 & Waardenburg & Pré & $\mathrm{NL}$ & $U$ & Sim & Regular \\
\hline 24 & Waardenburg & Pré & $\mathrm{NL}$ & U & Sim & Regular \\
\hline 25 & Waardenburg & Pré & $\mathrm{NL}$ & $U$ & Sim & Regular \\
\hline 26 & Waardenburg & Pré & AT & U & Sim & Regular/Libras \\
\hline 27 & Waardenburg & Pré & $\mathrm{NL}$ & $U$ & Sim & Regular/Libras \\
\hline 28 & Waardenburg & Pré & $\mathrm{NL}$ & B & Sim & Regular \\
\hline 29 & Waardenburg & Pré & $\mathrm{NL}$ & B & Sim & Regular \\
\hline 30 & X-Frágil & Pré & $\mathrm{NL}$ & U & Sim & Regular \\
\hline
\end{tabular}

Fonte: Elaborado pela autora.

AT= atraso; $\mathbf{B}=$ bilateral; $\mathbf{D A}=$ deficiência auditiva; $\mathbf{D N P M =}$ desenvolvimento neuropsicomotor; $\mathbf{I C}=$ implante coclear; Libras= Língua Brasileira de Sinais; $\mathbf{N L}=$ normal; $\mathbf{U}=$ unilateral.

Contemplando os objetivos específicos delineados no estudo, quanto à análise das variáveis idade na cirurgia do IC e tempo de uso do dispositivo com a percepção da fala e da linguagem oral atual, optou-se em apresentar os resultados em conjunto das síndromes com casuística viável, ou seja, Waardenburg e Usher. No 
entanto, nas síndromes com casuística única ou dupla, a apresentação foi individual, devido ao número reduzido de participantes.

Em benefício da coerência para melhor compreensão da análise, foram apresentados primeiramente dados obtidos com os participantes que adquiriram a deficiência auditiva no momento pré-lingual e, posteriormente os que adquiriram no momento peri e pós-lingual. Optou-se, ainda, por não realizar a análise dos resultados dos usuários de IC unilateral e bilateral separadamente, pelo fato da amostra dos casos bilaterais serem insuficientes para análise estatística.

Salienta-se que os dados nos testes para avaliação da percepção da fala foram analisados seguindo as categorias de audição proposta por Geers (1994) (Quadro 2), apresentada previamente na metodologia. Do mesmo modo, os dados nos testes para avaliação da linguagem oral foram analisados baseados nas categorias de linguagem proposta por Bevilacqua, Delgado e Moret (1996) (Quadro 3), também expostas no capítulo de metodologia.

Na Figura 1 são apresentados os resultados das variáveis idade na cirurgia do IC e o tempo de uso desse dispositivo nos 13 participantes que apresentaram SW e que adquiriram deficiência auditiva antes da ocorrência da aquisição da fala, ditos pré-linguais.

Figura 1 - Dados quanto a idade na cirurgia de implante coclear (em anos) e o tempo de uso do dispositivo (em anos) nos 13 participantes com síndrome de Waardenburg

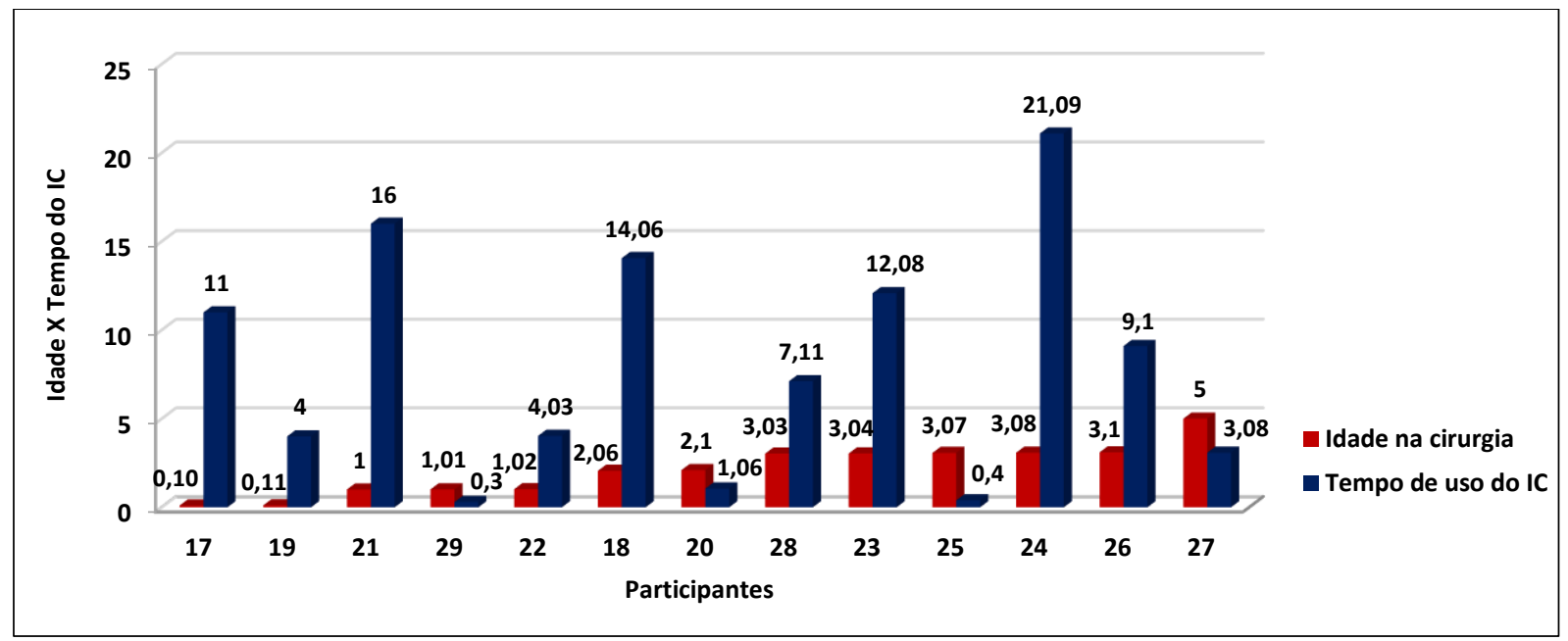

Fonte: Elaborada pela autora.

IC= implante coclear. 
Observa-se que entre os indivíduos estudados a idade mínima na cirurgia para inserção do IC ocorreu aos 10 meses e a máxima aos 5 anos, sendo a média 4 anos. Referente ao tempo de uso do dispositivo (IC), a figura indica o mínimo de 3 meses, máximo de 21 anos e 9 meses e a média de 8 anos de uso.

A percepção da fala dos participantes com SW e deficiência auditiva de aquisição pré-lingual usuários de IC, foi avaliada de acordo com a idade de cada indivíduo e os protocolos utilizados estão apresentados a seguir nas Figuras 2, 3 e 4.

Figura 2 - Dados quanto ao teste de percepção da fala nos participantes com síndrome de Waardenburg - Protocolo GASP

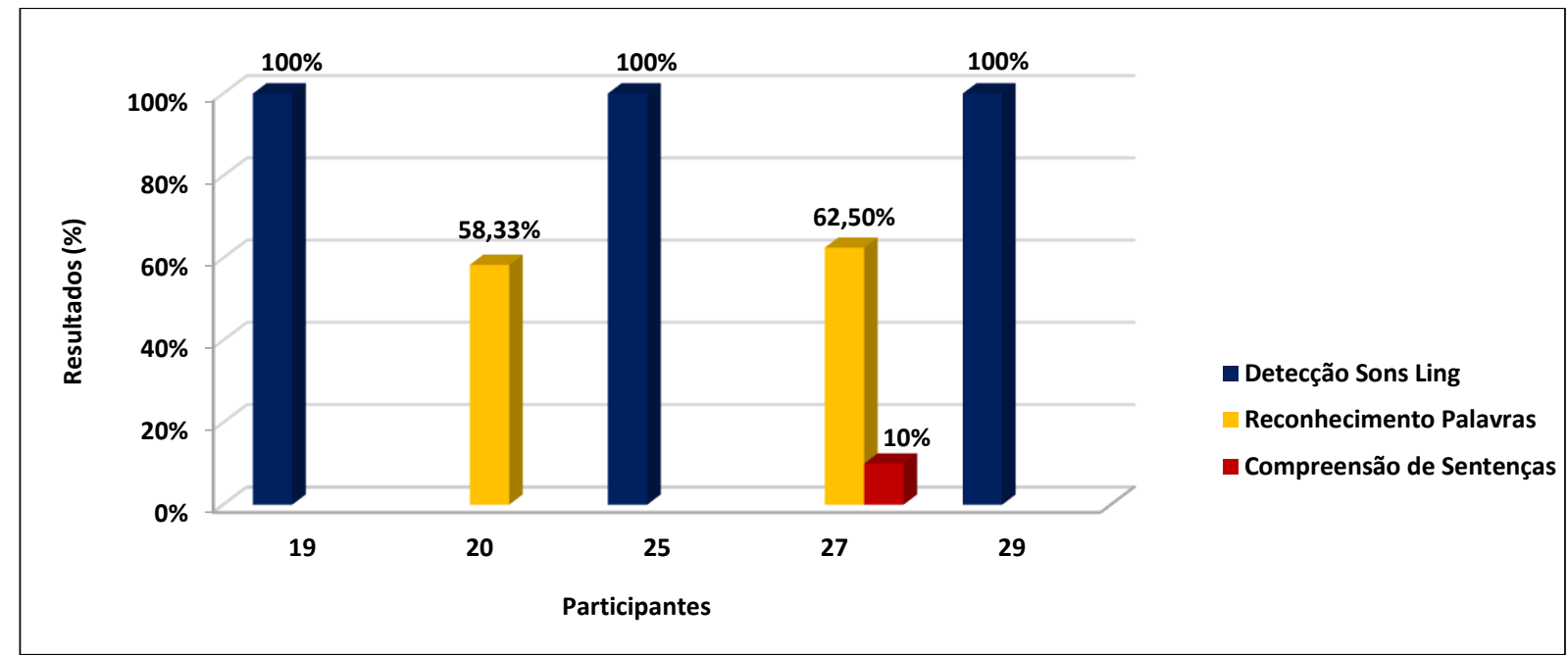

Fonte: Elaborada pela autora.

Figura 3 - Dados quanto ao teste de percepção da fala nos participantes com síndrome de Waardenburg - Protocolo Delgado

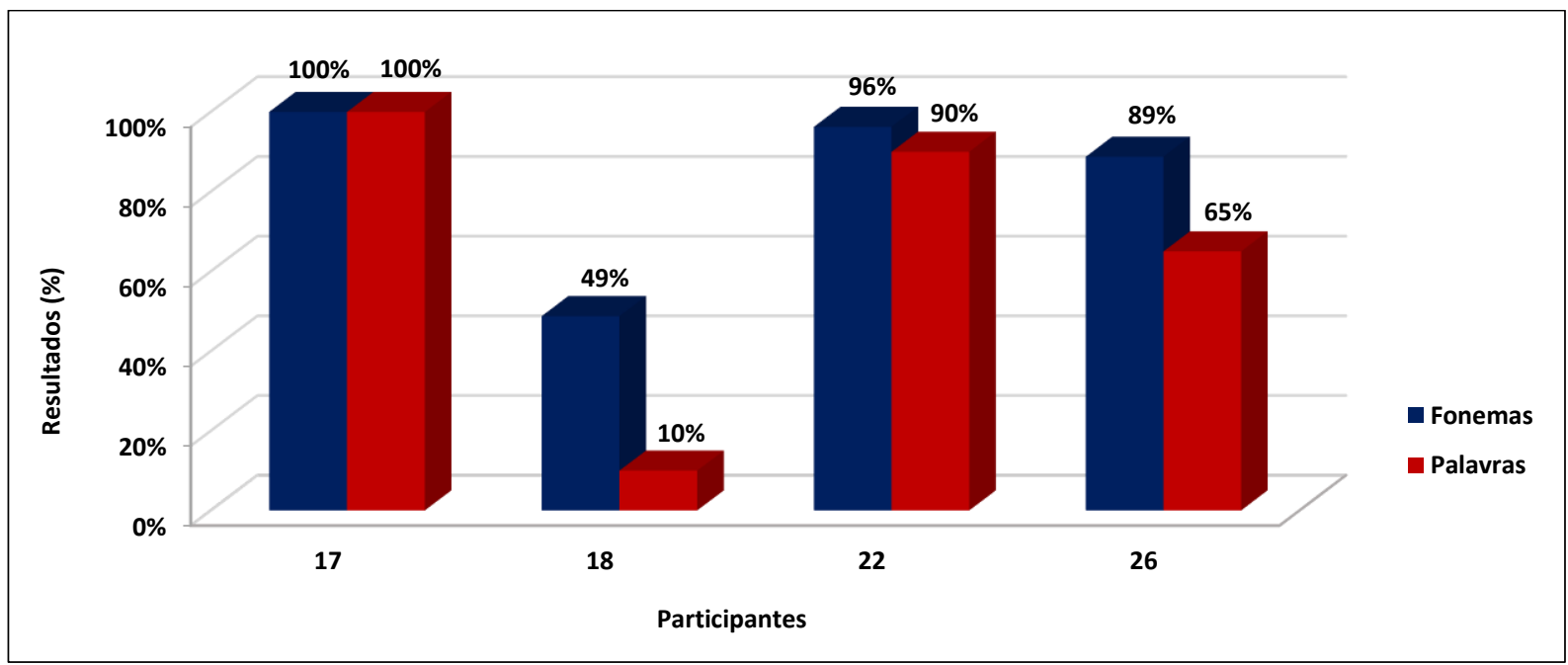

Fonte: Elaborada pela autora. 
Figura 4 - Dados quanto ao teste de percepção da fala nos participantes com síndrome de Waardenburg - Protocolo Sentenças do Dia a Dia (situações silêncio e ruído)

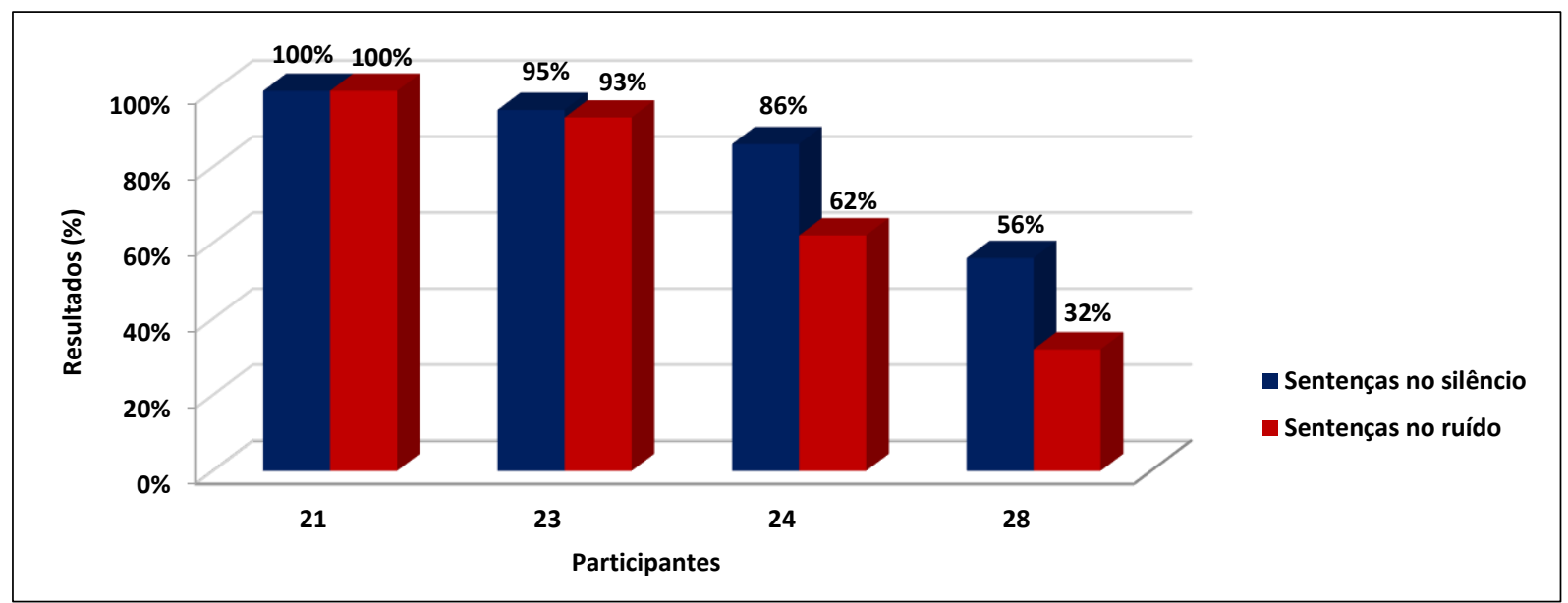

Fonte: Elaborada pela autora.

A maioria dos participantes $(n=8)$ com SW apresentou-se em conjunto aberto, com nível de reconhecimento de palavras (DELGADO; BEVILACQUA, 1999) ou de sentenças do dia a dia (OLIVEIRA, 1992) no silêncio e no ruído, enquanto cinco encontravam-se em fase de detecção dos sons, reconhecimento de palavras e compreensão de sentenças em conjunto fechado - GASP (BEVILACQUA; TECH, 1996).

A análise estatística para a correlação entre a idade na cirurgia do IC com a percepção da fala e linguagem oral nos participantes com SW, utilizando o teste estatístico de Spearman Rank Order Correlation, considerando o nível de significância $\mathrm{p} \leq 0,05$ está apresentada na Tabela 1.

Tabela 1 - Correlação entre a idade na cirurgia de implante coclear com percepção da fala e linguagem oral atual nos participantes com síndrome de Waardenburg

\begin{tabular}{lccc}
\hline \multicolumn{1}{c}{ Variáveis } & Coeficiente & $\mathbf{p}$ & Número amostral \\
\hline $\begin{array}{l}\text { Idade na cirurgia } X \\
\text { Percepção da fala atual }\end{array}$ & 0,22 & 0,447 & 13 \\
$\begin{array}{l}\text { Idade na cirurgia } X \\
\text { Linguagem oral atual }\end{array}$ & 0,04 & 0,878 & 13 \\
\hline
\end{tabular}

Fonte: Elaborada pela autora.

Atentando-se aos valores de $p$ valor observou-se que não houve diferença significante entre a idade na cirurgia do IC com a percepção da fala $(p=0,447)$ e linguagem oral atual $(p=0,878)$ para indivíduos com SW. 
A Tabela 2 apresenta a análise estatística para a correlação entre o tempo de uso do IC com a percepção da fala e linguagem oral atual na SW, verificada por meio do teste estatístico de Spearman Rank Order Correlation, considerando o nível de significância $p \leq 0,05$.

Tabela 2 - Correlação entre tempo de uso do dispositivo com a percepção da fala e linguagem oral atual nos participantes com síndrome de Waardenburg

\begin{tabular}{lccc}
\hline \multicolumn{1}{c}{ Variáveis } & Coeficiente & $\mathbf{p}$ & Número amostral \\
\hline $\begin{array}{l}\text { Tempo de uso do IC X } \\
\text { Percepção da fala atual }\end{array}$ & 0,76 & $0,002^{*}$ & 13 \\
$\begin{array}{l}\text { Tempo de uso do IC X } \\
\text { Linguagem oral atual }\end{array}$ & 0,55 & $0,049^{*}$ & 13 \\
\hline
\end{tabular}

Fonte: Elaborada pela autora.

${ }^{*} p \leq 0,05$ estatisticamente significante.

Observou-se que houve diferença estatisticamente significante entre o tempo de uso do IC, a percepção da fala $(p=0,002)$ e a linguagem oral atual $(p=0,49)$ nos indivíduos com SW, ou seja, o tempo de uso do dispositivo interferiu nos resultados de percepção da fala e da linguagem oral nos indivíduos avaliados.

A Figura 5 representa os resultados dos dados apresentados por seis indivíduos com a SU que adquiriram a deficiência auditiva antes da aquisição da fala, ou seja, na fase pré-lingual, quanto às variáveis idade na cirurgia do IC e o tempo de uso do dispositivo.

Figura 5 - Dados quanto à idade na cirurgia do implante coclear (em anos) e o tempo de uso do dispositivo (em anos) nos participantes com síndrome de Usher

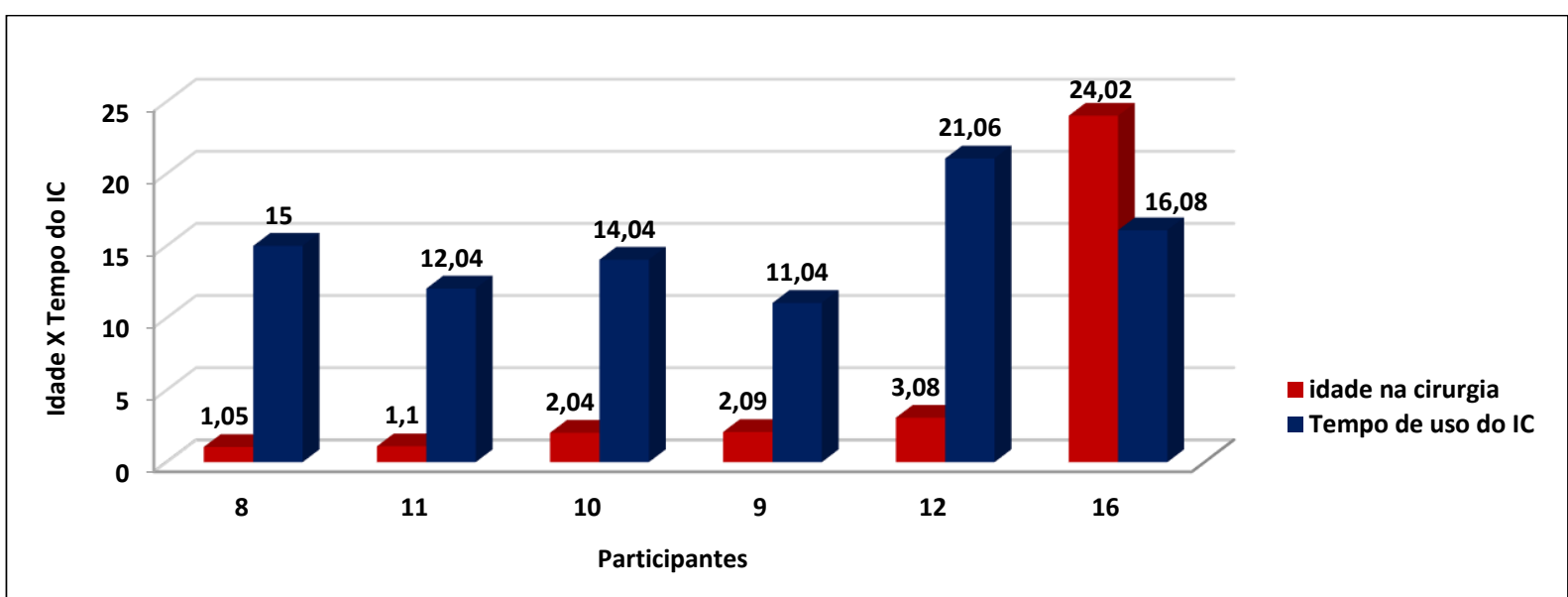

Fonte: Elaborada pela autora.

IC= implante coclear. 
A idade na cirurgia do IC foi no mínimo de 1 ano e 5 meses, máxima de 24 anos e 2 meses, com média de 5 anos de idade e o tempo de uso do dispositivo de 11 anos e 4 meses até de 21 anos e 6 meses, com média de 15 anos.

As Figuras 6 e 7 apresentam a percepção da fala dos seis participantes com SU, conforme dois protocolos: GASP (com a prova de identificação de sentenças) e Delgado (fonemas e palavras).

Observa-se que apenas um participante (16) encontrou-se em conjunto fechado visualizado no teste de identificação de sentenças do protocolo GASP e os cinco demais em conjunto aberto, demonstrado por meio dos testes de percepção da fala utilizando palavras (protocolo Delgado) e Sentenças do Dia a Dia (silêncio e ruído), representados nas Figuras 6 e 7 .

Figura 6 - Dados quanto ao teste de percepção da fala nos participantes com síndrome de Usher Protocolo Delgado e GASP

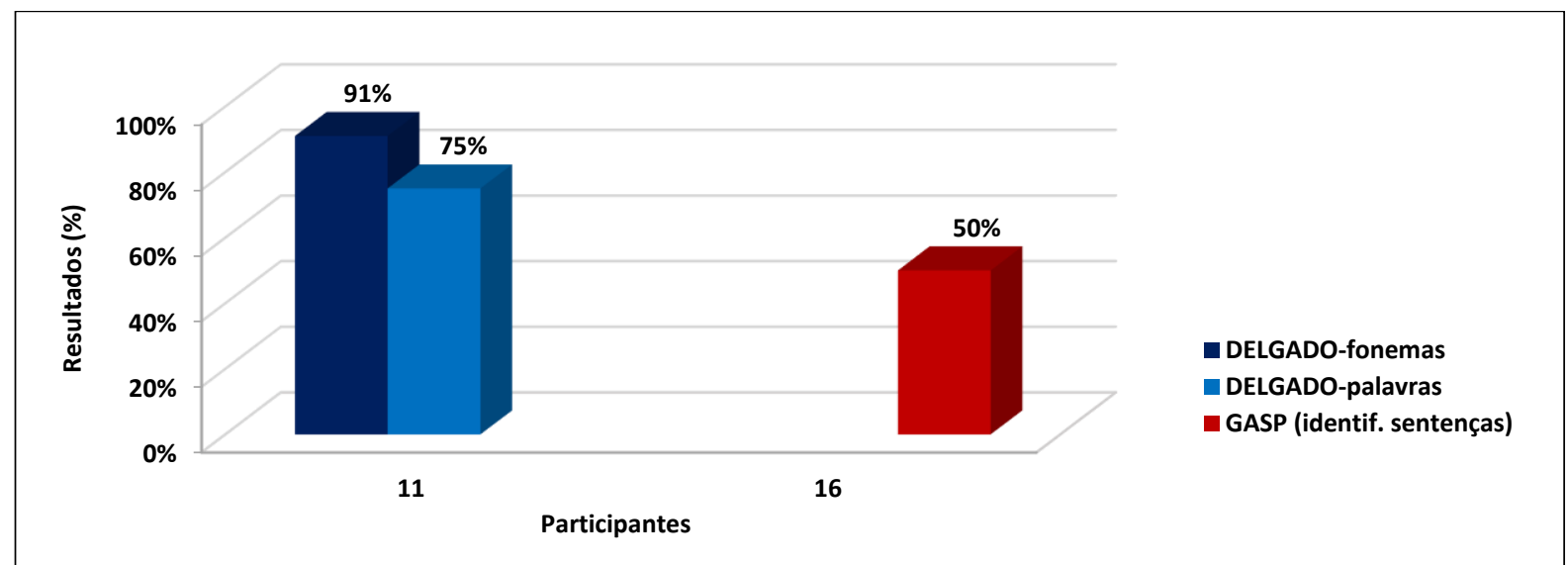

Fonte: Elaborada pela autora.

Figura 7 - Dados quanto ao teste de percepção da fala nos participantes com síndrome de Usher Protocolo Sentenças do Dia a Dia (situações silêncio e ruído)

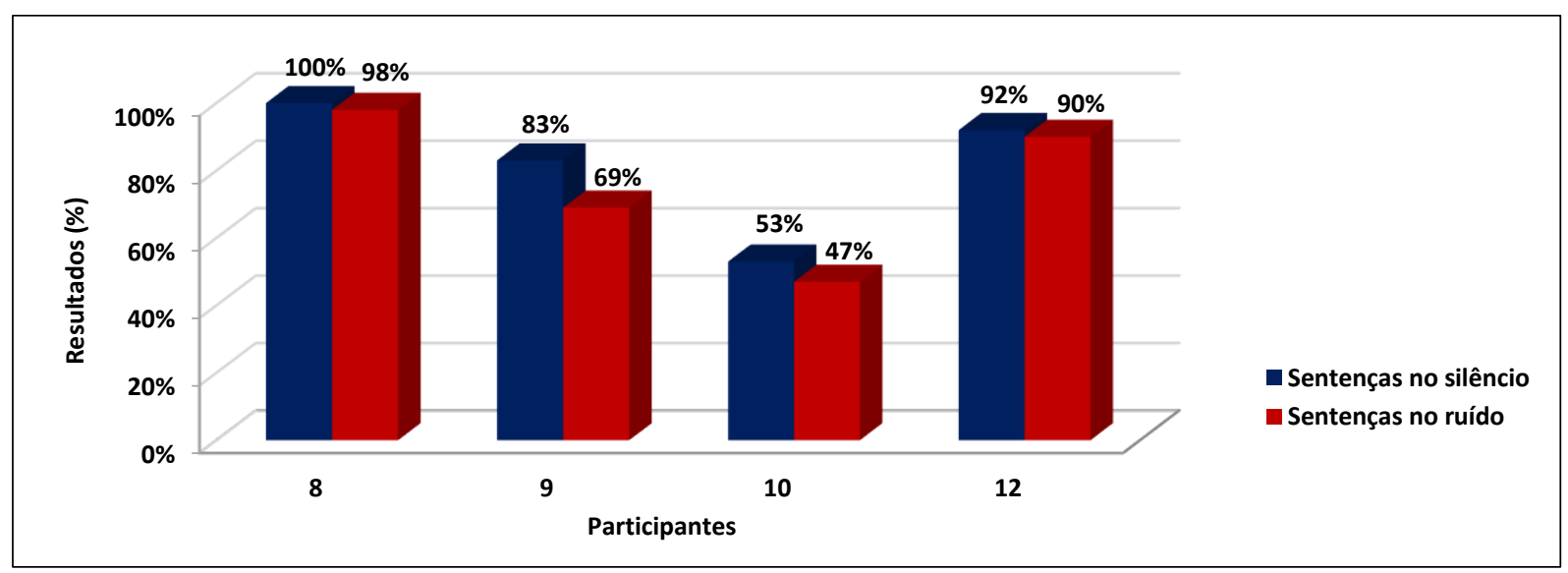

Fonte: Elaborada pela autora. 
Salienta-se que no grupo da SU (pré-lingual) não foi realizado teste de correlação entre as variáveis idade na cirurgia do IC e tempo de uso do dispositivo com a percepção da fala e linguagem oral atual devido ao número reduzido $(n=6)$ de participantes, seguindo orientação do profissional estatístico.

Entre os participantes com a SU, foram encontrados três pós-linguais, nos quais a deficiência auditiva se instalou em um momento em que os mesmos estavam estabelecendo e/ou já apresentavam linguagem oral estabelecida, sendo seus dados apresentados no Quadro 6.

Quadro 6 - Dados quanto à percepção da fala e linguagem oral atual dos três participantes pós-linguais com síndrome de Usher

\begin{tabular}{|c|c|c|c|c|c|}
\hline Participante & $\begin{array}{c}\text { Perda } \\
\text { auditiva }\end{array}$ & $\begin{array}{c}\text { Idade } \\
\text { no IC }\end{array}$ & $\begin{array}{c}\text { Tempo de } \\
\text { uso do IC }\end{array}$ & $\begin{array}{c}\text { Percepção da } \\
\text { fala atual }\end{array}$ & $\begin{array}{c}\text { Linguagem } \\
\text { oral atual }\end{array}$ \\
\hline 13 & Profunda & 13,5 & 23,2 & $\begin{array}{c}\text { Reconhecimento sentenças } \\
\text { Conjunto aberto }\end{array}$ & Fluente \\
\hline 14 & Profunda & 58,10 & 1,0 & $\begin{array}{c}\text { Reconhecimento sentenças } \\
\text { Conjunto aberto }\end{array}$ & Fluente \\
\hline 15 & Profunda & 11,8 & 1,4 & $\begin{array}{c}\text { Reconhecimento palavras } \\
\text { Conjunto aberto }\end{array}$ & Não fluente \\
\hline
\end{tabular}

Fonte: Elaborada pela autora.

IC= implante coclear.

A idade dos indivíduos no momento da cirurgia do IC variou de 11 anos e 8 meses a 58 anos e 10 meses, apresentando média de 28 anos. O tempo de uso do IC variou de 1 ano a 23 anos e 2 meses, com média de 8 anos. Quanto à percepção da fala, os 0 participantes encontravam-se em reconhecimento de palavras ou sentenças do dia a dia (no silêncio e no ruído), em conjunto aberto, e referente à linguagem oral, 2 participantes estavam fluentes.

A comparação das categorias de audição proposta por Geers (1994), entre os indivíduos com síndromes de Waardenburg e Usher pré-linguais usuários de IC está disponibilizada na Figura 8. 
Figura 8 - Dados quanto à comparação das categorias de audição entre os participantes com síndromes de Waardenburg e Usher

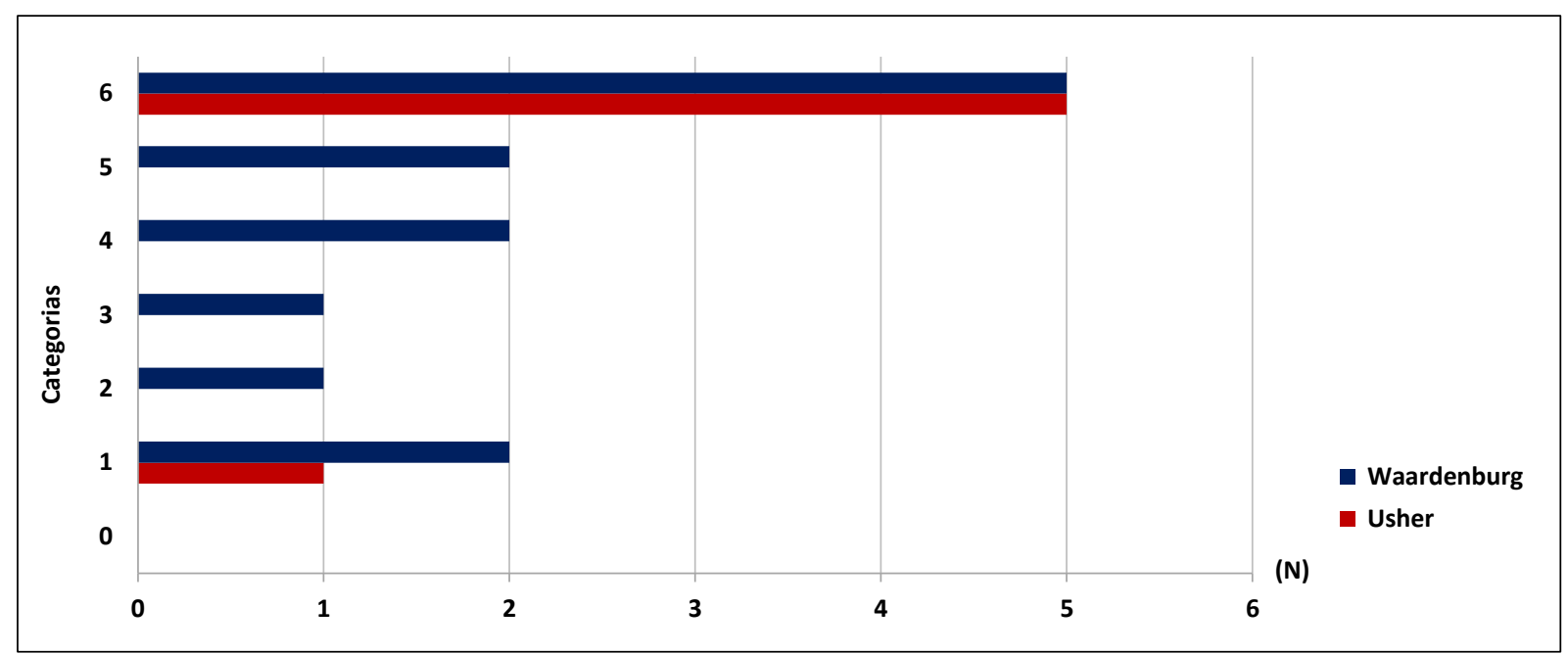

Fonte: Elaborada pela autora.

Na Figura 8, observa-se que 10 participantes pertenciam à categoria 6 (5 Waardenburg e 5 Usher), 2 (Waardenburg) à categoria 5, 2 (Waardenburg) à categoria 4, 1 (Waardenburg) à categoria 3, 1 (Waardenburg) à categoria 2 e 3 à categoria 1 (2 Waardenburg e 1 Usher). No entanto, a maioria $(n=10)$ dos participantes encontravamse em nível de reconhecimento em conjunto aberto representada pela categoria 6.

A comparação das categorias de linguagem proposta por Bevilacqua, Delgado e Moret (1996), entre os indivíduos com SW $(n=13)$ e de Usher $(n=6)$ prélinguais, usuários de IC, está representada na Figura 9.

Figura 9 - Dados quanto à comparação das categorias de linguagem entre os participantes com as síndromes de Waardenburg $(n=13)$ e Usher $(n=6)$

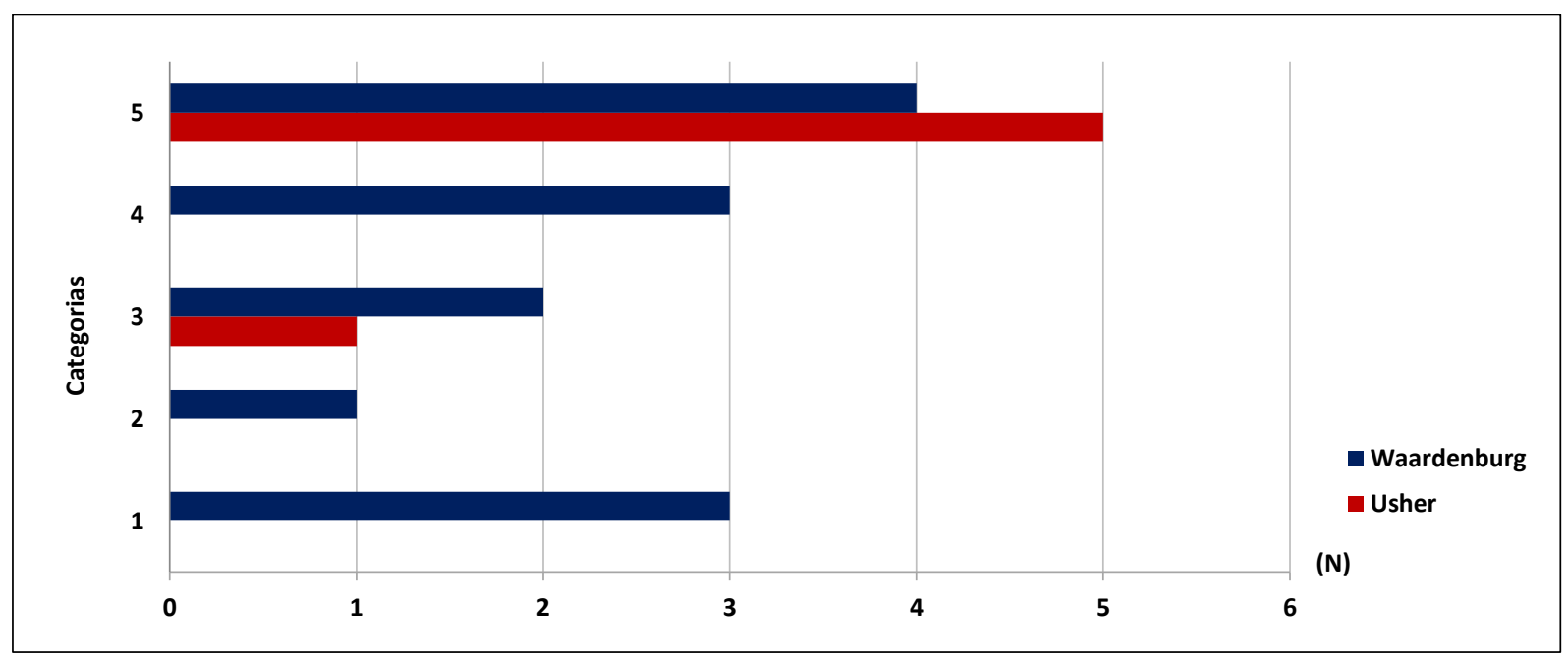

Fonte: Elaborada pela autora. 
Observa-se que na categoria 5, foram encontrados 9 participantes (5 Usher e 4 Waardenburg), na categoria 4 foram 3 participantes da SW, na categoria 3 foram 3 participantes (2 Waardenburg e 1 Usher), na categoria 2 apenas 1 participante e na categoria 1 foram 3 participantes da SW. Dos 19 participantes analisados, 9 apresentavam fluência na comunicação, 3 estavam em nível de frases complexas, 3 em frases simples, 1 em palavras isoladas e 3 ainda não apresentavam emissão oral.

Os demais participantes do estudo $(n=8)$, apresentavam outras síndromes genéticas com deficiência auditiva e usuários de IC, sendo seis com deficiência auditiva pré-lingual (Down, Charcot Marie Tooth, X-Frágil, Donai-Barrow, Patau, Cardiofacial de Cayler), um com deficiência auditiva peri-lingual (Down) e um com deficiência auditiva pós-lingual (Kaern Sayre), que por representarem poucos indivíduos, estão apresentados individualmente nos Quadros 7 e 8 . Dos seis participantes com deficiência auditiva pré-lingual, representados no Quadro 7, a idade na cirurgia variou de 2 anos e 1 mês a 6 anos e 10 meses, com média de 3 anos, e o tempo de uso do IC de 1 ano e 6 meses a 10 anos e 4 meses, com média de 6 anos. Quatro participantes apresentaram percepção da fala em conjunto fechado e dois em conjunto aberto, variando entre as categorias de audição 1,5 e 6 . Referente à linguagem oral atual, nenhum apresentou-se fluente, variando a categoria de linguagem de 1 a 4 . 
Quadro 7 - Dados quanto à percepção da fala e linguagem oral atual dos participantes com deficiência auditiva pré-lingual com outras síndromes genéticas

\begin{tabular}{|c|c|c|c|c|}
\hline $\begin{array}{l}\text { Síndrome } \\
\text { genética }\end{array}$ & $\begin{array}{l}\text { Idade na } \\
\text { cirurgia } \\
\text { de IC }\end{array}$ & $\begin{array}{l}\text { Tempo } \\
\text { de uso } \\
\text { do IC }\end{array}$ & $\begin{array}{c}\text { Percepção auditiva } \\
\text { atual }\end{array}$ & $\begin{array}{l}\text { Linguagem oral } \\
\text { atual }\end{array}$ \\
\hline $\begin{array}{l}\text { Charcot } \\
\text { Marie } \\
\text { Tooth }\end{array}$ & $6 a 10 \mathrm{~m}$ & $9 a 9 m$ & $\begin{array}{c}\text { Conjunto aberto } \\
\text { (62\% sentenças silêncio) } \\
\text { Categoria audição: } 5\end{array}$ & $\begin{array}{c}\text { Não fluente } \\
\text { Categoria linguagem: } 4\end{array}$ \\
\hline $\begin{array}{l}\text { Cardiofacial } \\
\text { Cayler }\end{array}$ & $4 a 8 m$ & $4 a 8 m$ & $\begin{array}{c}\text { Conjunto fechado } \\
\text { (GASP - reconhecimento } \\
\text { palavras) } \\
\text { Categoria audição: } 5\end{array}$ & $\begin{array}{c}\text { Não fluente } \\
\text { Categoria linguagem: } 2\end{array}$ \\
\hline $\begin{array}{l}\text { Donai- } \\
\text { Barrow }\end{array}$ & $3 a$ & $4 a 1 m$ & $\begin{array}{l}\text { Conjunto fechado } \\
\text { (GASP - detecção sons Ling) } \\
\text { Categoria audição: } 1\end{array}$ & $\begin{array}{c}\text { Não fluente } \\
\text { Categoria linguagem: } 1\end{array}$ \\
\hline Down & $2 \mathrm{a} 1 \mathrm{~m}$ & $3 a 6 m$ & $\begin{array}{l}\text { Conjunto fechado } \\
\text { (GASP - detecção sons Ling) } \\
\text { Categoria audição: } 1\end{array}$ & $\begin{array}{c}\text { Não fluente } \\
\text { Categoria linguagem: } 1\end{array}$ \\
\hline Patau & $2 a 2 m$ & $1 \mathrm{a} 6 \mathrm{~m}$ & $\begin{array}{l}\text { Conjunto fechado } \\
\text { (GASP- detecção sons Ling) } \\
\text { Categoria audição: } 1\end{array}$ & $\begin{array}{c}\text { Não fluente } \\
\text { Categoria linguagem: } 1\end{array}$ \\
\hline X-Frágil & $2 a 2 m$ & $10 a 4 m$ & $\begin{array}{c}\text { Conjunto aberto } \\
\text { (Delgado - 95\% palavras e } \\
98,7 \% \text { fonemas) } \\
\text { Categoria audição: } 6\end{array}$ & $\begin{array}{c}\text { Não fluente } \\
\text { Categoria linguagem: } 4\end{array}$ \\
\hline
\end{tabular}

Fonte: Elaborada pela autora.

$\mathbf{a}=$ anos; $\mathbf{m}=$ meses; $\mathbf{G A S P}=$ Procedimento para Avaliação de Crianças Deficientes Auditivas Profundas; $\mathbf{I C}=$ implante coclear.

Destaca-se, no Quadro 8, dois participantes que adquiriram a deficiência auditiva nas fases peri-lingual $(n=1)$ e pós-lingual $(n=1)$. A idade na cirurgia do IC variou de 18 anos e 2 meses a 25 anos e 7 meses e o tempo de uso do dispositivo variou de 1 ano a 4 anos e 6 meses. Quanto à percepção da fala e linguagem oral, um participante apresentou reconhecimento de palavras em conjunto aberto com fala fluente e outro apenas detecção dos sons, sem linguagem oral estabelecida. 
Quadro 8 - Dados quanto à percepção da fala e linguagem oral atual dos participantes peri e póslinguais com outras síndromes genéticas

\begin{tabular}{|l|c|c|c|c|c|}
\hline $\begin{array}{c}\text { Síndrome } \\
\text { genética }\end{array}$ & $\begin{array}{c}\text { Perda } \\
\text { auditiva }\end{array}$ & $\begin{array}{c}\text { Idade } \\
\text { no IC }\end{array}$ & $\begin{array}{c}\text { Tempo de } \\
\text { uso IC }\end{array}$ & $\begin{array}{c}\text { Percepção da } \\
\text { fala atual }\end{array}$ & $\begin{array}{c}\text { Linguagem } \\
\text { oral atual }\end{array}$ \\
\hline Kaern Sayre & Profunda & 25,7 & 4,6 & $\begin{array}{c}\text { Reconhecimento palavras } \\
\text { Conjunto aberto }\end{array}$ & Fluente \\
\hline Down & Profunda & 18,02 & 1,0 & Detecção dos sons do Ling & Não fala \\
\hline
\end{tabular}

Fonte: Elaborada pela autora.

IC= implante coclear.

\subsection{RESULTADOS REFERENTE A QUALIDADE DE VIDA DOS INDIVÍDUOS COM SÍNDROMES GENÉTICAS USUÁRIOS DE IMPLANTE COCLEAR}

Para contemplar o objetivo geral foi verificado o impacto na qualidade de vida na perspectiva do participante adulto ou da família/responsável das crianças, que apresentam síndromes genéticas associadas à deficiência auditiva e são usuários de IC, por meio de questionários. Nos pais ou responsáveis pelas crianças aplicou-se o questionário CCIPP e nos participantes adultos aplicou-se o questionário NCIQ.

Na sequência, segue a apresentação quanto à distribuição dos dados demonstrados por meio do diagrama de caixa (Box Plot), utilizando as referências de valores mínimos e máximos, primeiro e terceiro quartil, mediana e outliers, estes últimos quando presentes, para os pais ou responsáveis pelas crianças e para os participantes adultos.

A Figura 10 apresenta os resultados da qualidade de vida por domínios do questionário CCIPP na perspectiva dos pais de crianças com síndrome genética usuárias de IC $(n=21)$, enquanto a Figura 11 dispõe os resultados da qualidade de vida também por subdomínios do questionário $\mathrm{NCIQ}$ na perspectiva dos participantes adultos que apresentam síndrome genética usuárias de IC $(n=9)$. Considerou-se que quanto maior o valor do escore da escala, melhor a perspectiva dos pais em relação à qualidade de vida das crianças, proporcionada pelo uso do IC. 
Figura 10 - Dados quanto à percepção da qualidade de vida na perspectiva dos pais de crianças com síndrome genética usuárias de implante coclear, por meio dos domínios do questionário $\operatorname{CCIPP}(n=21)$

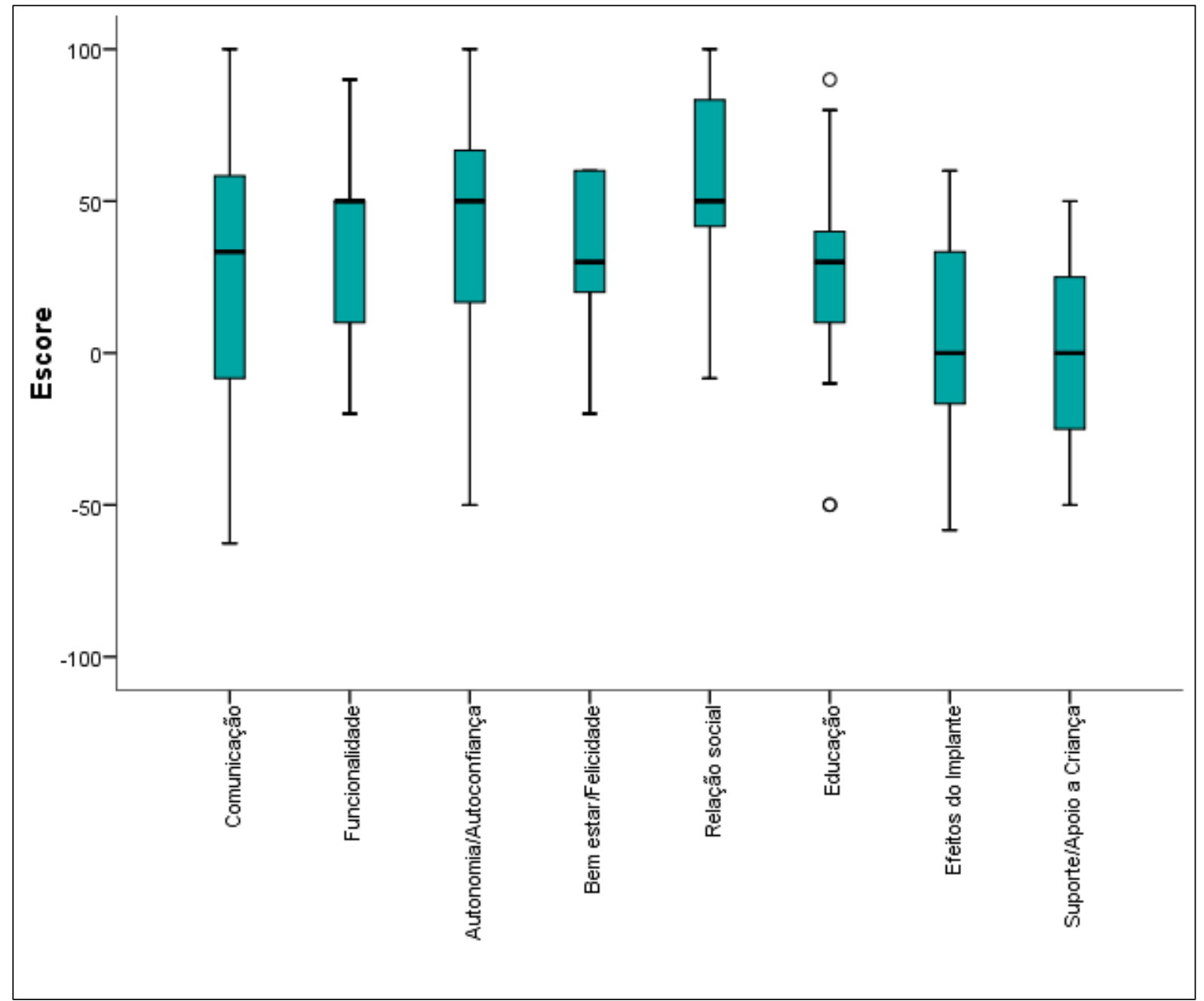

Fonte: Elaborada pela autora.

Por meio da Figura 10, observa-se que os valores de referência mínimo e máximo de cada subdomínio são amplos e a variabilidade dos dados também é relativamente grande em todos os subdomínios, evidenciando que a interferência do dispositivo na qualidade de vida dos participantes é dependente de vários fatores. $\mathrm{Na}$ perspectiva dos pais, o dispositivo proporcionou melhora mais acentuada à qualidade de vida das crianças nos domínios de relação social, com mediana de 50,00\% (média $52,94 \%$ e $D p=33,19 \%$ ), a seguir, na autonomia/autoconfiança, com mediana de $50,00 \%$ (média $45,24 \%$ e $D p=39,14 \%$ ), funcionalidade com mediana de 50,00\% (média $37,62 \%$ e $D p=30,48 \%$ ), seguido da comunicação com a mediana 33,33\% (média $28,75 \%$ e $\mathrm{Dp}=46,24 \%$ ), bem estar/felicidade com mediana de 30,00\% (média $30,48 \%$ e $D p=23,12 \%$ ) e por último, a educação, com mediana de $30,00 \%$ (média 
$24,29 \%$ e $D p=36,41 \%$ ), com dois valores de outliers. Por outro lado, a qualidade de vida com o uso do IC não atingiu a perspectiva dos pais nos seguintes domínios, nesta ordem: efeitos do implante, com a mediana em $0 \%$ (média 7,62\% e Dp=30,75\%) e suporte/apoio da criança com mediana $0 \%$ (média 3,57\% e Dp=30,40\%).

Figura 11 - Dados quanto à da percepção da qualidade de vida na perspectiva dos indivíduos adultos com síndrome genética usuárias de implante coclear, por meio dos subdomínios do questionário NCIQ $(n=9)$

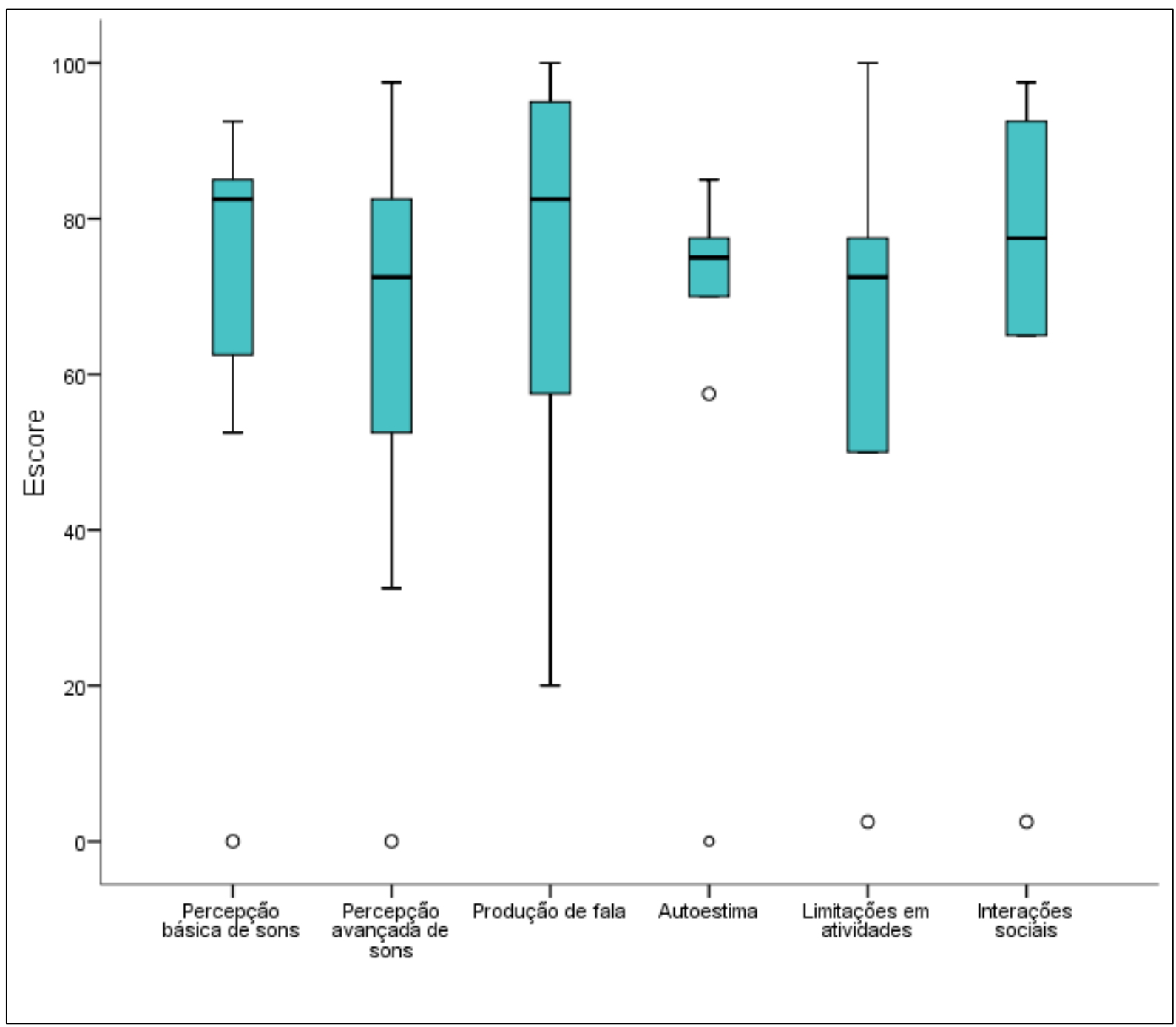

Fonte: Elaborada pela autora.

A avaliação da qualidade de vida dos participantes adultos foi investigada por meio dos subdomínios do instrumento NCIQ baseado em três domínios, físico, psicológico e social. Os subdomínios da qualidade de vida avaliados são percepção básica de sons, percepção avançada dos sons, produção de fala, autoestima, limitações em atividades e interações sociais, nos quais observa-se, por meio da 
Figura 11, que os valores de referência mínimo e máximo, na maioria, foram amplos, e a variabilidade dos dados também foi relativamente grande em todos os subdomínios, excluindo o subdomínio autoestima. Com estes resultados, nota-se que a interferência do IC na qualidade de vida dos participantes adultos foi variável. $\mathrm{Na}$ perspectiva dos participantes, o dispositivo melhorou muito a qualidade de vida em todos os subdomínios, sendo a percepção básica de sons com mediana de 82,50\% (média $=69,72 \%$ e $D p=0,29$ ), percepção avançada dos sons com mediana de $72,50 \%$ (média $=63,06 \%$ e $D p=0,31$ ), produção de fala com mediana de $82,50 \%$ (média $=70,56 \%$ e $\mathrm{Dp}=0,30$ ), autoestima com mediana de 75,00\% (média $=65,00 \%$ e $\mathrm{Dp}=0,29$ ), limitações em atividades, sendo a mediana de $72,50 \%$ (média $=64,72 \%$ e $D p=0,27$ ) e interações sociais com mediana de 75,00\% (média=67,86\% e Dp=0,31). Observa-se, ainda, na mesma figura, que há presença de valores desviantes (outliers) em todos os subdomínios, excluindo o da produção de fala. A presença de tais valores atípicos podem ser explicados por fatores inerentes como: comorbidades; prejuízos sensoriais e cognitivos, entre outros que interferem na qualidade de vida de cada indivíduo submetido ao questionário, porém neste estudo optou-se por analisar os resultados obtidos pela maioria dos indivíduos. 
6 DISCUSSÃD 



\section{DISCUSSÃO}

Na prática clínica, a atuação fonoaudiológica integrada à genética tem demonstrado uma importante complementaridade no processo diagnóstico e de intervenção dos distúrbios da comunicação associados às síndromes genéticas. Considerando a experiência de alguns clínicos e pesquisadores na atuação com indivíduos sindrômicos, com ou sem anomalias estruturais do sistema nervoso central, e no diagnóstico dos distúrbios da comunicação sob o olhar interdisciplinar, não se pode desconsiderar a questão genética como um dos fatores determinantes ou associados aos distúrbios da comunicação, nem descrever síndromes genéticas sem associá-las às manifestações fonoaudiológicas específicas ao seu espectro clínico. Assim, motivados pela necessidade de se estabelecer paralelos entre fenótipos e as alterações de comunicação, observadas na maioria dos usuários, o HRAC-USP, iniciou, na década de 90, o trabalho fonoaudiológico junto ao setor de genética clínica. A partir de então, a união das áreas (Fonoaudiologia e Genética) como ciências complementares têm contribuído não somente para o estudo da comunicação humana e seus distúrbios, como também para uma melhor caracterização e elaboração de programas de reabilitação específicos para esse tipo de população (GIACHETI, 2010).

A partir do diagnóstico realizado pelo Serviço de Genética Clínica do HRAC-USP, foram incluídos, no presente estudo, 30 indivíduos com 9 síndromes genéticas distintas, sendo 13 indivíduos (44\%) com SW, nove (30\%) com Usher, dois (8\%) com síndrome de Down, um (3\%) com Charcot Marie Tooth, um (3\%) com Kaern Sayre, um (3\%) com X-Frágil, um (3\%) com Donai-Barrow, um (3\%) com Patau e um (3\%) com Cardiofacial de Cayler. Todos haviam sido submetidos ao IC em idades diversas, bem como a idade na ocasião da avaliação, que variou de um a 60 anos de idade, resultando em ampla variabilidade no tempo de uso do IC.

Neste contexto, observou-se que alguns indivíduos se encontravam no início recente do processo de reabilitação com o IC. Desta forma, os resultados referentes à percepção da fala e linguagem oral apresentados podem estar compatíveis com o tempo reduzido do uso do dispositivo, devendo assim, ser analisados cautelosamente. 
É fato que a reabilitação da fala e linguagem nos pacientes usuários de IC depende de vários fatores, sendo o tempo de uso do dispositivo um dos aspectos fundamentais para o processo.

É importante, ainda, observar a variação da idade na cirurgia do IC, de 10 meses a aproximadamente 60 anos, na perspectiva do período de aquisição da perda auditiva. Em 25 indivíduos (83,33\%), a alteração ocorreu na fase pré-lingual, em um $(3,33 \%)$, na fase peri-lingual e em quatro (13,33\%), na fase pós-lingual.

Ao analisar especificamente os indivíduos com deficiência auditiva prélingual, verificou-se que a idade na cirurgia variou de 10 meses a 24 anos, sendo 15 $(50 \%)$ indivíduos submetidos à cirurgia em idade $\leq 3$ anos e ampliação para $21(70 \%)$, quando considerados em idade $\leq 4$ anos. Apenas quatro (13,33\%) indivíduos receberam o IC após o período considerado sensível, com impacto nos benefícios da percepção da fala a serem alcançados na reabilitação auditiva.

Através da literatura analisada observou-se que a idade é um fator relevante que determina maiores ou menores esforços para o desenvolvimento das habilidades auditivas e o estabelecimento da linguagem oral com fluência. Consequentemente, o diagnóstico audiológico necessita ser o mais precoce possível, bem como o processo de habilitação/reabilitação auditiva.

Outro aspecto pertinente é que, a maioria dos participantes desse grupo (80\%) apresentava DNPM dentro dos padrões esperados para a idade, comprovados a partir de avaliação neuropsicológica realizada na etapa pré-cirúrgica e registrada no prontuário, o que permite supor que haviam condições para a realização de procedimentos comportamentais e, consequentemente, estabelecimento do diagnóstico da perda auditiva de grau acentuado precocemente.

Fatores como o momento da ocorrência da deficiência auditiva (pré, peri ou pós-lingual), o DNPM, a lateralidade do IC (uni ou bilateral), a assiduidade em fonoterapia e também o tipo de ensino são descritos como importantes e interferentes no prognóstico da reabilitação auditiva com o IC (BEVILACQUA; FORMIGONI, 2005; MORET; BEVILACQUA; COSTA, 2007; MEINZEN-DERR et al., 2010; MOOG; GEERS, 2010; COLLETTI et al., 2011; GEERS; SEDEY, 2011; KONTORINIS et al., 2011; HARRIS et al., 2013; DUNN et al., 2014; TREVISI et al., 2016; VAN NIEROP et al., 2016b; ALZHRANI et al., 2018; SIAGH, 2018). 
Quando o desenvolvimento motor se encontra dentro dos padrões de normalidade, certamente é um facilitador e preditor de bom prognóstico. Sabe-se que o atraso no DNPM pode repercutir, negativamente, para o progresso e sucesso dos resultados com o IC, dificultando também o trabalho do profissional nas sessões de fonoterapia. Ao considerar indivíduos com uma etiologia sindrômica específica e deficiência auditiva, observa-se que frequentemente há grande variação dentro de cada grupo. Pacientes com atraso no DNPM, muitas vezes, atingem pontuações mais baixas nos testes de percepção da fala e de linguagem oral.

Dos 30 participantes do presente estudo, 6 apresentaram atraso no DNPM com resultados limitados na interferência do aspecto neuropsicomotor para o prognóstico do IC. Para Colletti et al. (2011); Geers e Sedey (2011) e Harris et al. (2013), o desenvolvimento cognitivo desempenha papel importante e as habilidades cognitivas interferem diretamente nos resultados da percepção da fala e da linguagem oral de crianças que utilizam IC. Deste modo, o potencial cognitivo da criança para a aprendizagem também deve ser destacado para indicação do IC (ROBBINS; GREEN; BOLLARD, 2000; GEERS, 2002; BEVILACQUA; COSTA; AMANTINI, 2005).

Em muitos casos, o exato diagnóstico da síndrome genética pode não ser alcançado antes da indicação do IC e o grau do comprometimento cognitivo se torna evidente tempos depois da cirurgia. Crianças com comprometimento cognitivo evidente, mesmo com o IC, podem não conseguir desenvolver a linguagem oral, mas por outro lado, podem, com o dispositivo, ter acesso aos sons ambientais e a vozes familiares. Isso explica que, apesar dos resultados limitados obtidos com o IC, os estudos apresentados na literatura de crianças com deficiências adicionais geralmente relatam uma melhoria na qualidade de vida após o IC.

Sabe-se que o ingresso no meio escolar do indivíduo com deficiência auditiva pode gerar impacto positivo para o desenvolvimento de sua linguagem oral. No presente estudo, 26 (87\%) participantes que frequentaram ou frequentam o ensino regular, o realizaram com o protagonismo do IC. Destes, quatro participantes necessitaram de professor auxiliar da Língua Brasileira de Sinais (Libras) em sala de aula e apenas quatro (13\%) foram incluídos em escola especial, provavelmente devido ao grande prejuízo auditivo ou em decorrência de outros fatores agravantes.

No que se refere ao tratamento fonoaudiológico, constatou-se que todos os participantes do presente estudo realizaram ou realizam fonoterapia efetivamente. 
Pesquisadores enfatizam unanimemente que a participação efetiva em fonoterapia é imprescindível para o sucesso do IC. Autores como Bevilacqua e Formigoni (2005); Moret, Bevilacqua e Costa (2007); Meinzen-Derr et al. (2010); Kontorinis et al. (2011); Jatana et al. (2013); Magalhães et al. (2013); Trevisi et al. (2016); Alzhrani et al. (2018) e Siagh (2018) referem que os resultados com o IC dependem de vários fatores que conduzem a um bom prognóstico, colocando em destaque a habilitação/reabilitação sistemática. A terapia fonoaudiológica deve ser embasada nas habilidades auditivas e na estimulação da linguagem oral, com estratégias adequadas à faixa etária e nível cognitivo.

No que se relaciona a percepção da fala, a maioria dos participantes (64\%) encontravam-se em conjunto aberto, ou seja, apresentavam a capacidade de identificar a palavra exclusivamente por meio da audição e ainda, se comunicavam por meio da linguagem oral. Deste total, sete não apresentava fluência na fala, comunicando-se por meio de frases simples ou complexas sem uso de conectivos.

Analisar os benefícios da habilitação/reabilitação auditiva com o IC em indivíduos que apresentam síndromes genéticas ainda representa um desafio para os profissionais dos centros especializados e estudos que averiguam os benefícios desse dispositivo são restritos no cenário nacional e internacional. Assim, além dos resultados da percepção da fala e linguagem oral, o presente estudo se propôs a verificar o impacto do IC na qualidade de vida dos indivíduos em que a deficiência auditiva está presente no quadro da síndrome genética.

É certo que o conhecimento do prejuízo no sistema auditivo, como parte das características das diversas síndromes genéticas, alerta os profissionais dos centros de IC quanto às dificuldades encontradas a serem superadas nos momentos pré e pós-cirúrgicos, como também consideram a possibilidade de variabilidade no prognóstico com obtenção de resultados satisfatórios, parcialmente satisfatórios ou ainda insatisfatórios.

Todos os aspectos envolvidos nas etapas pré, peri e pós-cirúrgica necessitam ser corretamente estabelecidos e detalhadamente analisados para a obtenção de um prognóstico promissor com esse tipo de estratégia de habilitação/reabilitação auditiva. Ressalta-se a importância do acolhimento da família e/ou do indivíduo, o diagnóstico audiológico, incluindo a realização de exames por imagens como a tomografia computadorizada e a ressonância nuclear magnética, 
seguido das orientações sobre as expectativas quanto ao prognóstico, riscos da cirurgia, procedimento cirúrgico, necessidade do uso efetivo e cuidados com o IC, regularidade nos retornos de acompanhamento, importância da fonoterapia e comprometimento com o tratamento.

Especificamente, a orientação e o aconselhamento aos indivíduos que apresentam síndromes genéticas, aos pais e/ou familiares, em tempo oportuno e de maneira eficaz é imprescindível, incluindo informações detalhadas e realistas. Sobre estes aspectos, Van Nierop et al. (2016b) reforçam a importância da orientação e do aconselhamento aos indivíduos dentro do processo de habilitação/reabilitação auditiva.

O papel da família, o meio ambiente e a inclusão precoce no meio educacional são fortemente destacados como peças fundamentais no processo de habilitação/reabilitação auditiva em usuários de IC, para o desenvolvimento das habilidades auditivas e da linguagem oral (MOOG; GEERS, 2010; SZAGUN; STUMPER, 2012; ALZHRANI et al., 2018).

O IC é considerado por vários autores um recurso eficaz, sendo uma excelente opção de habilitação/reabilitação auditiva para adultos e crianças com síndromes genéticas, proporcionando a acessibilidade aos sons ambientais, da fala e ao desenvolvimento da linguagem oral, com impacto positivo na qualidade de vida em geral de seus usuários (GEERS; BRENNER; DAVIDSON, 2003; GEERS, 2004; PENNINGS et al., 2006; RAY et al., 2006; WILSON; DORMAN, 2008; THAI-VAN et al., 2010; WARNER-CZYZ et al., 2011; FORTUNATO-TAVARES et al., 2012; PIETOLA et al., 2012; VAN NIEROP et al., 2016a; ALZHRANI et al., 2018). Deste modo, diversos fatores, intrínsecos e extrínsecos ao indivíduo com deficiência auditiva, podem influenciar os resultados com esse dispositivo, caracterizando-se em um processo multifatorial (MORET, 2002; RAJPUT; BROWN; BAMIOU, 2003; BEVILACQUA; FORMIGONI, 2005; COSTA; BEVILACQUA; TABANEZ, 2006; DUNN et al., 2014; SIAGH, 2018).

Sabe-se que nem todos os usuários de IC beneficiam-se do acesso aos sons ambientais e aos sons da fala da mesma maneira, ocorrendo na prática clínica grande variabilidade de resultados. Na literatura, encontramos relatos de casos ou pequenas séries que descrevem essa variabilidade de resultados referentes à percepção da fala e linguagem oral do IC em síndromes genéticas. Na presente 
pesquisa, estudou-se o status quanto à percepção da fala, linguagem oral e qualidade de vida nas seguintes síndromes genéticas: Waardenburg; Usher; Down; Charcot Marie Tooth; Kaern Sayre; X-Frágil; Donai-Barrow; Patau e Cardiofacial de Cayler. Todos os indivíduos estudados apresentavam deficiência auditiva do tipo sensorioneural de grau severo/profundo com acometimento bilateral (média tonal variante de $80 \mathrm{dBNA}$ à ausência de resposta em $120 \mathrm{dBNA}$ ), usuários de IC unilateral ou bilateral, entretanto, nem todos os indivíduos com IC unilateral são, atualmente, usuários efetivos do AASI contralateral, mas todos utilizaram este dispositivo bilateralmente antes da realização da cirurgia do IC.

No que se refere à idade na cirurgia do IC, observou-se que, na maioria, ocorreu em idade precoce. Este achado é dependente de fatores como: momento do surgimento da deficiência auditiva; estabelecimento do diagnóstico audiológico; acesso a serviços que realizam a cirurgia de IC; condições de saúde do indivíduo e consentimento dos pais/responsáveis para realizar a cirurgia de IC. Neste sentido, a intervenção precoce vem sendo preconizada por vários autores (LOUNDON et al., 2003; PENNINGS et al., 2006; NIPARKO et al., 2010; JATANA et al., 2013; BEVILACQUA et al., 2014; ALZHRANI et al., 2018). Moret (2002) acrescentou, ainda, que a idade da criança no momento da ativação está relacionada ao bom prognóstico do IC.

Com relação ao tempo de uso do dispositivo, a maioria $(n=28,93 \%)$ dos participantes apresentou tempo maior ou igual a 12 meses. Sabe-se que o uso prolongado e efetivo do IC associado à fonoterapia sistemática resulta em vantagens na percepção da fala, assim como no desenvolvimento de uma linguagem oral fluente. As habilidades auditivas adquiridas após a ativação do dispositivo, considerando tempo de uso adequado asseguram para os usuários desde a detecção de sons até o reconhecimento e compreensão de sentenças em situações acústicas desfavoráveis como, por exemplo, compreender a fala em ambiente ruidoso.

Os resultados de um pequeno grupo de indivíduos pré-linguais (síndrome Cardiofacial de Cayler, Donnai-Barrow, Down, Patau, Usher e Waardenburg) do presente estudo foram pouco satisfatórios referente à percepção da fala, por estarem nas etapas de detecção dos sons e/ou reconhecimento da fala em conjunto fechado, linguagem oral não estabelecida ou não fluentes, quando comparados ao tempo de uso do IC. Esses resultados podem ser atribuídos aos comprometimentos adicionais 
que os indivíduos apresentavam, como a deficiência visual associada à deficiência auditiva, atraso no DNPM e comprometimento intelectual, associados à idade na cirurgia, uso frequente de Libras e ausência de fonoterapia.

As limitações nos resultados de percepção da fala e linguagem oral nos indivíduos com síndromes genéticas também são demonstradas nos estudos realizados por Kontorinis et al. (2011); Trevisi et al. (2016); Van Nierop et al. (2016b) e Young et al. (2017). Destaca-se o estudo realizado por Meinzen-Derr et al. (2010) sobre crianças com atraso cognitivo que apresentaram ganhos mensuráveis pósimplante, na percepção da fala e no reconhecimento de palavras ou sentenças, embora o progresso tenha ocorrido de forma mais lenta do que em crianças com IC sem atraso cognitivo. Desta forma, não se deve esperar que o progresso da percepção da fala e da linguagem oral em crianças com comprometimento cognitivo seja equivalente ao de crianças com desenvolvimento cognitivo normal. Outro estudo que merece menção é o de Black, Hickson e Black (2012), que conclui que mesmo que uma criança implantada não alcance o desempenho desejado, esse pode ser considerado de sucesso, dependendo do prognóstico determinado pela análise dos fatores que o influenciam.

Pode-se verificar que 21 pacientes apresentavam IC unilateral e apenas nove bilateral. Em ambas as situações, observou-se similaridade quanto aos resultados da percepção da fala, linguagem oral e qualidade de vida. Todavia, não se pode deixar de mencionar que os indivíduos com IC bilateral podem ter benefícios adicionais como: reestabelecimento da audição binaural; consequentemente diminuição do esforço auditivo; melhor percepção da fala no ruído; melhor localização dos sons (MORET, 2016).

Outros aspectos importantes a serem considerados no prognóstico com o IC dizem respeito ao tempo de privação, técnica cirúrgica, quantidade de eletrodos inseridos e ativados na cóclea, estratégia de codificação de fala utilizada, acompanhamento periódico do dispositivo e manutenção do componente externo do dispositivo. Apesar da sua importância, tais aspectos não foram abordados no presente estudo e serão analisados oportunamente. Ainda assim, considerando que todos os pacientes atenderam aos retornos previstos no protocolo da SIC-HRAC-USP, pode-se sugerir que o acompanhamento periódico do dispositivo foi realizado. 
Referente aos indivíduos pré-linguais deste estudo, a maioria apresentou resultados satisfatórios na avaliação mais recente, porém com uma certa variabilidade na percepção da fala (reconhecimento em conjunto aberto), como também na linguagem oral, sendo que alguns encontravam-se em processo de evolução e outros apresentavam-se fluentes. Em concordância com a literatura, acredita-se que estes resultados foram possíveis de serem atingidos nesta população, devido aos importantes aspectos já destacados, como idade na cirurgia, frequência diária de uso do IC, aspectos cognitivos da criança, regularidade nos retornos de acompanhamento do dispositivo, funcionalidade dos componentes internos e externos, fonoterapia, comprometimento e participação da família no processo de habilitação/reabilitação auditiva, comunicação da criança no ambiente escolar.

Dentre os indivíduos que adquiriram a deficiência auditiva no período póslingual, a maioria apresentou resultados satisfatórios com reconhecimento da fala em conjunto aberto, fluência na fala e relato de frequentar o ensino regular. Resultados semelhantes em casos pós-linguais foram relatados por Bacciu et al. (2015), que analisou a deficiência auditiva progressiva, adquirida após a aquisição da linguagem oral e utilização do AASI, efetivamente, antes do IC. Os benefícios do reconhecimento da fala em conjunto aberto a partir do IC destes indivíduos foram significativos comparativamente aos resultados pré-cirúrgicos e permaneceram estáveis.

A discussão quanto às variáveis idade na cirurgia e tempo de uso do IC com a percepção da fala e da linguagem oral, dos resultados em conjunto das síndromes com casuística viável, ou seja, Waardenburg e Usher será explicitada a seguir.

A SW foi descrita em 1951, pelo oftalmologista e geneticista P.J. Waardenburg como uma condição autossômica dominante, com penetrância e expressividade variáveis. Seus sinais clínicos incluem perda auditiva neurossensorial congênita, heterocromia total ou parcial da íris, hipopigmentação do cabelo (principalmente na região frontal) e distopia cantorum, além de critérios menores como sinófris, hipopigmentação da pele e uma base larga do nariz. Para ter a confirmação da SW o paciente deve apresentar dois critérios maiores e um menor (READ; NEWTON, 1997). Ainda assim, a deficiência auditiva é o sintoma mais preocupante da síndrome. 
No presente estudo, a idade para a inserção do IC nos participantes com SW foi satisfatória, bem como o tempo médio de uso do dispositivo no momento da coleta dos dados. Autores como Rajput, Brown e Bamiou (2003); Kontorinis et al. (2011); Amirsalari et al. (2012); Van Nierop et al. (2016b); Quintana Mirabal et al. (2016) e Alzhrani et al. (2018) são unânimes em afirmar a estreita relação entre a necessidade da intervenção precoce com a realização da cirurgia do IC e resultados satisfatórios. Sobre o tempo do uso do dispositivo, no qual se consegue obter todas as habilidade auditivas, a maioria dos autores propõe o tempo mínimo de um ano de uso, mas deve ser sempre considerada com muita cautela ao analisar os resultados referentes ao IC, observando a variabilidade de fatores negativamente interferentes.

Os resultados da percepção da fala demonstraram que os indivíduos que utilizam IC com SW apresentaram desempenho satisfatório quanto às habilidades auditivas, mesmo com pouco tempo de uso do IC, corroborando os achados de Kontorinis et al. (2011); Amirsalari et al. (2012); Quintana Mirabal et al. (2016); Van Nierop et al. (2016b) e Alzhrani et al. (2018).

O desempenho pós-operatório de populações especiais, pode ser variável, mas satisfatório. Portanto, a compreensão dos fatores subjacentes a essa variabilidade é clinicamente relevante. Rajput, Brown e Bamiou (2003) não encontraram bons resultados referentes à linguagem receptiva e à inteligibilidade da fala após 4 ou 5 anos de IC, sendo que o resultado da linguagem oral após o IC é produto de uma interação complexa entre fatores intrínsecos e extrínsecos não diretamente relacionados à perda auditiva, mas com a idade na cirurgia e ao ambiente familiar e educacional. Mediante esta realidade, o profissional tem que estar disponível para novas condutas e alternativas com o auxílio de Libras e sistemas auxiliares de audição, como por exemplo, o Sistema de Frequência Modulada (FM).

A maioria dos indivíduos com a SW do presente estudo apresentou linguagem oral estabelecida, mas poucos apresentavam fluência na fala. Autores como Kontorinis et al. (2011); Amirsalari et al. (2012) e Alzhrani et al. (2018) referiram em seus estudos que indivíduos com síndromes genéticas que recebem o IC podem alcançar níveis semelhantes de percepção auditiva e inteligibilidade de fala, como indivíduos sem síndrome, apesar dos resultados variáveis, mas isso não deve contra indicar o IC, que demonstra impacto positivo na percepção sensorial desses indivíduos, assim como no seu estilo de vida. 
Ainda neste grupo, não se observou correlação significante entre a idade na cirurgia do IC e a percepção da fala e linguagem oral atual. Esse resultado comprova que a idade na cirurgia, principalmente em indivíduos com deficiência prélingual é fundamental para o bom prognóstico da percepção da fala, atingindo todas as habilidades auditivas de modo satisfatório, como também a linguagem oral que reflete na fluência da comunicação. Já a correlação significante entre tempo de uso do IC e percepção da fala e linguagem oral, reforça, mais uma vez, o seu importante papel no desenvolvimento da comunicação oral, na presença da SW.

No que se relaciona à SU, vale ressaltar que, nesta condição genética, dois sentidos são acometidos, ainda que em graus variados. A deficiência auditiva pode estar presente desde o nascimento, enquanto que a visão poderá ser afetada gradativamente. A deficiência visual geralmente tem início na infância ou na adolescência e é causada pela retinose pigmentar. A perda de equilíbrio também é observada nesta condição. Na dependência da gravidade dos sinais e sintomas, a SU pode ser classificada em quatro tipos (FISHMAN et al., 1983). Assim, é provável que a grande maioria dos indivíduos com deficiência auditiva associada realize o IC antes de serem diagnosticados com esta síndrome. No entanto, o diagnóstico da deficiência auditiva e a cirurgia do IC precoces permitem o máximo desenvolvimento da linguagem oral antes de iniciar o sintoma visual, que ocorre geralmente da infância para a adolescência e/ou na fase adulta. De acordo com Pennings et al. (2006), indivíduos com SU em uma idade mais jovem, dificilmente experimentam problemas visuais e que, portanto, provavelmente utilizam seu córtex visual de forma semelhante à dos indivíduos com visão normal, o que proporciona o desenvolvimento das habilidades necessárias para a aquisição da linguagem oral.

No presente estudo, a idade na cirurgia do IC, na SU, foi satisfatória, bem como o tempo médio de uso do dispositivo no momento da coleta dos dados. Conforme apontado por Pennings et al. (2006), a melhora no desempenho audiológico ocorre em relação ao número de meses após o uso do IC, que para a maioria dos indivíduos é benéfico quando realizado dentro da primeira e mesmo da segunda década de vida. Evidencia que o IC realizado precocemente conduz ao melhor desempenho. Esses aspectos também são defendidos em estudo realizado por Alzhrani et al. (2018). 
Em particular, na SU, onde há o prejuízo sensorial da visão, a realização da cirurgia para inserção do IC o mais rápido possível e o uso adequado do dispositivo são aspectos indiscutíveis e averiguados no estudo de Loundon et al. (2003). Para diminuir o impacto devastador de um distúrbio sensorial duplo, Jatana et al. (2013) ressaltaram que o desenvolvimento das habilidades auditivas e da linguagem oral é de especial importância para as crianças acometidas por essa síndrome, sendo provável que as mesmas desenvolvam o reconhecimento da fala em conjunto aberto e linguagem oral.

Os resultados referentes a percepção da fala (reconhecimento em conjunto aberto) e linguagem oral (fluência), na maioria dos indivíduos com SU, tanto pré quanto pós-linguais foram satisfatórios, com resultados semelhantes aos estudos de Pietola et al. (2012); Jatana et al. (2013) e Alzhrani et al. (2018). Em geral, o IC em adultos cegos e surdos, incluindo aqueles com SU, é tão bem-sucedido quanto em outros adultos surdos pré-linguais e pós-linguais.

Considerando as categorias de audição proposta por Geers (1994), nos participantes pré-linguais do presente estudo, a categoria 6 é a que mais se destaca, na qual as crianças apresentam o reconhecimento de palavras em conjunto aberto, são capazes de ouvir palavras fora do contexto e extraem grande informação fonêmica reconhecendo a palavra exclusivamente por meio da audição. $\mathrm{Na}$ sequência, está a categoria 5, que de acordo com Comerlatto (2015), as crianças quando classificadas nesta categoria, geralmente apresentam algum nível de reconhecimento da fala em conjunto aberto.

Quanto às categorias de linguagem proposta por Bevilacqua, Delgado e Moret (1996), a maioria dos participantes deste estudo atingiu a categoria 5 com construção de frases de várias palavras, usando elementos conectivos, conjugando verbos, usando plurais, ou seja, são indivíduos fluentes na linguagem oral. Conforme descrito, inúmeras são as variáveis que podem contribuir para os diferentes e, em alguns casos, desfavoráveis resultados. De acordo com os estudos revisados nesta pesquisa, todos ressaltaram que os resultados obtidos principalmente nos indivíduos com síndromes genéticas são variáveis e podem ser influenciados por fatores intrínsecos e extrínsecos. Para aqueles com comprometimento neuropsicomotor e intelectual, a aquisição da linguagem oral pode ser severamente prejudicada, mesmo após longo período de acompanhamento do IC, sugerindo a necessidade de modos 
alternativos de comunicação. Desse modo, é consenso que a presença dessas alterações deva ser considerada no planejamento terapêutico personalizado.

Os resultados do desempenho na percepção da fala e na linguagem oral com o IC por si só podem não descrever com precisão os benefícios obtidos com o dispositivo, assim como, não justificam a variabilidade dos resultados encontrados neste estudo. Desta forma, outras ferramentas de avaliação que abarquem aspectos além dos relacionados à audição e à linguagem, como a qualidade de vida, podem colaborar na avaliação dos benefícios e limitações do IC, fornecendo importantes informações do impacto desse dispositivo na vida do usuário e de seus familiares.

O impacto positivo na qualidade de vida de indivíduos que apresentam síndromes genéticas, na perspectiva dos pais ou responsáveis e deles próprios, parece indicar o importante papel do IC, ainda que exista a possibilidade de variabilidade de resultados quanto à comunicação (GEERS; BRENNER; DAVIDSON, 2003; RAY et al., 2006; WILSON; DORMAN, 2008). Seus benefícios em crianças com deficiência auditiva severa ou profunda vão além dos bons resultados na percepção auditiva, produção da fala e desenvolvimento da linguagem oral (WARNER-CZYZ et al., 2011). Pietola et al. (2012), em estudo realizado com um grupo de indivíduos com uma determinada síndrome, usuários de IC, concluíram que a qualidade de vida geral é potencializada pelo dispositivo.

Quando se refere à qualidade de vida observa-se que vários fatores estão envolvidos. Minayo, Harts e Buss (2000) referiram que a avaliação deste aspecto só é possível por meio de medidas subjetivas, envolvendo questionários que abordam aspectos da funcionalidade, definindo um estado normal para determinada idade, além de função social e seu desvio, ou morbidade. Concorda-se com Meinzen-Derr et al. (2010), quanto à menção de que as medidas de qualidade de vida são considerações importantes para as populações que não conseguem atingir os objetivos de comunicação auditivo-oral.

É importante ressaltar que à medida que o profissional reconhece os aspectos positivos e aqueles que ainda estão frágeis nesse tipo de população, forneça a oportunidade de delinear novas condutas terapêuticas buscando melhores desempenhos com o dispositivo. Resultados de qualidade de vida podem auxiliar no processo de intervenção, no processo da habilitação/reabilitação de crianças com 
variabilidade de resultados pós-implante e no direcionamento de condutas profissionais (FORTUNATO-TAVARES et al., 2012).

No presente estudo, dentre os domínios relacionados à qualidade de vida das crianças, descritos no questionário CCIPP, na perspectiva dos pais, a subescala que mais se evidenciou foi a relação social, seguida da autonomia/autoconfiança, funcionalidade, comunicação, bem estar/felicidade e, por último, a educação. $O$ suporte/apoio da criança e os efeitos do implante foram pontuados como inferiores ou negativos em relação as demais escalas. Verificou-se na perspectiva dos pais, que seus filhos após o IC, com o desenvolvimento de suas habilidades auditivas e/ou de fala, apresentaram melhora nas relações sociais, tiveram mais autonomia e autoconfiança no seu dia a dia, transformando-os em indivíduos socialmente e emocionalmente mais independentes. Relataram, assim, que o IC interferiu positivamente na vida de seus filhos. Almeida et al. (2015) descreveram o efeito positivo na qualidade de vida das crianças e de suas famílias e mencionaram que todos os domínios referentes à criança apresentaram melhoria de qualidade de vida após ativação do IC, sendo que no estudo em questão os pais apresentaram maior satisfação em relação aos domínios autoconfiança e relações sociais, sugerindo que a audibilidade, proporcionada pelo IC, associada à evolução das habilidades auditivas e linguísticas, gera aceitação e postura positiva da criança com relação à suas competências e habilidades nas situações de comunicação e, consequentemente, a ampliação de suas relações sociais.

Com resultados semelhantes, utilizando o mesmo instrumento, Silva (2017) verificou que os benefícios do IC (em pacientes não sindrômicos) impactaram na diminuição da necessidade de suporte da família à criança, que o domínio social apresentou o impacto mais significativo, seguido dos domínios da comunicação, funcionamento geral, autoconfiança, educação, bem-estar/felicidade e efeitos do IC sobre a família. Também com resultados positivos quanto à qualidade de vida, Van Nierop et al. (2016a) relataram que uma melhora significativa pós-implante, em crianças com síndromes, foi encontrada em quatro dos seis subdomínios do questionário utilizado: percepção sonora básica; percepção sonora avançada; produção de fala e limitações de atividade. Os dois subdomínios não significativos foram autoestima e interação social. 
De modo geral, pode-se confirmar que os pais são importantes críticos no processo de evolução da intervenção terapêutica de seus filhos, sendo que sua satisfação é um marcador do desenvolvimento e demonstrou que o uso do IC superou as expectativas de intervenção, como já havia sido apontado por Nikolopoulos et al. (2001) e Incesulu, Vural e Erkam (2003).

No questionário $\mathrm{NCIQ}$, aplicado aos indivíduos adultos, dos três domínios avaliados (físico, social e psicológico), os mais pontuados foram a percepção básica dos sons e produção de fala (domínio físico), seguido das interações sociais (domínio social) e autoestima (domínio psicológico), limitações em atividades (domínio social) e percepção avançada dos sons (domínio físico). A percepção básica dos sons e produção de fala foram os de maior pontuação, provavelmente pelo fato dos participantes terem melhor e maior acesso aos sons da fala após o IC e, com isso, reduzirem o impacto da deficiência auditiva para as situações de comunicação no seu dia a dia, com maior controle sobre a intensidade da sua própria voz e melhor inteligibilidade da fala. As interações sociais e autoestima também foram bem pontuadas, o que demonstra que o IC possibilita melhoras nos âmbitos social e emocional dos usuários, colaborando na melhor qualidade de vida. Sobre este tema, o estudo de Sousa (2017) revelou efeitos positivos na qualidade de vida para os diferentes aspectos e destacou que o domínio mais bem pontuado por meio do questionário NICQ foi o social, seguido pelos domínios psicológicos e físicos. Destacou que as variáveis gênero, idade, tempo de IC, nível de instrução e condição de estimulação não influenciaram nos aspectos da qualidade de vida.

Em suma, observa-se que o IC atua positivamente na qualidade de vida de seus usuários à medida que existe o uso efetivo do dispositivo, habilitação/reabilitação sistemática, apoio e comprometimento familiar, inserção no ensino regular, acompanhamento do dispositivo por equipe capacitada, proporcionando, assim, o desenvolvimento das habilidades auditivas e benefícios na comunicação, de modo a contribuir para melhor interação nas atividades de vida diária e nas relações sociais.

Por fim, é legitimo destacar que os benefícios obtidos com o IC variaram dentro do grupo estudado, visto que inúmeros fatores foram capazes de interferir nos resultados tais como: fonoterapia; idade do diagnóstico audiológico e da intervenção; alteração no DNPM, bem como fatores relacionados ao uso do dispositivo; motivação e ao apoio/comprometimento familiar. Associado a isso, a qualidade de vida também 
deve ser considerada, uma vez que se relaciona à percepção que cada indivíduo tem em relação a sua situação de vida.

Acredita-se que a comparação entre os dados obtidos por meio deste instrumento clínico e os resultados dos testes de percepção da fala poderá contribuir de maneira significativa para a compreensão mais detalhada do impacto e efetividade desta tecnologia, bem como para o monitoramento da evolução do indivíduo ao longo do tempo de uso do IC. Assim, as equipes de IC devem utilizar suas experiências e analisá-las caso a caso, a fim de garantir expectativas realistas quanto aos resultados.

É interessante observar que o presente estudo reflete não apenas a realidade da incidência das síndromes genéticas na população, como também a existência de perda auditiva sensorioneural de graus severo e profundo como sintomatologia, o que justifica a indicação do IC como estratégia de habilitação/reabilitação da função auditiva, ainda que em um grupo com características e resultados heterogêneos.

O estudo vem confirmar que o IC se justifica como estratégia de habilitação/reabilitação da função auditiva, na presença de síndromes genéticas, pois interfere positivamente na percepção da fala, linguagem oral e na qualidade de vida. Traz ainda um direcionamento aos profissionais quanto à intervenção e conduta terapêutica para cada indivíduo, respeitando-se a singularidade do atendimento clínico.

Por fim, verificou-se que a hipótese, inicialmente aventada, sobre a influência positiva do IC na percepção da fala, linguagem oral, como também, na qualidade de vida para indivíduos que apresentam deficiência auditiva no quadro de síndrome genética pôde ser ratificada, contribuindo para a melhor compreensão da reabilitação desta população. 

7 CONCLUSÃם 



\section{CONCLUSÃO}

A partir dos resultados obtidos no presente estudo, é possível concluir que:

a) há variabilidade nos resultados da percepção da fala e linguagem oral dos indivíduos com síndromes genéticas usuários de IC. No entanto, o desenvolvimento esperado da percepção da fala e da linguagem oral pode ser compatível com indivíduos com deficiência auditiva sem síndrome genética ao associar-se os resultados obtidos nos testes e categorias de percepção da fala e linguagem oral, desde que tais indivíduos não apresentem limitações motoras, sensoriais e cognitivas;

b) especificamente para indivíduos com SW, a idade na cirurgia do IC não interferiu nas variáveis percepção da fala e linguagem oral, mas o tempo de uso foi determinante;

c) para a SU, devido à reduzida casuística, não foi possível correlacionar as variáveis idade na cirurgia do IC e tempo de uso do dispositivo com a percepção da fala e linguagem oral;

d) para as demais síndromes constatou-se variabilidade na percepção da fala, linguagem oral, idade na cirurgia e tempo de uso do dispositivo nos indivíduos com deficiência auditiva de ocorrência peri e pós-lingual. $\mathrm{Na}$ deficiência auditiva de ocorrência pré-lingual constatou-se variabilidade na percepção da fala e da linguagem oral, entretanto, a idade na cirurgia foi precoce e o uso do dispositivo adequado;

e) na avaliação da qualidade de vida, na perspectiva dos pais ou responsáveis pelas crianças e pelos indivíduos adultos, a influência do IC apresentou impacto positivo, em sua maioria. O IC foi capaz de proporcionar melhor qualidade de vida aos usuários com síndromes genéticas. 

REFERÊNCIAS 



\section{REFERÊNCIAS}

ALMEIDA, R. P. et al. Avaliação da qualidade de vida em crianças usuárias de implante coclear. CoDAS, São Paulo, v. 27, n. 1, p. 29-36, 2015.

ALZHRANI, F. et al. The outcome of cochlear implantation among children with genetic syndromes. Eur Arch Otorhinolaryngol, Heidelberg, v. 275, n. 2, p. 365369, 2018.

AMIRSALARI, S. et al. Cochlear implantation outcomes in children with Waardenburg syndrome. Eur Arch Otorhinolaryngol, Heidelberg, v. 269, n. 10, p. 2179-2183, Oct. 2012.

ARCHBOLD, M. et al. Parents and their deaf child: their perceptions three years after cochlear implantation. Deafness Educ Int, London, v. 4, n. 1, p. 12-40, 2002.

BACCIU, A. et al. Cochlear implantation in patients with Cogan syndrome: long-term results. Eur Arch Otorhinolaryngol, Heidelberg, v. 272, p. 11, n. 3201-3207, Nov. 2015.

BARNARD, J. M. et al. A prospective longitudinal study of U.S. children unable to achieve open-set speech recognition 5 years after cochlear implantation. Otol Neurotol, Hagerstown, v. 36, n. 6, p. 985-992, July 2015.

BENTO, R. F. et al. Resultados auditivos com o implante coclear multicanal em pacientes submetidos a cirurgia no Hospital das Clínicas da Faculdade de Medicina da Universidade de São Paulo. Rev Bras Otorrinolaringol, São Paulo, v. 70, n. 5, p. 632-637, out. 2004.

BEVILACQUA, M. C.; TECH, E. A. Elaboração de um procedimento de avaliação de percepção de fala em crianças deficientes auditivas profundas a partir de 05 anos de idade. In: MARCHESAN, I. Q. I.; ZORZI, J. L.; GOMES, I. C. (ed.) Tópicos em fonoaudiologia. São Paulo, SP: Louvise, 1996. p. 411-433.

BEVILACQUA, M. C.; FORMIGONI, G. M. P. O Desenvolvimento das habilidades auditivas. In: BEVILACQUA, M. C.; MORET, A. L. M. (org.). Deficiência auditiva: conversando com familiares e profissionais de saúde. São José dos Campos: Pulso, 2005. p. 179-201.

BEVILACQUA, M. C.; DELGADO, E. M. C.; MORET, A. L. M. Estudos de casos clínicos em crianças do Centro Educacional do Deficiente Auditivo (CEDAU) do Hospital de Pesquisa e Reabilitação de Lesões Lábios Palatais - USP. In: ENCONTRO INTERNACIONAL DE AUDIOLOGIA, 11., Bauru. Anais [...]. HRACUSP, 1996.

BEVILACQUA, M. C.; COSTA, A. O.; AMANTINI, R. B. Considerações sobre o implante coclear em crianças. In: BEVILACQUA, M. C.; MORET, A. L. M. (org.). Deficiência auditiva: conversando com familiares e profissionais da saúde. São José dos Campos: Pulso, 2005. p 123-138. 
BEVILACQUA, M. C.; MORET, A. L. M.; COSTA, A. O. Conceituação e indicação do implante coclear. In: BEVILACQUA, M. C. et al. Tratado de audiologia. São Paulo: Santos, 2011. p. 407-426.

BEVILACQUA, M. C. et al. Resultado e prognóstico auditivo da criança pré e póslingual com implante coclear. In: BENTO, R. F. et al. (ed.). Tratado de implante coclear e próteses auditivas implantáveis. Rio de Janeiro, Thieme, 2014. p. 309315.

BLACK, J.; HICKSON, L.; BLACK, B. Defining and evaluating success in pediatric cochlear implantation - an exploratory study. Int J Pediatr Otorhinolaringol, v. 76, n. 9, p. 1317-1326, Sept. 2012.

CASTIQUINI, E. A. T.; BEVILACQUA, M. C. Escala de integração auditiva significativa: procedimento adaptado para avaliação da percepção da fala. Rev Soc Bras Fonoaudiol, São Paulo, v. 4, n. 6, p. 51-60, 2000.

COELHO, A. C. C. et al. Relação entre voz e percepção de fala em crianças com implante coclear. Pró-Fono, Barueri, v. 21, n. 1, p. 7-12, mar. 2009.

COLLETTI, L. et al. Infants versus older children fitted with cochlear implants: performance over 10 years. Int J Pediatr Otorhinolaryngol, Amsterdam, v. 75, n. 4, p. 504-509, 2011.

COMERLATTO, M. P. S. Habilidades auditivas e de linguagem de crianças usuárias de implante coclear: análise dos marcadores clínicos de desenvolvimento. 2015. Tese (Doutorado em Otorrinolaringologia) - Faculdade de Medicina da Universidade de São Paulo, São Paulo, 2015.

COSTA, O. A.; BEVILACQUA, M. C.; TABANEZ, L. N. Implantes cocleares em crianças. In: LAVINSK, Y. L. Tratamento em otologia. Rio de Janeiro: Revinter, 2006. cap. 79 , p. $478-484$.

DELGADO, E. M. C.; BEVILACQUA, M. C. Lista de palavras como procedimento de avaliação da percepção dos sons da fala para crianças deficientes auditivas. PróFono, Barueri, v. 11, n. 1, p. 59-64, mar. 1999.

DOWELL, R. C.; COWAN, R. S. C. Evaluation of benefit: infants and children. In: CLARK, G. M.; COWAN, R. S.C.; DOWELL, R. C. Cochlear implantation for infants and children. San Diego: Singular Publishing Group, 1997. p. 205-221.

DUNN, C. C. et al. Longitudinal speech perception and language performance in pediatric cochlear implant users: the effect of age at implantation. Ear Hear, Baltimore, v. 35, n. 2, p. 148-160, Mar./Apr. 2014.

FISHMAN, G. A. et al. Usher's syndrome. Ophthalmic and neuro-otologic findings suggesting genetic heterogeneity. Arch Ophthalmol, Chicago, v. 101, n. 9, p. 13671374, Sept. 1983.

FORTUNATO-TAVARES, T. et al. Crianças com implante coclear: habilidades comunicativas e qualidade de vida. Braz J Otorhinolaryngol, São Paulo, v. 78, n. 1, p. 15-25, fev. 2012. 
GEERS, A. E. Techniques for assessing auditory speech perception and lipreading enhancement in young deaf children. Volta Rev, v. 96, n. 5, p. 85-96, 1994.

GEERS, A. E. Factors affecting the development of speech, language, and literacy in children with cochlear implantation. Lang Speech Hear Serv Sch, Washington, v. 33, n. 3, p. 172-183, July 2002.

GEERS, A. E. Speech, language and reading skills after early cochlear implantation. Arch Otolaryngol Head Neck Surg, Chicago, v. 130, n. 5, p. 634-638, May 2004.

GEERS, A. E.; SEDEY, A. L. Language and verbal reasoning skills in adolescents with 10 or more years of cochlear implant experience. Ear Hear, Baltimore, v. 32, Suppl 1, p. 39S-48S, Feb. 2011.

GEERS, A. E.; BRENNER, C. DAVIDSON, L. Factors associated with development of speech perception skills in children implanted by age five. Ear Hear, Baltimore, v. 24, Suppl 1, p. 24S-35S, Feb. 2003.

GIACHETI, C. M. Fonoaudiologia e genética: estudos contemporâneos. In: FERNANDES, F. D.; MENDES, B.; NAVAS. A. L. (org.). Tratado de fonoaudiologia. 2. ed. São Paulo, SP: Roca, 2010. p. 52-59.

GODINHO, R.; KEOGH, I.; EAVEY, R. Perda auditiva genética. Rev Bras Otorrinolaringol, São Paulo, v. 69, n. 1, p. 100-104, jan. 2003.

HARRIS, M. S. et al. Verbal short-term memory development and spoken language outcomes in deaf children with cochlear implants. Ear Hear, Baltimore, v. 34, n. 2, p. 179-192, Mar./Apr. 2013.

HINDERINK, J. B.; KRABBE, P. F.; VAN DEN BROEK, P. Development and application of a health - related quality-of-life instrument for adults with cochlear implants: the Nijmegen cochlear implant questionnaire. Otolaryngol Head Neck Surg, Rochester, v. 123, n. 6, p. 756-765, Dec. 2000.

INCESULU, A.; VURAL, M.; ERKAM, U. Children with cochlear implants: parental perspective. Otol Neurotol, Hagerstown, v. 24, n. 4, p. 605-611, July 2003.

JATANA, K. R. et al. Usher syndrome: characteristics and outcomes of pediatric cochlear implant recipient. Otol Neurotol, Hagerstown, v. 34, n. 3, p. 484-489, Apr. 2013.

KIRK, K. I.; HUDGINS, M. Speech perception and spoken word recognition in children with cochlear implants. In: YOUNG, N.; KIRK, K. I. (ed.). Pediatric cochlear implantation: learning and the brain. New York, NY: Springer, 2016. p. 145-161.

KONTORINIS, G. et al. Outcomes and special considerations of cochlear implantation in Waardenburg syndrome. Otol Neurotol, Hagerstown, v. 32, n. 6 , p. 951-955, Aug. 2011.

LIBERATI, A. et al. The PRISMA Statement for reporting systematic reviews and meta-analyses of studies that evaluate health care interventions: explanation and elaboration. PLoS Med, San Francisco, v. 6, n. 7, p. e1000100, July 2009. 
LOUNDON, N. et al. Usher syndrome and cochlear implantation. Otol Neurotol, Hagerstown, v. 24, n. 2, p. 216-221, Mar. 2003.

MAGALHÃES, A. T. M. et al. Audiological outcomes of cochlear implantation in Waardenburg syndrome. Int Arch Otorhinolaryngol, São Paulo, v. 17, n. 3, p. 285290, July 2013.

MARTINS, M. B. B. et al. Implante coclear: nossa experiência e revisão de literatura. Int Arch Otorhinolaryngol, São Paulo, v. 16, n. 4, p. 476-481, dez. 2012.

MEINZEN-DERR, J. et al. Language performance in children with cochlear implants and additional disabilities. Laryngoscope, St. Louis, v. 120, n. 2, p. 405-413, Feb. 2010.

MINAYO, M. C. S.; HARTS, Z. M. A.; BUSS, P. M. Qualidade de vida e saúde: um debate necessário Ciênc Saúde Coletiva, Rio de Janeiro, v. 5, n. 1, p. 7-18, 2000.

MOOG, J. S.; GEERS, A. E. Early educational placement and later language outcomes for children with cochlear implants. Otol Neurotol, Hagerstown, v. 31, n. 8, p. 1315-1319, Oct. 2010.

MORET, A. L. M. Implante coclear: audição e linguagem em crianças deficientes auditivas neurossensoriais profundas pré-linguais. 2002. Tese (Doutorado em Distúrbios da Comunicação Humana) - Hospital de Reabilitação de Anomalias Craniofaciais da Universidade de São Paulo, Bauru, SP, 2002.

MORET, A. L. M. Percepção auditiva da fala em crianças e adolescentes com implante coclear bilateral sequencial. 2016. 80 p. Tese (Livre-Docência em Fonoaudiologia) - Faculdade de Odontologia de Bauru, Universidade de São Paulo, Bauru, SP, 2016.

MORET, A. L. M.; BEVILACQUA, M. C.; COSTA, A. O. Implante coclear: audição e linguagem em crianças deficientes auditivas pré-linguais. Pró-Fono, Barueri, v. 19, n. 3, p. 295-304, set. 2007.

MORETTIN, M. et al. Avaliação da qualidade de vida em crianças com implante coclear: revisão sistemática. Braz J Otorhinolaryngol, São Paulo, v. 79, n. 3, p. 375-381, 2013.

NASCIMENTO, L. T. Uma proposta e avaliação da linguagem oral. 1997. Monografia (Especialização em Audiologia) - Hospital de Reabilitação de Lesões Lábio Palatais da Universidade de São Paulo, Bauru, SP, 1997.

NASCIMENTO, L. T.; BEVILACQUA, M. C. Avaliação da percepção da fala com ruído competitivo em adultos com implante coclear. Rev Bras Otorrinolaringol, São Paulo, v. 71, n. 4, p. 432-438, ago. 2005.

NIKOLOPOULOS, T. P. et al. Pediatric cochlear implantation: the parents' perspective. Arch Otolaryngol Head Neck Surg, Chicago, v. 127, n. 4, p. 363-367, Apr. 2001. 
NIPARKO, J. K. et al. Spoken language development in children following cochlear implantation. JAMA, Chicago, v. 303, n. 15, p. 1498-1506, Apr. 2010.

OLIVEIRA, S. T. Avaliação da percepção da fala utilizando sentenças do dia a dia. 1992. Dissertação (Mestrado) - Pontifícia Universidade Católica de São Paulo, São Paulo, 1992.

O'NEILL, C. et al. Variations in gains in auditory performance from pediatric cochlear implantation. Otol Neurotol, Hagerstown, v. 1, n. 23, p. 44-48, Jan. 2002.

O'NEILL, C. et al. Parents and their cochlear implanted child: questionnaire development to assess parental views and experiences. Int J Pediatr Otorhinolaryngol, Amsterdam, v. 68, n. 2, p. 149-160, 2004.

PENNINGS, R. J. E. et al. Audiologic performance and benefit of cochlear implantation in Usher syndrome type I. Laryngoscope, St. Louis, v. 116, n. 5, p. 717722, May 2006.

PEREIRA, É. F.; TEIXEIRA, C. S.; SANTOS, A. Quality of life: approaches, concepts and assessment. Rev Bras Educ Fís Esporte, São Paulo, v. 26, n. 2, p. 241-250, 2012.

PIETOLA, L. et al. Speech recognition and communication outcomes with cochlear implantation in Usher syndrome type 3. Otol Neurotol, Hagerstown, v. 33, n. 1, p. 38-41, Jan. 2012.

QUINTANA MIRABAL, S. E. et al. Implante coclear en niños con hipoacusia de causa genética por Síndrome Waardenburg y mutación 35delG. Rev Haban Cienc Méd, La Habana, v. 15, n. 3, p. 335-347, jun. 2016.

RAJPUT, K.; BROWN, T.; BAMIOU, D. E. Aetiology of hearing loss and other related factors versus language outcome after cochlear implantation in children. Int $\mathbf{J}$ Pediatr Otorhinolaryngol, Amsterdam, v. 67, n. 5, p. 497-504, May 2003.

RAY, J. et al. Non-users and limited users of cochlear implants. Cochlear Implants Int, London, v. 7, n. 1, p. 49-58, Mar 2006.

READ, A. P.; NEWTON, V. E. Waardenburg syndrome. J Med Genet, London, v. 34, n. 8, p. 656-665, Aug. 1997.

ROBBINS, A. M.; OSBERGER, M. J. Meaningful use of speech scale. Indianapolis: Indiana University School of Medicine Press, 1991.

ROBBINS, A. M.; GREEN, J.; BOLLARD, P. Language development in children following one year of Clarion implant use. Ann Otol Rhinol Laryngol Suppl, St. Louis, v. 185, p. 94-95, Dec. 2000.

SANTOS, N. P.; COUTO, M. I. V.; MARTINHO-CARVALHO, A. C. Nijmegen Cochlear Implantation Questionnaire (NCIQ): tradução, adaptação cultural e aplicação em adultos usuários de implante coclear. CoDAS, São Paulo, v. 29, n. 6, e20170007, 2017. 
SIAGH, R. F. S. Crianças usuárias de implante coclear com atraso do desenvolvimento da percepção auditiva da fala: análise dos fatores que influenciam o desempenho. 2018. Tese (Doutorado em Fonoaudiologia) - Faculdade de Odontologia de Bauru, Universidade de São Paulo, Bauru, SP, 2018.

SILVA, J. M. Qualidade de vida de crianças com implante coclear. 2017.

Dissertação (Mestrado em Fonoaudiologia) - Faculdade de Odontologia de Bauru, Universidade de São Paulo, Bauru, SP, 2017.

SOUSA, A. F. Qualidade de vida e implante coclear: resultados em adultos com deficiência auditiva pós-lingual. 2017. Dissertação (Mestrado em Ciências da Reabilitação) - Faculdade de Medicina, Universidade de São Paulo, São Paulo, 2017.

SZAGUN, G.; STUMPER, B. Age or experience? The influence of age at implantation and social and linguistic environment on language development in children with cochlear implants. J Speech Lang Hear Res, Rockville, v. 55, n. 6, p. 1640-1654, Dec. 2012.

THAI-VAN, H. et al. Plasticity of tonotopic maps in humans: influence of hearing loss, hearing aids and cochlear implants. Acta Otolaryngol, Stockholm, v. 130, n. 3, p. 333-337, Mar. 2010.

TREVISI, P. et al. Outcomes of long-term audiological rehabilitation in Charge syndrome. Acta Otorhinolaryngol Ital, Pisa, v. 36, n. 3, p. 206-214, June 2016.

VAN NIEROP, J. W. I. et al. Patients with Pendred syndrome: is cochlear implantation beneficial? Clin Otolaryngol, Oxford, v. 41, n. 4, p. 386-394, Aug. 2016a.

VAN NIEROP, J. W. I. et al. Pediatric cochlear implantation in patients with Waardenburg syndrome. Audiol Neurotol, Basel, v. 21, n. 3, p. 187-194, 2016b.

WARNER-CZYZ, A. D. et al. Health related quality of life in children and adolescents who use cochlear implants. Int J Pediatr Otorhinolaryngol, Amsterdam, v. 75, n. 1, p. 95-105, 2011.

WILSON, B. S.; DORMAN, M. F. Cochlear implants: current designs and future possibilities. J Rehabil Res Dev, Washington, v. 45, n. 5, p. 695-730, 2008.

WORLD HEALTH ORGANIZATION. Prevent of blindness and deafness: grades of hearing impairment. c2018. Disponível em: http://www.who.int/pbd/deafness/hearing _impairment_grades/en. Acesso em: 15 jan. 2018.

YOUNG, N. M. et al. Outcomes and time to emergence of auditory skills after cochlear implantation of children with Charge syndrome. Otol Neurotol, Hagerstown, v. 38, n. 8, p. 1085-1091, Sept. 2017. 
APÊNDICES 



\section{APÊNDICE A}

Identificação

Estudos identificados nas bases de dados eletrônicas $(n=1.369)$

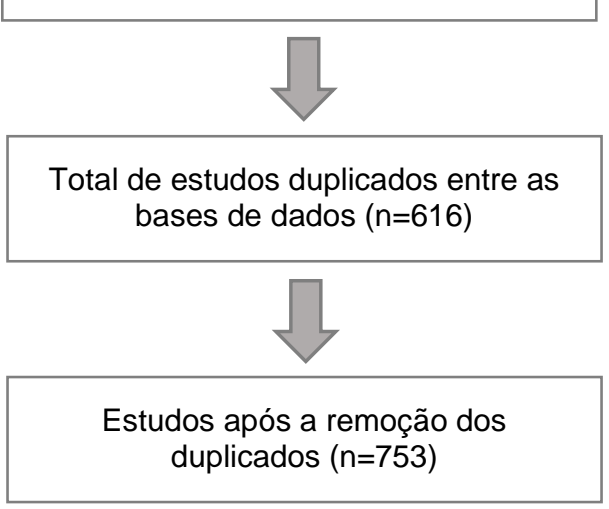

Seleção

Estudos selecionados para análise pelo título/resumo $(n=117)$
Estudos excluídos

Não aborda o tema proposto $(\mathrm{n}=29)$

Estudo de caso $(n=43)$

Série de casos $(n=30)$

Elegibilidade

Estudos selecionados para leitura na íntegra pelo resumo $(n=15)$

Inclusão

Foram incluídos para a revisão da literatura 15 estudos apresentados posteriormente

Fonte: Adaptado de Liberati et al. (2009). 


\title{
APÊNDICE B
}

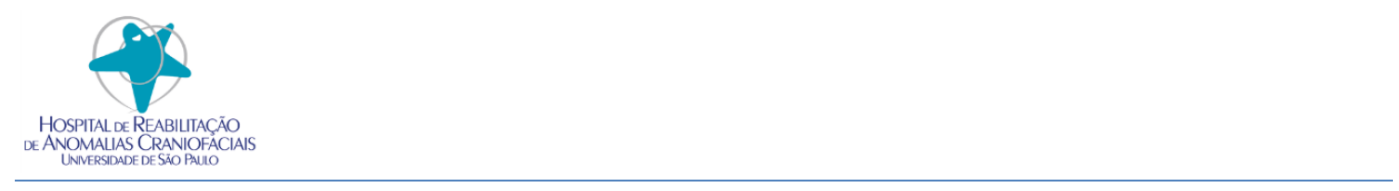

\author{
HOSPITAL DE REABILITAÇÃO DE ANOMALIAS CRANIOFACIAIS \\ SEÇÃO DE IMPLANTE COCLEAR (SIC)
}

\section{TERMO DE CONSENTIMENTO LIVRE E ESCLARECIDO}

Você está sendo convidado(a) a participar, como voluntário(a), da pesquisa intitulada "Percepção auditiva da fala, linguagem oral e qualidade de vida em indivíduos com síndromes genéticas usuários de implante coclear" realizada pela pesquisadora Karina Costa Brosco Mendes, sob orientação da Professora Dra. Ana Paula Fukushiro.

No objetivo deste estudo vou verificar se os indivíduos com síndromes genéticas que receberam o implante coclear percebem os sons e conseguem adquirir a fala da mesma forma que os indivíduos que não apresentam síndromes genéticas, e também, como o implante coclear está influenciando na qualidade de vida dos adultos, das crianças e seus familiares. Este estudo tem alguns objetivos específicos:

- Quero saber se a sua idade na época da cirurgia e o tempo que fez uso do implante coclear influenciaram para você perceber melhor os sons;

- Quero saber se a sua idade na época que fez a cirurgia e o tempo que fez uso do implante coclear influenciaram na sua fala atual e;

- Quero saber se o desenvolvimento da sua audição e fala ocorreu da mesma forma que os indivíduos que receberam o implante coclear sem síndromes genéticas. coclear.

O estudo irá colaborar para melhorar a sua comunicação e sua qualidade de vida com o implante

Caso decida aceitar o convite, você responderá a um questionário de 60 questões, mas antes será orientado como respondê-lo. Você responderá o questionário por aproximadamente 1 hora estando sentado confortavelmente em uma cadeira dentro de uma sala convencional e bem ventilada. Você terá a garantia de que os resultados encontrados serão explicados.

Você responderá o questionário durante sua rotina de atendimento e você não terá despesas adicionais não havendo, portanto, ressarcimento com alimentação, locomoção e hospedagem.

O benefício desse estudo é buscar com os resultados maior qualidade no seu tratamento, assim como também, na sua qualidade de vida com o implante coclear.

Os riscos envolvidos na participação desta pesquisa são: cansaço pelo tempo de aplicação do questionário ou algum constrangimento que as perguntas do questionário possam causar. Se ocorrer cansaço paramos o questionário para você descansar tomar água e ir ao banheiro caso queira e se ocorrer constrangimento paramos de realizar a pesquisa.

Sua participação é voluntária, o que significa que você poderá se recusar a participar ou desistir a qualquer momento, retirando seu consentimento, sem que isso lhe traga algum prejuízo ou penalidade. Todas as informações obtidas nos questionários serão sigilosas e o seu nome não será identificado em nenhum momento. Os dados serão guardados em local seguro e a divulgação dos resultados será feita de forma a não te identificar.

Você terá direito a indenização e assistência integral e imediata, de forma gratuita, pelo tempo que for necessário no caso de problemas causados pela pesquisa. Informo que o Sr.(a) terá acesso, em qualquer uma das partes do estudo, sobre qualquer esclarecimento de dúvidas.

Este documento deverá ser assinado por você em duas vias, você receberá uma via e a outra ficará comigo que sou o pesquisador.

Se tiver alguma coisa para dizer ou dúvida sobre a ética da pesquisa, entre em contato com o Comitê de Ética em Pesquisa-HRAC-USP, à Rua Silvio Marchione, 3-20 - Vila Universitária - CEP 17012-900 Bauru/SP, de segunda à sexta das 8 às 18 h, ou pelo telefone (14) 3235-8421, e-mail: cephrac@usp.br.

O pesquisador responsável pelo estudo poderá fornecer qualquer esclarecimento, assim como tirar as dúvidas. Neste caso, você poderá entrar em contato com Karina Costa Brosco Mendes na Seção de Implante Coclear, no endereço Rua Sílvio Marchione, 3-20, Bauru-SP, pelo telefone (14) 3235-8410/30185459 ou pelo e-mail: karinacpa@usp.br 


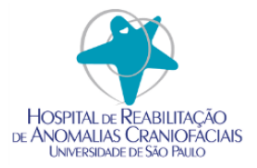

\section{HOSPITAL DE REABILITAÇÃO DE ANOMALIAS CRANIOFACIAIS SEÇÃO DE IMPLANTE COCLEAR (SIC)}

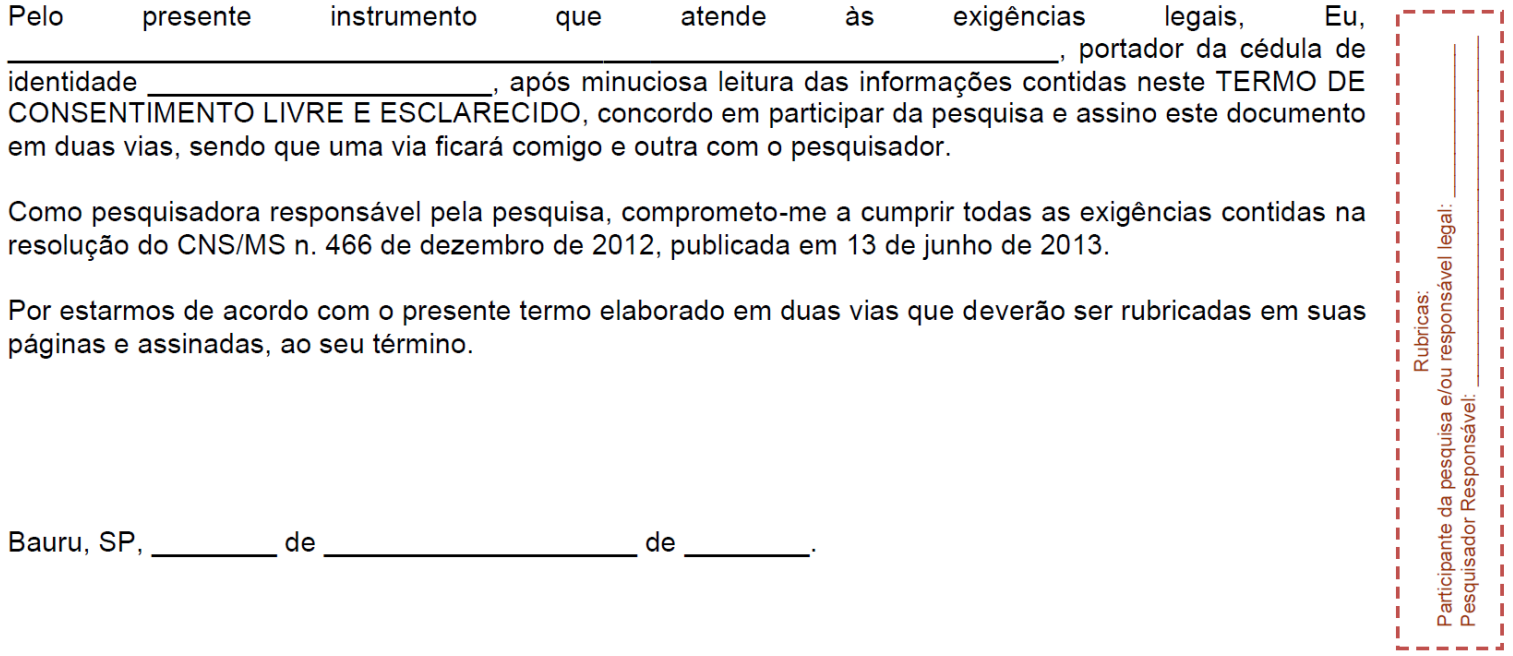

Assinatura do Participante da Pesquisa $\quad$ Nome/Assinatura do Pesquisador(a) 


\section{APÊNDICE C}

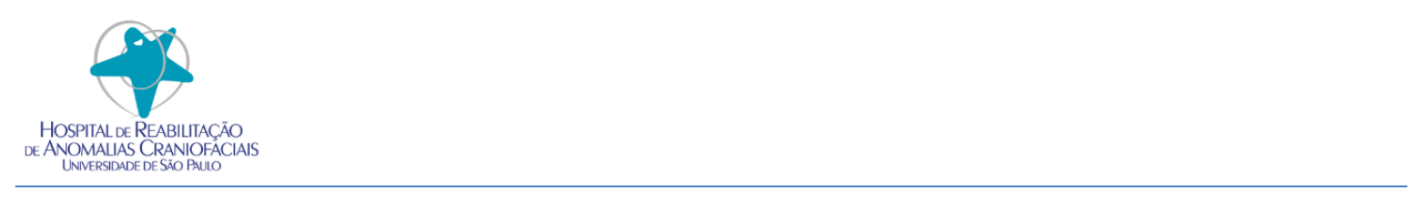

\section{HOSPITAL DE REABILITAÇÃO DE ANOMALIAS CRANIOFACIAIS SEÇÃO DE IMPLANTE COCLEAR (SIC)}

\section{TERMO DE CONSENTIMENTO LIVRE E ESCLARECIDO}

Você está sendo convidado(a) a participar, como voluntário(a), da pesquisa intitulada "Percepção auditiva da fala, linguagem oral e qualidade de vida em indivíduos com síndromes genéticas usuários de implante coclear" realizada pela pesquisadora Karina Costa Brosco Mendes, sob orientação da Professora Dra. Ana Paula Fukushiro.

No objetivo deste estudo vou verificar se os indivíduos com síndromes genéticas que receberam o implante coclear percebem os sons e conseguem adquirir a fala da mesma forma que os indivíduos que não apresentam síndromes genéticas, e também, como o implante coclear está influenciando na qualidade de vida dos adultos, das crianças e seus familiares. Este estudo tem alguns objetivos específicos:

- Quero saber se a idade de seu filho na época que fez a cirurgia e o tempo que ele fez uso do implante coclear influenciou para ele perceber melhor os sons

- Quero saber se a idade de seu filho na época que fez a cirurgia e o tempo que ele fez uso do implante coclear influenciou na fala atual que ele apresenta e;

- Quero saber se o desenvolvimento da audição e da fala de seu filho está ocorrendo da mesma forma que os indivíduos que receberam o implante coclear sem síndromes genéticas coclear.

O estudo irá colaborar para melhorar a comunicação e a qualidade de vida de seu filho com o implante

Caso decida aceitar o convite, você responderá a um questionário de 74 questões, mas antes será orientado como respondê-lo. Você responderá o questionário por aproximadamente 1 hora estando sentado confortavelmente em uma cadeira dentro de uma sala convencional e bem ventilada. Você terá a garantia de que os resultados encontrados serão explicados.

Você responderá o questionário durante sua rotina de atendimento e você não terá despesas adicionais não havendo, portanto, ressarcimento com alimentação, locomoção e hospedagem.

O benefício desse estudo é buscar através dos resultados encontrados, maior qualidade no tratamento, assim como também, na sua qualidade de vida de seu filho com o implante coclear.

Os riscos envolvidos na participação desta pesquisa são: cansaço pelo tempo de aplicação do questionário ou algum constrangimento que as perguntas do questionário possam causar. Se ocorrer cansaço paramos o questionário para você descansar tomar água e ir ao banheiro caso queira e se ocorrer constrangimento paramos de realizar a pesquisa.

Sua participação é voluntária, o que significa que você poderá se recusar a participar ou desistir a qualquer momento, retirando seu consentimento, sem que isso lhe traga algum prejuízo ou penalidade. Todas as informações obtidas nos questionários serão sigilosas e o seu nome não será identificado em nenhum momento. Os dados serão guardados em local seguro e a divulgação dos resultados será feita de forma a não te identificar.

Você terá direito a indenização e assistência integral e imediata, de forma gratuita, pelo tempo que for necessário no caso de problemas causados pela pesquisa. Informo que o Sr.(a) terá acesso, em qualquer uma das partes do estudo, sobre qualquer esclarecimento de dúvidas.

Este documento deverá ser assinado por você em duas vias e você receberá uma via e a outra ficará comigo que sou o pesquisador.

Se tiver alguma coisa para dizer ou dúvida sobre a ética da pesquisa, entre em contato com o Comitê de Ética em Pesquisa-HRAC-USP, à Rua Silvio Marchione, 3-20 - Vila Universitária - CEP 17012-900 Bauru/SP, de segunda à sexta das 8 às $18 \mathrm{~h}$, ou pelo telefone (14) 3235-8421, e-mail: cephrac@usp.br.

O pesquisador responsável pelo estudo poderá fornecer qualquer esclarecimento, assim como tirar as dúvidas. Neste caso, você poderá entrar em contato com Karina Costa Brosco Mendes na Seção de Implante Coclear, no endereço Rua Sílvio Marchione, 3-20, Bauru-SP, pelo telefone (14) 3235-8410/30185459 ou pelo e-mail: karinacpa@usp.br

\footnotetext{
Hospital de Reabilitação de Anomalias Craniofaciais, Universidade de São Paulo

Rua Sílvio Marchione, 3-20 - Vila Universitário - CEP. 17.012-900 - Bauru - SP

Fone/FAX:(0xx14) 32266500 / e-mail: spp@usp.brhttp://www.hrac.usp.br
}

Term_Consent_V2.0 


\section{HOSPITAL DE REABILITAÇÃO DE ANOMALIAS CRANIOFACIAIS SEÇÃO DE IMPLANTE COCLEAR (SIC)}

\begin{tabular}{c} 
Pelo presente instrumento que atende à exigências $\begin{array}{c}\text { legais, } \\
\text { portador da cédula de }\end{array}$ \\
\hline
\end{tabular}
identidade , após minuciosa leitura das informações contidas neste TERMO DE CONSENTIMENTO LIVRE E ESCLARECIDO, concordo em participar da pesquisa e assino este documento em duas vias, sendo que uma via ficará comigo e outra com o pesquisador.

Como pesquisadora responsável pela pesquisa, comprometo-me a cumprir todas as exigências contidas na resolução do CNS/MS n. 466 de dezembro de 2012, publicada em 13 de junho de 2013.

Por estarmos de acordo com o presente termo elaborado em duas vias que deverão ser rubricadas em suas páginas e assinadas, ao seu término.

Bauru, SP de de

Nome/Assinatura do Pesquisador(a) 

ANEXDS 



\section{ANEXO A - Parecer de Aprovação do Comitê de Ética em Pesquisa}

\section{USP - HOSPITAL DE REABILITAÇÃO DE ANOMALIAS CRANIOFACIAIS}

\section{PARECER CONSUBSTANCIADO DO CEP}

\section{DADOS DO PROJETO DE PESQUISA}

Título da Pesquisa: Percepção auditiva da fala, linguagem oral e qualidade de vida em indivíduos portadores de síndromes genéticas usuários de implante coclear.

Pesquisador: Karina Brosco Mendes

Área Temática:

Versão: 1

CAAE: 02881918.6 .0000 .5441

Instituição Proponente: Hospital de Reabilitação de Anomalias Craniofaciais da USP

Patrocinador Principal: Financiamento Próprio

\section{DADOS DO PARECER}

\section{Número do Parecer: 3.046 .495}

\section{Apresentação do Projeto:}

Trata-se de um projeto de Tese de Doutorado, de autoria de Karina Costa Brosco Mendes sob orientação de Profa. Dra. Ana Paula Fukushiro e co-orientação de Profa. Kátia de Freitas Alvarenga.

Serão analisados 18 prontuários de pacientes diagnosticados com deficiência auditiva sensorioneural de grau severo/profundo bilateral, independente do sexo e idade que foram submetidos ao implante coclear, matriculados na Seção de Implante Coclear do Hospital de Reabilitação de Anomalias Craniofaciais da Universidade de São Paulo, SIC/HRAC - USP. Trata-se de um estudo retrospectivo, longitudinal, transversal e descritivo na primeira etapa e prospectivo, transversal na segunda etapa.

Na primeira etapa serão analisados os seguintes procedimentos: - pesquisa do limiar na situação de uso do dispositivo eletrônico - IC ligado; IC e AASI contralateral ligados (audição bimodal); IC coclear bilateral ligados, percepção auditiva da fala e da linguagem oral, IT-MAIS/MAIS, GASP, Lista de palavras, Procedimento de avaliação da percepção da fala para adultos deficientes auditivos profundos, Teste de reconhecimento de sentenças proposto por Oliveira (1992), Meaningful Use of Speech Scale (MUSS) e Categorias de Linguagem. Na segunda etapa além das medidas clínicas, a efetividade da intervenção auditiva por meio do implante coclear será analisada quanto ao impacto na qualidade de vida. Para os pacientes adultos será utilizado o questionário Nijmegen Cochlear Implantation Questionnaire (NCIQ) traduzido e adaptado culturalmente para o Português Brasileiro por Santos, Couto e Martinho Carvalho(2017), composto por 60 questões, dispendendo 01 hora

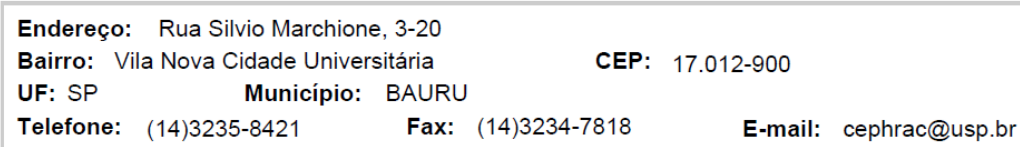




\section{USP - HOSPITAL DE REABILITAÇÃO DE ANOMALIAS CRANIOFACIAIS

Continuação do Parecer: 3.046 .495

para aplicação em sala arejada e para os pais ou responsáveis pelas crianças será utilizado o questionário Children with cochlear implants: parental perspectives (CCIPP) traduzido, adaptado e validado para o Português Brasileiro por Fortunato-Tavares et al. (2012), com 74 questões também dispendendo 01 hora para aplicação em sala arejada. Os questionários serão aplicados pela pesquisadora responsável no atendimento de acompanhamento da rotina do programa de implante coclear.

Hipótese:

A hipótese deste estudo concentra-se na ideia de que os resultados esperados com o uso do implante coclear na perda auditiva sensorioneural podem ter influência das características da síndrome genética, sendo esta mais evidenciada no desenvolvimento da linguagem oral quando comparado ao desenvolvimento das habilidades auditivas para a percepção auditiva da fala, assim como também, na qualidade de vida.

\section{Objetivo da Pesquisa:}

Objetivo Primário:

Caracterizar o desenvolvimento da percepção auditiva da fala e da linguagem oral de indivíduos com síndromes genéticas usuários de implante coclear, assim como, verificar o impacto na qualidade de vida na perspectiva do paciente adulto ou da família das crianças.

Objetivo Secundário:

- Analisar a correlação entre a idade na cirurgia e tempo de uso do implante coclear com a percepção auditiva da fala atual, de acordo com a síndrome genética.

- Analisar a correlação entre a idade na cirurgia e tempo de uso do implante coclear com a linguagem oral atual, de acordo com a síndrome genética.

- Verificar o impacto da idade na cirurgia do implante coclear no desenvolvimento da percepção auditiva da fala e da linguagem oral de acordo com marcadores clínicos de desenvolvimento disponíveis.

\section{Avaliação dos Riscos e Benefícios:}

Riscos:

Os riscos diretos ao participante de pesquisa serão aplicados apenas na segunda fase do projeto, como: cansaço pelo tempo de aplicação do questionário ou algum constrangimento que as perguntas do mesmo possam causar. Frente a isso, a pesquisadora pausará a coleta de informação por um tempo até que o mesmo esteja restabelecido. A pesquisa também será interrompida,

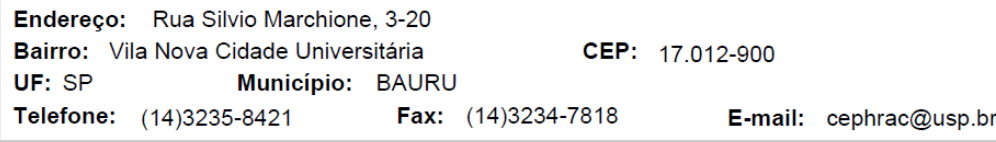




\section{USP - HOSPITAL DE
REABILITAÇÃO DE
ANOMALIAS CRANIOFACIAIS}

Continuação do Parecer: 3.046 .495

dando, inclusive, o direito ao participante em desistir do estudo mediante constrangimento. Salienta-se que a coleta de informações será realizada em ambiente iluminado, ventilado, tranquilo e reservado.

Benefícios:

Os benefícios desse estudo será buscar através dos resultados encontrados, maior qualidade no tratamento fonoaudiológico, assim como também, na qualidade de vida dos indivíduos portadores de síndromes genéticas usuários de implante coclear.

\section{Comentários e Considerações sobre a Pesquisa:}

A pesquisa tem mérito e está bem fundamentada e irá contribuir para o desenvolvimento da comunicação e melhor aproveitamento do implante coclear nesse tipo de população, assim como também para a fonoaudiologia voltada à genética.

\section{Considerações sobre os Termos de apresentação obrigatória:}

Carta de encaminhamento;

Formulário HRAC;

Folha de Rosto da Plataforma Brasil;

Termo de Consentimento Livre e Esclarecido;

Termo de Compromisso, Confidencialidade e Autorização de Utilização de Dados em Projetos de Pesquisa Termo de Permissão para uso de Registros para Fins Científicos;

Termo de Compromisso de Tornar Públicos os Resultados da Pesquisa e Destinação de Materiais ou Dados Coletados;

Termo de Compromisso do Pesquisador Responsável.

\section{Recomendações:}

Padronizar no TCLE o tipo e tamanho da letra.

\section{Conclusões ou Pendências e Lista de Inadequações:}

Sugiro ao CEP a aprovação do projeto.

\section{Considerações Finais a critério do CEP:}

O pesquisador deve atentar que o projeto de pesquisa aprovado por este CEP refere-se ao protocolo submetido para avaliação. Portanto, conforme a Resolução CNS 466/12, o pesquisador é responsável por "desenvolver o projeto conforme delineado", se caso houver alterações nesse projeto, este CEP deverá ser comunicado em emenda via Plataforma Brasil, para nova avaliação.

Cabe ao pesquisador notificar via Plataforma Brasil o relatório final para avaliação. Os Termos de

Endereço: Rua Silvio Marchione, 3-20

Bairro: Vila Nova Cidade Universitária

UF: SP Município: BAURU

Telefone: (14)3235-8421
CEP: $17.012-900$

(14)3234-7818
E-mail: cephrac@usp.br 


\section{USP - HOSPITAL DE REABILITAÇÃO DE ANOMALIAS CRANIOFACIAIS

Continuação do Parecer: 3.046 .495

Consentimento Livre e Esclarecidos e/ou outros Termos obrigatórios assinados pelos participantes da pesquisa deverão ser entregues ao CEP. Os relatórios semestrais devem ser notificados quando solicitados no parecer.

Este parecer foi elaborado baseado nos documentos abaixo relacionados:

\begin{tabular}{|c|c|c|c|c|}
\hline Tipo Documento & Arquivo & Postagem & Autor & Situação \\
\hline Outros & Checklist_Prot_Pesq_99_2018.pdf & $\begin{array}{c}14 / 11 / 2018 \\
14: 38: 45\end{array}$ & $\begin{array}{l}\text { Rafael Mattos de } \\
\text { Deus }\end{array}$ & Aceito \\
\hline $\begin{array}{l}\text { Informações Básicas } \\
\text { do Projeto }\end{array}$ & $\begin{array}{l}\text { PB_INFORMAÇÕES_BÁSICAS_DO_P } \\
\text { ROJETO 1098516.pdf }\end{array}$ & $\begin{array}{c}14 / 11 / 2018 \\
09: 04: 03\end{array}$ & & Aceito \\
\hline $\begin{array}{l}\text { Projeto Detalhado / } \\
\text { Brochura } \\
\text { Investigador }\end{array}$ & Projeto_detalhado.docx & $\begin{array}{c}14 / 11 / 2018 \\
08: 57: 33\end{array}$ & $\begin{array}{l}\text { Karina Brosco } \\
\text { Mendes }\end{array}$ & Aceito \\
\hline Outros & Carta_enc_CEP.pdf & $\begin{array}{c}09 / 11 / 2018 \\
00: 49: 06\end{array}$ & $\begin{array}{l}\text { Karina Brosco } \\
\text { Mendes }\end{array}$ & Aceito \\
\hline Outros & Term_compr_conf_dados.pdf & $\begin{array}{c}09 / 11 / 2018 \\
00: 46: 44\end{array}$ & $\begin{array}{l}\text { Karina Brosco } \\
\text { Mendes }\end{array}$ & Aceito \\
\hline Outros & Term_compr_resultados.pdf & $\begin{array}{c}09 / 11 / 2018 \\
00: 44: 52\end{array}$ & $\begin{array}{l}\text { Karina Brosco } \\
\text { Mendes }\end{array}$ & Aceito \\
\hline $\begin{array}{l}\text { TCLE / Termos de } \\
\text { Assentimento / } \\
\text { Justificativa de } \\
\text { Ausência } \\
\end{array}$ & TCLE_pais_resp.docx & $\begin{array}{c}09 / 11 / 2018 \\
00: 42: 01\end{array}$ & $\begin{array}{l}\text { Karina Brosco } \\
\text { Mendes }\end{array}$ & Aceito \\
\hline $\begin{array}{l}\text { TCLE / Termos de } \\
\text { Assentimento / } \\
\text { Justificativa de } \\
\text { Ausência }\end{array}$ & TCLE_adulto.docx & $\begin{array}{c}09 / 11 / 2018 \\
00: 41: 22\end{array}$ & $\begin{array}{l}\text { Karina Brosco } \\
\text { Mendes }\end{array}$ & Aceito \\
\hline $\begin{array}{l}\text { Declaração de } \\
\text { Instituição e } \\
\text { Infraestrutura }\end{array}$ & Form_cadast_HRAC.pdf & $\begin{array}{c}09 / 11 / 2018 \\
00: 38: 48\end{array}$ & $\begin{array}{l}\text { Karina Brosco } \\
\text { Mendes }\end{array}$ & Aceito \\
\hline $\begin{array}{l}\text { Declaração de } \\
\text { Pesquisadores }\end{array}$ & Term_pesq_responsavel.pdf & $\begin{array}{c}09 / 11 / 2018 \\
00: 36: 48\end{array}$ & $\begin{array}{l}\text { Karina Brosco } \\
\text { Mendes }\end{array}$ & Aceito \\
\hline Folha de Rosto & Folh_rosto.pdf & $\begin{array}{c}09 / 11 / 2018 \\
00: 32: 05\end{array}$ & $\begin{array}{l}\text { Karina Brosco } \\
\text { Mendes }\end{array}$ & Aceito \\
\hline
\end{tabular}

\section{Situação do Parecer:}

Aprovado

\section{Necessita Apreciação da CONEP:}

Não

Endereço: Rua Silvio Marchione, 3-20

Bairro: Vila Nova Cidade Universitária

UF: SP

Município: BAURU

Telefone: (14)3235-8421

Fax: (14)3234-7818

CEP: $17.012-900$ 


\section{USP - HOSPITAL DE REABILITAÇÃO DE ANOMALIAS CRANIOFACIAIS}

Continuação do Parecer: 3.046 .495

BAURU, 29 de Novembro de 2018

Assinado por:

Renata Paciello Yamashita

(Coordenador(a)) 


\section{ANEXO B - Questionário Nijmegen Cochlear Implantation Questionnaire (NCIQ) traduzido e adaptado culturalmente para o Português Brasileiro por Santos, Couto e Martinho-Carvalho (2017)}

Por favor, responda às seguintes 60 questões sobre a situação do IC (apenas utilize "não aplicável" [N/A] se nenhuma das possibilidades for aplicável).

\begin{tabular}{|c|c|c|c|c|c|c|}
\hline \multirow{2}{*}{\multicolumn{7}{|c|}{\begin{tabular}{|l|} 
1. Você consegue ouvir ruídos de fundo (descarga da \\
privada, aspirador de pó)?
\end{tabular}}} \\
\hline & & & & & & \\
\hline \multicolumn{7}{|l|}{$\begin{array}{l}\text { 2. O seu problema auditivo atrapalha o seu contato } \\
\text { com pessoas de audição normal? }\end{array}$} \\
\hline \multicolumn{7}{|l|}{ 3. Se precisar, você consegue sussurrar? } \\
\hline \multicolumn{7}{|l|}{$\begin{array}{l}\text { 4. Você se sente à vontade em grupo apesar de seu } \\
\text { problema auditivo? }\end{array}$} \\
\hline \multicolumn{7}{|l|}{$\begin{array}{l}\text { 5. Você consegue ter uma conversa com uma pessoa } \\
\text { em um ambiente silencioso (com ou sem leitura } \\
\text { labial)? }\end{array}$} \\
\hline \multicolumn{7}{|l|}{$\begin{array}{l}\text { 6. O seu problema auditivo Ihe causa grandes } \\
\text { transtornos no trabalho ou no estudo? }\end{array}$} \\
\hline \multicolumn{7}{|l|}{$\begin{array}{l}\text { 7. Você consegue ouvir os passos de outras pessoas } \\
\text { em sua casa (ex: no corredor ou na escada)? }\end{array}$} \\
\hline \multicolumn{7}{|l|}{$\begin{array}{l}\text { 8. O seu problema auditivo Ihe causa grandes } \\
\text { transtornos ao se comunicar com surdos? }\end{array}$} \\
\hline \multicolumn{7}{|l|}{ 9. Se precisar, você consegue gritar? } \\
\hline \multicolumn{7}{|l|}{ 10. O seu problema auditivo lhe incomoda? } \\
\hline \multicolumn{7}{|l|}{$\begin{array}{l}\text { 11. Você consegue ter uma conversa com } 2 \text { ou mais } \\
\text { pessoas em um ambiente silencioso (com ou sem } \\
\text { leitura labial)? }\end{array}$} \\
\hline \multicolumn{7}{|l|}{$\begin{array}{l}\text { 12. O seu problema auditivo Ihe causa grandes } \\
\text { transtornos no trânsito? }\end{array}$} \\
\hline \multicolumn{7}{|l|}{$\begin{array}{l}\text { 13. Você consegue ouvir quando o seu próprio } \\
\text { telefone ou campainha tocam? }\end{array}$} \\
\hline \multicolumn{7}{|l|}{$\begin{array}{l}\text { 14. O seu problema auditivo lhe causa grandes } \\
\text { transtornos quando você está com um grupo de } \\
\text { pessoas (passatempo, esportes, férias)? }\end{array}$} \\
\hline \multicolumn{7}{|l|}{$\begin{array}{l}\text { 15. Você consegue ser entendido por desconhecidos } \\
\text { sem o uso de gestos? }\end{array}$} \\
\hline \multicolumn{7}{|l|}{$\begin{array}{l}\text { 16. Você fica irritado se não consegue acompanhar } \\
\text { uma conversa? }\end{array}$} \\
\hline \multicolumn{7}{|l|}{$\begin{array}{l}\text { 17. Quando você está em uma loja cheia de pessoas, } \\
\text { você consegue entender o vendedor? }\end{array}$} \\
\hline \multicolumn{7}{|l|}{$\begin{array}{l}\text { 18. O seu problema auditivo Ihe causa grandes } \\
\text { transtornos durante atividades de lazer? }\end{array}$} \\
\hline \multicolumn{7}{|l|}{$\begin{array}{l}\text { 19. Quando você está ocupado em casa, você } \\
\text { consegue ouvir (e não sentir) uma batida forte na } \\
\text { porta de entrada? }\end{array}$} \\
\hline \multicolumn{7}{|l|}{$\begin{array}{l}\text { 20. A sua dificuldade auditiva lhe causa grandes } \\
\text { problemas no seu relacionamento com as pessoas } \\
\text { com quem você vive (sua família/ parceiro(a))? }\end{array}$} \\
\hline \multicolumn{7}{|l|}{$\begin{array}{l}\text { 21. Você consegue adaptar a sua voz a situações } \\
\text { diferentes (ambiente barulhento ou ambiente } \\
\text { silencioso)? }\end{array}$} \\
\hline \multicolumn{7}{|l|}{ 22. Você evita falar com desconhecidos? } \\
\hline \multicolumn{7}{|l|}{ 23. Você consegue apreciar músicas? } \\
\hline \multicolumn{7}{|l|}{$\begin{array}{l}\text { 24. O seu problema auditivo Ihe causa grandes } \\
\text { transtornos na sua rotina em casa? }\end{array}$} \\
\hline \multicolumn{7}{|l|}{$\begin{array}{l}\text { 25. Você consegue ouvir carros se aproximando no } \\
\text { trânsito? }\end{array}$} \\
\hline \multicolumn{7}{|l|}{$\begin{array}{l}\text { 26. Quando está em grupo, você é deixado de lado } \\
\text { devido ao seu problema auditivo? }\end{array}$} \\
\hline \multicolumn{7}{|l|}{$\begin{array}{l}\text { 27. Desconhecidos conseguem perceber pela sua voz } \\
\text { que você é surdo ou deficiente auditivo? }\end{array}$} \\
\hline $\begin{array}{l}\text { 28. Você pede para outras pessoas falarem mais alto } \\
\text { ou de forma mais clara se estiverem falando muito } \\
\text { baixo ou sem clareza? }\end{array}$ & & & & & & \\
\hline
\end{tabular}




\section{LISTA DE CÓDIGOS}

\begin{tabular}{|l|c|c|}
\hline \multicolumn{1}{|c|}{ Domínio } & Questão & Recodificação (pontuação de 6) \\
\hline Físico & & \\
\hline Percepção básica de sons & $1,7,13,19,25,31,37,42,47,52$ & 50 \\
\hline Percepção avançada de sons & $5,11,17,23,29,35,40,45,50,60$ & 27 \\
\hline Produção da fala & $3,9,15,21,27,33,56,57,58,59$ & \\
\hline Psicológico & & $10,16,22,34,39,49,54$ \\
\hline Autoestima & $4,10,16,22,28,34,39,44,49,54$ & \\
\hline Social & & $6,12,18,24,30,36,41,46,51,55$ \\
\hline Limitações em atividades & $6,12,18,24,30,36,41,46,51,55$ & $2,8,14,20,26,38,43,48,53$ \\
\hline Interações sociais & $2,8,14,20,26,32,38,43,48,53$ & \\
\hline
\end{tabular}


ANEXO C - Children with cochlear implants: parental perspectives (CCIPP) traduzido, adaptado e validado para o Português Brasileiro por Fortunato-Tavares et al. (2012)

\title{
Crianças com implante coclear: perspectivas dos pais
}

\author{
Desenvolvido por Sue Archibold e Mark Lutman. \\ Development support by The Royal National Institute for Deaf People. \\ Traduzido e adaptado para o Português Brasileiro por Talita Fortunato- Tavares, Debora Befi-Lopes, Ricardo F. \\ Bento e Claudia R. F. Andrade.
}

\section{Nome da Criança:}

Gostaríamos de ajudar a responder este questionário.

Reconhecemos que você está na melhor posição para descrever o que o implante coclear significa para sua criança e para sua familia.

Este questionário é direcionado para os pais. Ele deve ser respondido após pelo menos um ano de uso do implante coclear.

Ele consiste de frases com as quais você pode concordar ou discordar.

Você deve marcar uma das cinco caixas para indicar sua opinião: concordo plenamente, concordo, nem concordo nem discordo, discordo, discordo plenamente.

As frases foram baseadas em entrevistas com pais que possuem filhos com implante coclear.

Por favor, forneça sua resposta inicial ao invés de ficar pensando por um longo período.

Por favor, marque somente uma caixa por frase e não deixe nenhuma sem responder.

Se alguma frase não se aplicar à sua situação como, por exemplo, se não houver irmãos, por favor, escreva 'N/A' (significando não aplicável) para sabermos que você não se esqueceu de respondê-la.

Muito obrigado por usar seu tempo para responder ao questionário.

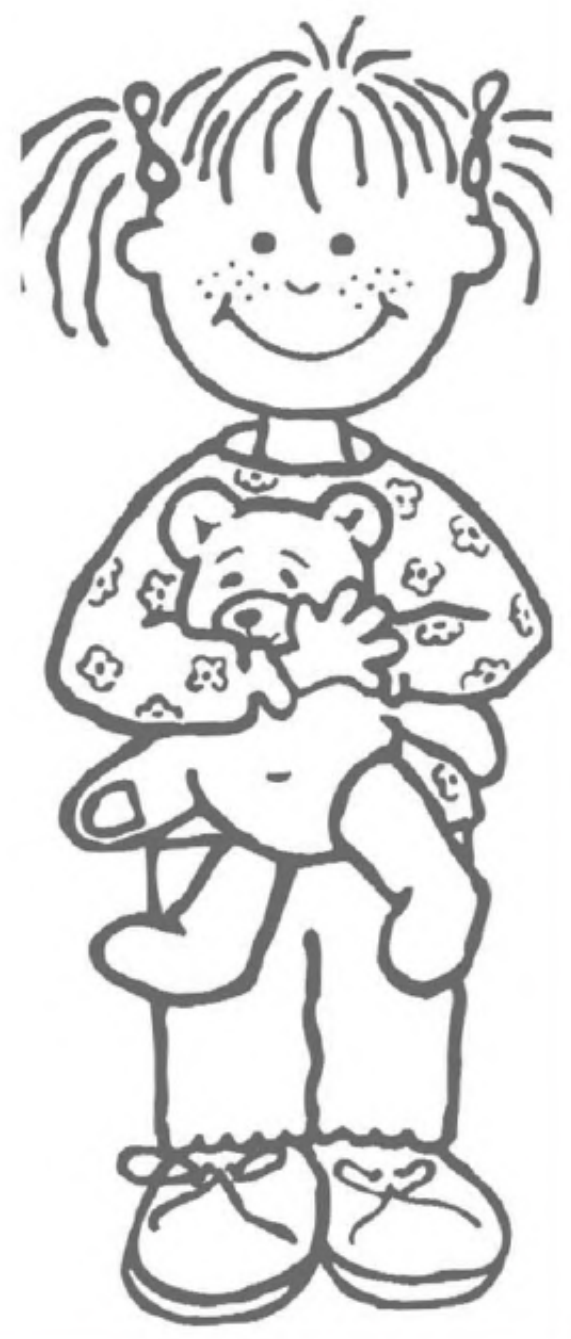




\section{Perspectivas e experiências dos pais $\begin{gathered}\text { Concordo } \\ \text { Plenamente }\end{gathered}$ concordo $\begin{gathered}\text { Nem } \\ \text { concordo } \\ \text { nem } \\ \text { Discordo }\end{gathered} \quad$ Discordo $\begin{gathered}\text { Discordo } \\ \text { Plenamente }\end{gathered}$}

1. A comunicação é difícil mesmo com pessoas que ela conhece bem.

2. Imediatamente após a cirurgia a habilidade de minha filha de se comunicar era pior que agora.

3. A ajuda que eu forneço a ela se tornou mais produtiva agora que ela tem o implante.

4. Antes da cirurgia ela não apresentava benefício nenhum com as próteses auditivas.

5. Ela não tem uma relação próxima com os avôs

6. Ela é totalmente dependente do implante o tempo todo.

7. Ela sabe quando eu quero chamar sua atenção porque ela consegue me ouvir chamá-la.

8. Eu me preocupo que o implante quebre.

9. Ela não está apta para a escola regular.

10. Tem sido um problema conseguir alguém para cuidar da família quando vamos ao Centro de Implante.

11. $\overline{\text { progresso durante os primeiros meses pareceu muito }}$ devagar.

12. Quase nunca eu posso deixá-la fazer alguma coisa sozinha.

13. O programa no Centro de Implante deveria enfatizar fala e audiçăo.

14. Eu me preocupo que ela irá me culpar pela decisão de implantar.

15. Ela tem precisado de mais ajuda minha desde que recebeu o implante.

16. Ela ainda demonstra sinais de frustração em seu comportamento.

17. Eu me preocupo que minha filha será rejeitada pela Comunidade Surda por causa do implante.

18. A qualidade da fala dela me preocupa.

19. Muita ajuda no começo do tratamento significa que a criança precisará de menos ajuda mais tarde.

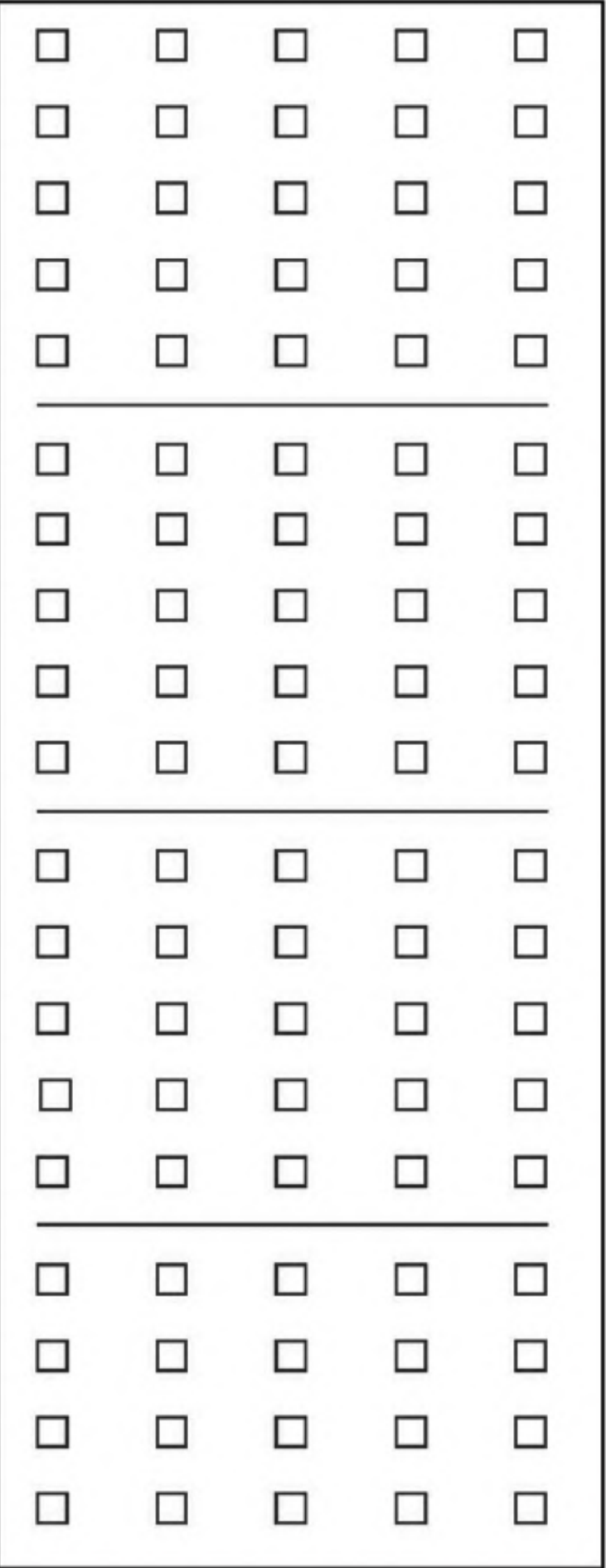




\section{Perspectivas e experiências dos pais}

20. Eu tenho mais tempo para mim devido ao aumento da independência de minha filha.

21. Somente equipes experientes devem realizar cirurgias de implante coclear.

22. Os custos para se locomover até o Centro de Implante são um problema.

23. Na escola ela está acompanhando bem as crianças da sua idade.

24. O apoio em Libras ou sinais é útil por um periodo considerável após o implante.

25. Eu gostaria de participar de encontros com outras famílias que tem criança implantada.

26. O progresso após o implante tem excedido minhas expectativas.

27. Agora nós podemos conversar mesmo que ela não consiga ver meu rosto (por exemplo, no carro ou no escuro).

28. Tomar a decisão de realizar a cirurgia foi a parte mais dificil para mim.

29. A espera pelos resultados da avaliação antes da cirurgia foi um período difícil para mim.

30. Antes do implante ela estava socialmente isolada.

31. A escola local e os serviços de apoio supriram adequadamente todas as nossas necessidades relacionadas ao uso do implante na escola.

32. Uma mudança significativa tem sido a melhora na autoconfiança de minha filha.

33. Ela era muito dependente de nós antes do implante.

34. Nós sentimos necessidade de apoio do Centro de Implante com relação ao futuro de minha filha.

35. Agora ela se diverte ouvindo música, assistindo TV, ou jogando video-game.

36. Nós somos dependentes do Centro de Implante para apoio técnico do implante.

37. Eu me preocupo com o futuro de minha filha relativo à escola.

\begin{tabular}{|c|c|c|c|c|}
\hline $\begin{array}{l}\text { Concordo } \\
\text { Plenamente }\end{array}$ & concordo & $\begin{array}{l}\text { Nem } \\
\text { Concordo } \\
\text { nem } \\
\text { Discordo }\end{array}$ & Discordo & $\begin{array}{l}\text { Discordo } \\
\text { Plenamente }\end{array}$ \\
\hline$\square$ & Г & $\square$ & [ & $\square$ \\
\hline$\square$ & Б & $\square$ & Б & $\square$ \\
\hline$\square$ & $\square$ & $\square$ & $\square$ & $\square$ \\
\hline$\square$ & ए & $\square$ & ए & $\square$ \\
\hline$\square$ & [ & $\square$ & ए & $\square$ \\
\hline$\square$ & Б & $\square$ & $\square$ & $\square$ \\
\hline$\square$ & [ & $\square$ & [ & $\square$ \\
\hline$\square$ & L & $\square$ & ए & $\square$ \\
\hline$\square$ & [ & $\square$ & $\square$ & $\square$ \\
\hline$\square$ & [ & $\square$ & $\square$ & $\square$ \\
\hline$\square$ & $\square$ & $\square$ & [ & $\square$ \\
\hline$\square$ & L & $\square$ & $\square$ & $\square$ \\
\hline$\square$ & L & $\square$ & $\square$ & $\square$ \\
\hline$\square$ & [ & $\square$ & $\square$ & $\square$ \\
\hline$\square$ & $\square$ & $\square$ & $\square$ & $\square$ \\
\hline$\square$ & $\square$ & $\square$ & $\square$ & $\square$ \\
\hline$\square$ & $\square$ & $\square$ & $\square$ & $\square$ \\
\hline$\square$ & 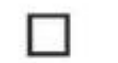 & $\square$ & $\square$ & $\square$ \\
\hline
\end{tabular}




\section{Perspectivas e experiências dos pais}

38. O processo de cirurgia não foi mais invasivo do que eu esperava.

39. Ela não faz amigos fora da familia facilmente.

40. É essencial que minha filha esteja encorajada a usar o processador o tempo todo.

41. Ela é sociável dentro da familia.

42. Uma atitude positiva é de grande ajuda para o sucesso com o uso do implante.

43. Ajustes e checagens regulares do sistema de implante são essenciais.

44. Pelo menos uma visita por ano de funcionários do Centro de Implante na casa/escola é essencial.

45. Ela compartilha situações em familia mais frequentemente agora do que antes do implante.

46. Antes de proceder à cirurgia pais deveriam obter o maior número de informaçöes possivel sobre o dispositivo.

47. Ela é tão independente quanto a maioria das crianças da idade dela.

48. Pais deveriam ter a opção de usar língua de sinais na escola.

49. Foi útil conhecer outra família com criança implantada antes de decidir implantar.

50. Eu estou feliz com o progresso dela na escola.

51. Agora eu posso deixá-la brincar fora porque ela está ciente dos sons do trânsito.

52. O fator mais importante em escolher um dispositivo de implante é a confiabilidade.

53. Ela ainda está inapta a lidar com situações novas.

54. Eu estou confiante que estimulação elétrica a longo prazo não será um problema.

55. Todo o processo de implantação ainda é estressante.

56. Eu esperava que ela falasse assim que colocasse o implante.

\begin{tabular}{|c|c|c|c|c|}
\hline $\begin{array}{l}\text { Concordo } \\
\text { Plenamente }\end{array}$ & Concordo & $\begin{array}{c}\text { Nem } \\
\text { Concordo } \\
\text { nem } \\
\text { Discordo }\end{array}$ & Discordo & $\begin{array}{c}\text { Discordo } \\
\text { Plenamente }\end{array}$ \\
\hline$\square$ & $\square$ & $\square$ & $\square$ & $\square$ \\
\hline$\square$ & $\square$ & $\square$ & $\square$ & $\square$ \\
\hline$\square$ & $\square$ & $\square$ & $\square$ & $\square$ \\
\hline$\square$ & $\square$ & $\square$ & $\square$ & $\square$ \\
\hline$\square$ & $\square$ & $\square$ & $\square$ & $\square$ \\
\hline$\square$ & $\square$ & $\square$ & $\square$ & $\square$ \\
\hline$\square$ & $\square$ & $\square$ & $\square$ & $\square$ \\
\hline$\square$ & $\square$ & $\square$ & $\square$ & $\square$ \\
\hline$\square$ & $\square$ & $\square$ & $\square$ & $\square$ \\
\hline$\square$ & $\square$ & $\square$ & $\square$ & $\square$ \\
\hline$\square$ & $\square$ & $\square$ & $\square$ & $\square$ \\
\hline$\square$ & $\square$ & $\square$ & $\square$ & $\square$ \\
\hline$\square$ & $\square$ & $\square$ & $\square$ & $\square$ \\
\hline$\square$ & $\square$ & $\square$ & $\square$ & $\square$ \\
\hline$\square$ & $\square$ & $\square$ & $\square$ & $\square$ \\
\hline$\square$ & $\square$ & $\square$ & $\square$ & $\square$ \\
\hline$\square$ & $\square$ & $\square$ & $\square$ & $\square$ \\
\hline$\square$ & $\square$ & $\square$ & $\square$ & $\square$ \\
\hline$\square$ & $\square$ & $\square$ & $\square$ & $\square$ \\
\hline
\end{tabular}


Perspectivas e experiências dos pais

\begin{tabular}{|ccc|}
\hline $\begin{array}{c}\text { Concordo } \\
\text { Plenamente }\end{array}$ Concordo & $\begin{array}{c}\text { Nem } \\
\text { Concordo } \\
\text { nem } \\
\text { Discordo }\end{array}$ & Discordo \\
\hline
\end{tabular}

57. Eu me preocupo que agora ela não faça parte nem do mundo surdo nem do mundo ouvinte.

58. Foi importante para mim que minha filha pudesse ouvir os sons do trânsito por motivos de segurança.

59. O comportamento dela melhorou depois do implante.

60. Agora eu acredito que minha filha terá perspectivas de emprego razoáveis.

61. Ela se tornou argumentadora desde que recebeu o implante.

62. Os pais de uma criança com implante precisam ser pacientes já que os benefícios podem demorar a aparecer.

63. Tem sido dificil sair do trabalho para as consultas no Centro de Implante.

64. Ela é menos frustrada agora do que antes do implante.

65. Ela faz parte de relações familiares do mesmo modo que outros membros da familia.

66. Eu acho mais fácil me comunicar com ela pela fala do que por sinais.

67. Eu dou a mesma quantidade de ajuda agora do que antes do implante.

68. Eu optei pelo implante para que minha filha pudesse ter a chance de fazer parte do mundo ouvinte.

69. Ela é totalmente dependente do implante na escola.

70. Ela continua sendo uma criança feliz e é muito agradávele feliz de estar perto dela.

71. O desenvolvimento de linguagem oral (fala) tem se desenvolvido otimamente.

72. Agora ela é falante e envolve outros em conversas.

73. Outras crianças da família ficam ressentidas, incomodadas com o tempo e a atenção tomados pelo implante.

(Marque aqui se não há outras crianças na familia)

74. A relação dela com irmãos ou irmãs tem melhorado.

(Marque aqui se não há irmãos ou irmãs.)

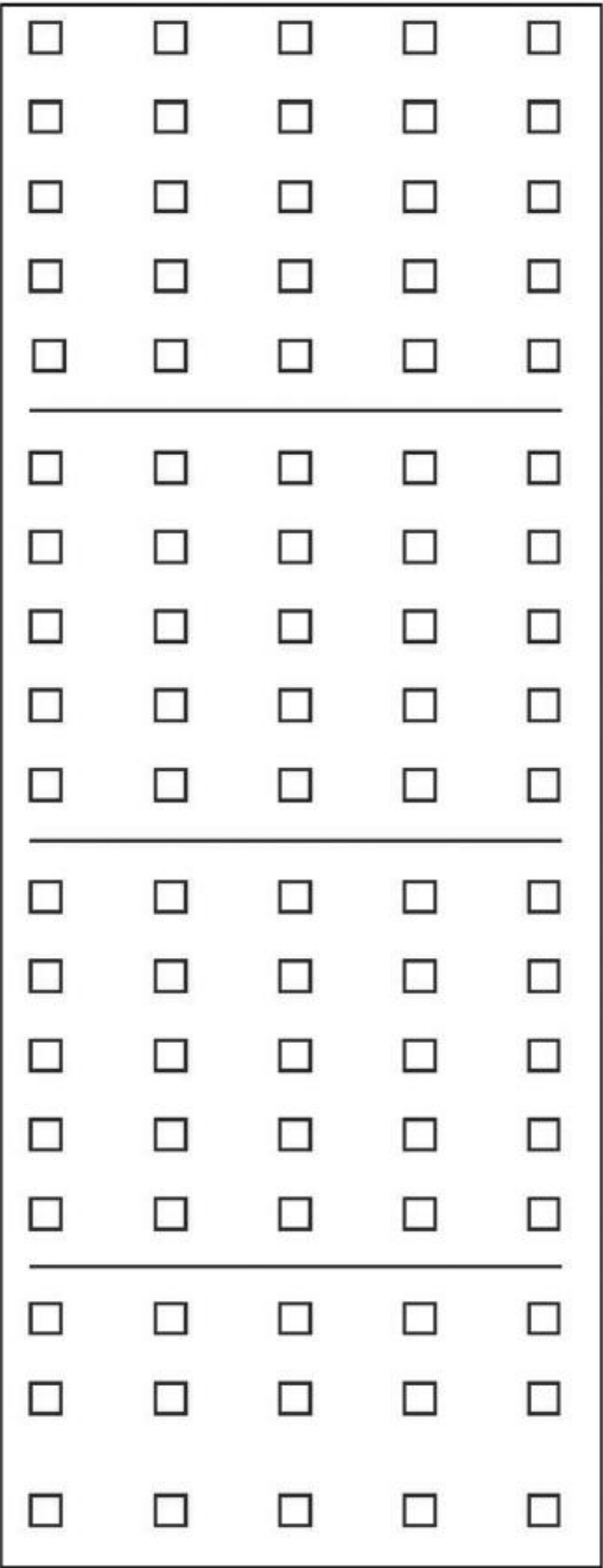




\section{Muito obrigado por preencher o questionário!}

Data de nascimento da criança

Seu nome

Sua relação com a criança

(pai, mãe, responsável pela criança etc.)

Mês e ano da cirurgia

Data de hoje

Por favor, use este espaço para fazer comentários sobre observações não abordadas neste questionário. 


\section{Crianças com implante coclear: perspectivas dos pais}

Desenvolvido por Sue Archibold e Mark Lutman.

Development support by The Royal National Institute for Deaf People.

Traduzido e adaptado para o Português Brasileiro por Talita Fortunato- Tavares, Debora Befi-Lopes, Ricardo F. Bento e Claudia R. F. Andrade.

\section{Nome da Criança:}

Gostaríamos de ajudar a responder este questionário.

Reconhecemos que você está na melhor posição para descrever o que o implante coclear significa para sua criança e para sua família.

Este questionário é direcionado para os pais. Ele deve ser respondido após pelo menos um ano de uso do implante coclear.

Ele consiste de frases com as quais você pode concordar ou discordar.

Você deve marcar uma das cinco caixas para indicar sua opiniäo: concordo plenamente, concordo, nem concordo nem discordo, discordo, discordo plenamente.

As frases foram baseadas em entrevistas com pais que possuem filhos com implante coclear.

Por favor, forneça sua resposta inicial ao invés de ficar pensando por um longo período.

Por favor, marque somente uma caixa por frase e não deixe nenhuma sem responder.

Se alguma frase não se aplicar à sua situação como, por exemplo, se não houver irmãos, por favor, escreva ' $N / A$ ' (significando não aplicável) para sabermos que você não se esqueceu de respondê-la.

Muito obrigado por usar seu tempo para responder ao questionário.

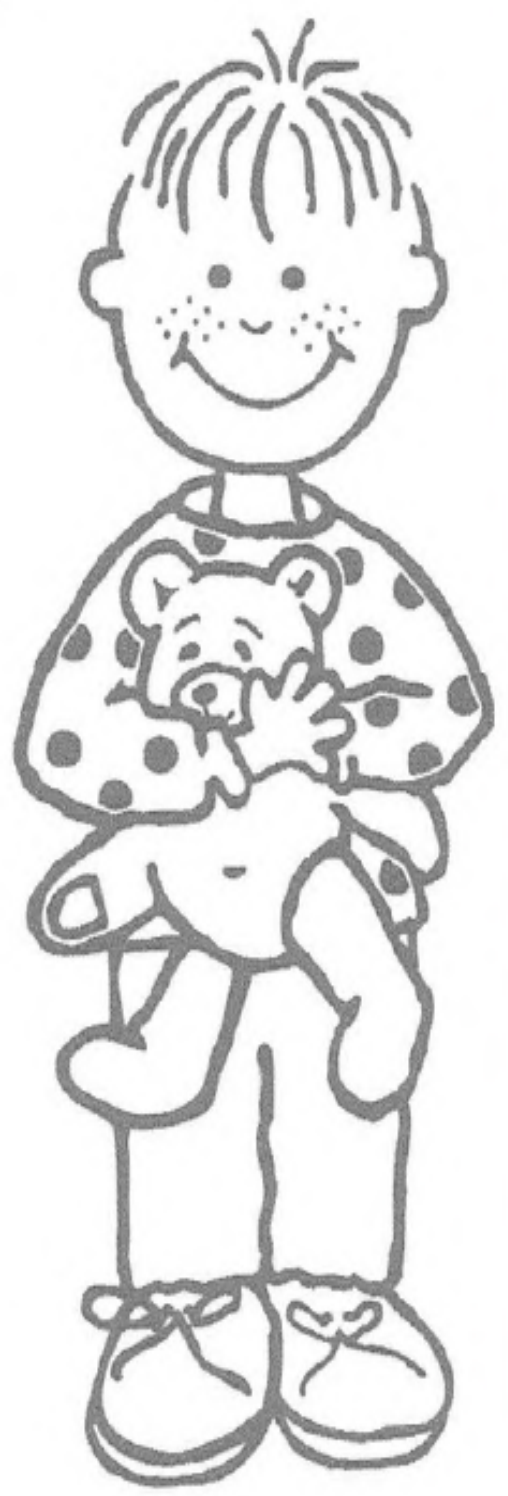




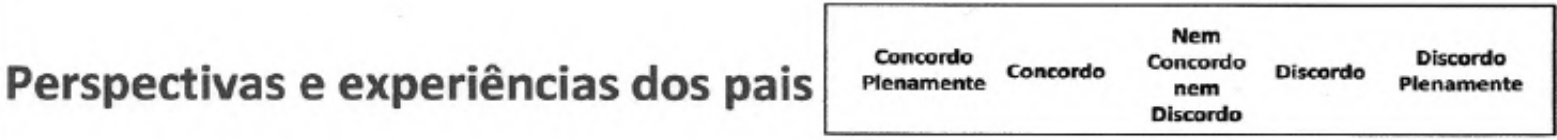

\section{A comunicaçăo é difícil mesmo com pessoas que ele conhece} bem.

2. Imediatamente após a cirurgia a habilidade de minha filha de se comunicar era pior que agora.

3. A ajuda que eu forneço a ele se tornou mais produtiva agora que ele tem o implante.

4. Antes da cirurgia ele não apresentava benefício nenhum com as próteses auditivas.

5. Ele não tem uma relação próxima com os avôs.

6. Ele é totalmente dependente do implante o tempo todo.

7. Ele sabe quando eu quero chamar sua atenção porque ele consegue me ouvir chamá-lo.

8. Eu me preocupo que o implante quebre.

9. Ele näo está apto para a escola regular.

10. Tem sido um problema conseguir alguém para cuidar da familia quando vamos ao Centro de Implante.

11. 0 progresso durante os primeiros meses pareceu muito devagar.

12. Quase nunca eu posso deixá-lo fazer alguma coisa sozinho.

13. O programa no Centro de Implante deveria enfatizar fala e audição.

14. Eu me preocupo que ele irá me culpar pela decisão de implantar.

15. Ele tem precisado de mais ajuda minha desde que recebeu o implante.

16. Ele ainda demonstra sinais de frustração em seu comportamento.

17. Eu me preocupo que meu filho será rejeitado pela Comunidade Surda por causa do implante.

18. A qualidade da fala dele me preocupa.

19. Muita ajuda no começo do tratamento significa que a criança precisará de menos ajuda mais tarde.
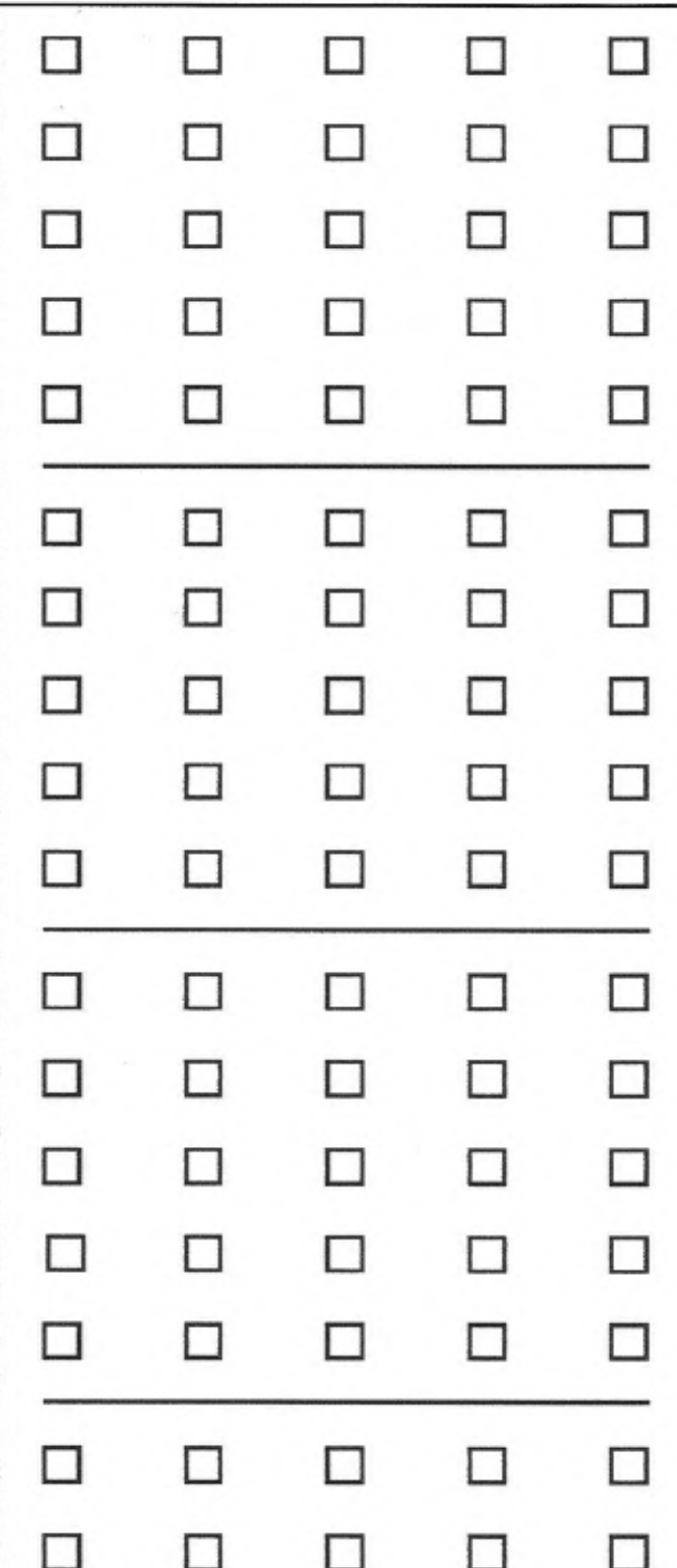


\section{Perspectivas e experiências dos pais}

20. Eu tenho mais tempo para mim devido ao aumento da independência de meu filho.

21. Somente equipes experientes devem realizar cirurgias de implante coclear.

22. Os custos para se locomover até o Centro de Implante são um problema.

23. Na escola ele está acompanhando bem as crianças da sua idade.

24. 0 apoio em Libras ou sinais é útil por um periodo considerável após o implante.

25. Eu gostaria de participar de encontros com outras famílias que tem uma criança implantada.

26. O progresso após o implante tem excedido minhas expectativas.

27. Agora nós podemos conversar mesmo que ele não possa ver meu rosto (por exemplo, no carro ou no escuro).

28. Tomar a decisão de realizar a cirurgia foi a parte mais difícil para mim.

29. A espera pelos resultados da avaliação antes da cirurgia foi um periodo dificil para mim.

30. Antes do implante ele estava socialmente isolado.

31. A escola local e os serviços de apoio supriram adequadamente todas as nossas necessidades relacionadas ao uso do implante na escola.

32. Uma mudança significativa tem sido a melhora na autoconfiança de meu filho.

33. Ele era muito dependente de nós antes do implante.

34. Nós sentimos necessidade de apoio do Centro de Implante com relaçăo ao futuro de meu filho.

35. Agora ele se diverte ouvindo música, assistindo TV, ou jogando video-game.

36. Nós somos dependentes do Centro de Implante para apoio técnico do implante.

37. Eu me preocupo com o futuro de meu filho relativo à escola.

\begin{tabular}{|c|c|c|c|c|}
\hline $\begin{array}{l}\text { Concordo } \\
\text { Plenamente }\end{array}$ & Concordo & $\begin{array}{c}\text { Nem } \\
\text { Concordo } \\
\text { nem } \\
\text { Discordo }\end{array}$ & Discordo & $\begin{array}{c}\text { Discordo } \\
\text { Plenamente }\end{array}$ \\
\hline
\end{tabular}

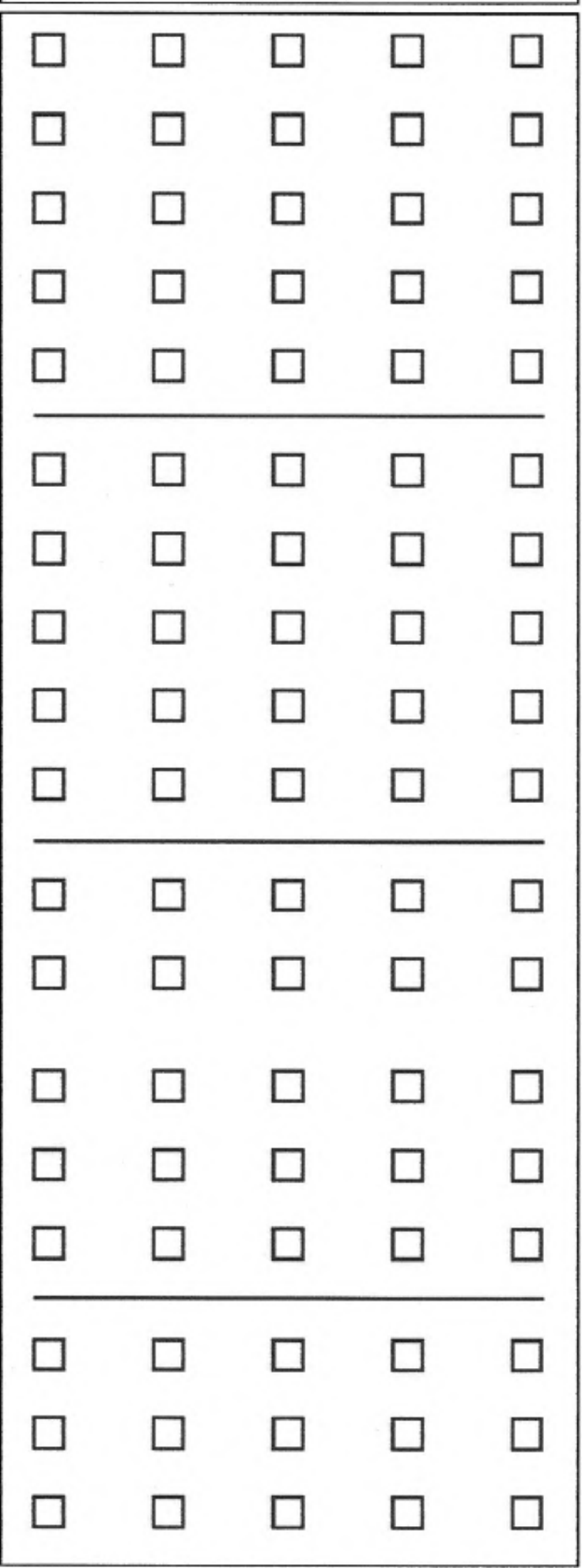




\section{Perspectivas e experiências dos pais}

\begin{tabular}{|c|c|c|c|c|}
\hline $\begin{array}{l}\text { Concordo } \\
\text { Plenamente }\end{array}$ & Concordo & $\begin{array}{c}\text { Nem } \\
\text { Concordo } \\
\text { nem } \\
\text { Discordo }\end{array}$ & Discordo & $\begin{array}{l}\text { Discordo } \\
\text { Plenamente }\end{array}$ \\
\hline
\end{tabular}

38. O processo de cirurgia năo foi mais invasivo do que eu esperava.

39. Ele não faz amigos fora da familia facilmente.

40. É essencial que meu filho esteja encorajado a usar o processador o tempo todo.

41. Ele é sociável dentro da familia.

42. Uma atitude positiva é de grande ajuda para o sucesso com o uso do implante.

43. Ajustes e checagens regulares do sistema de implante säo essenciais.

44. Pelo menos uma visita por ano de funcionários do Centro de Implante na casa/escola é essencial.

45. Ele compartilha situaçőes em familia mais frequentemente agora do que antes do implante.

46. Antes de proceder à cirurgia pais deveriam obter o maior número de informações sobre o dispositivo possivel.

47. Ele é tăo independente quanto a maioria das crianças da idade dele.

48. Pais deveriam ter a opçăo de usar língua de sinais na escola.

49. Foi útil conhecer outra familia com criança implantada antes de decidir implantar.

50. Eu estou feliz com o progresso dele na escola.

51. Agora eu posso deixá-lo brincar fora porque ele está ciente dos sons do trânsito.

52. O fator mais importante em escolher um dispositivo de implante é a confiabilidade.

53. Ele ainda está inapto a lidar com situações novas.

54. Eu estou confiante que estimulação elétrica a longo prazo não será um problema.

55. Todo o processo de implantaçăo ainda é estressante.

56. Eu esperava que ele falasse assim que colocasse o implante.

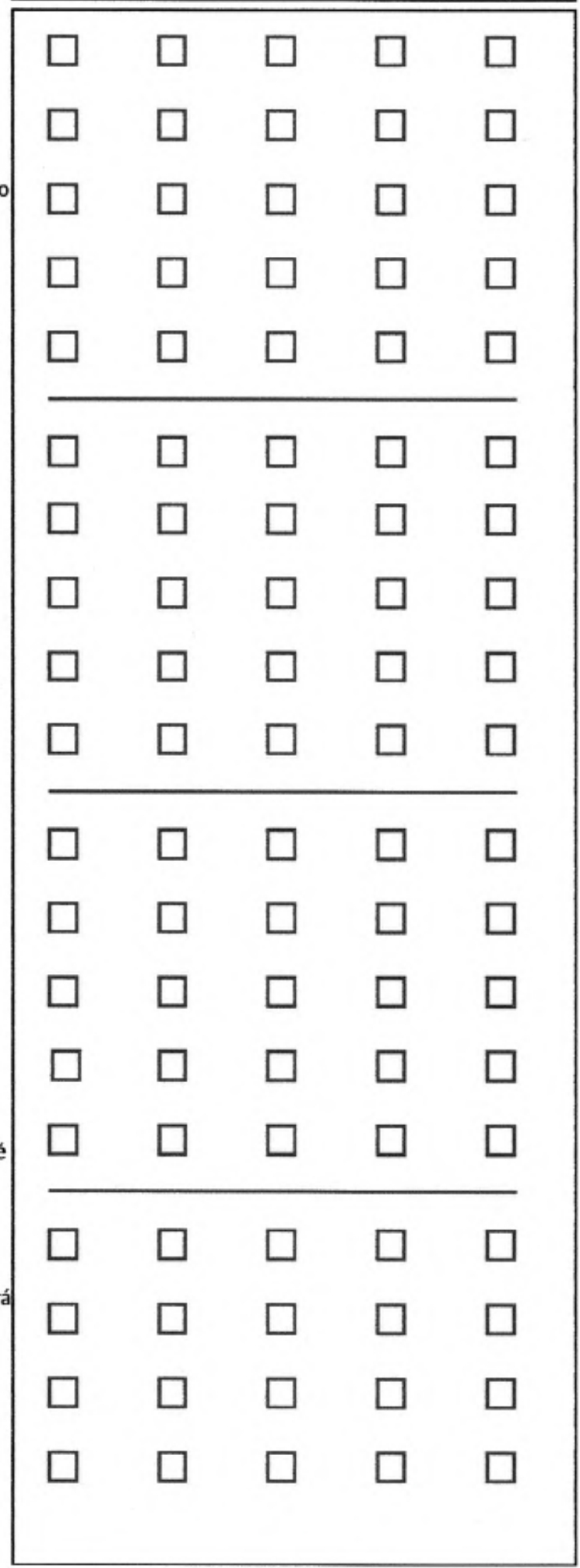




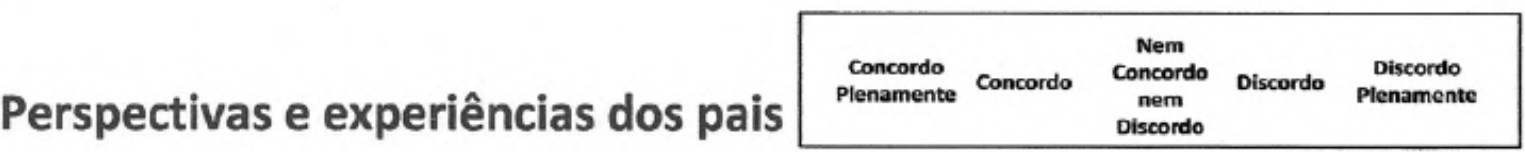

57. Eu me preocupo que agora ele não faça parte nem do mundo surdo nem do mundo ouvinte.

58. Foi importante para mim que o meu filho pudesse ouvir os sons do trânsito por motivos de segurança.

59. 0 comportamento dele melhorou depois do implante.

60. Agora eu acredito que meu filho terá perspectivas de emprego razoáveis.

61. Ele se tornou argumentador desde que recebeu o implante.

62. Os pais de uma criança com implante precisam ser pacientes já que os benefícios podem demorar a aparecer.

63. Tem sido dificil sair do trabalho para as consultas no Centro de Implante.

64. Ele é menos frustrado agora do que antes do implante.

65. Ele faz parte de relaçöes familiares do mesmo modo que outros membros da família.

66. Eu acho mais fácil me comunicar com ele pela fala do que por sinais.

67. Eu dou a mesma quantidade de ajuda agora do que antes do implante.

68. Eu optei pelo implante para que meu filho pudesse ter a chance de fazer parte do mundo ouvinte.

69. Ele é totalmente dependente do implante na escola.

70. Ele continua sendo uma criança feliz e é muito agradável e feliz de estar perto dele.

71. 0 desenvolvimento de linguagem oral (fala) tem se desenvolvido otimamente.

72. Agora ele é falante e envolve outros em conversas.

73. Outras crianças na familia ficam ressentidas, incomodadas com o tempo e a atenção tomados pelo implante.

(Marque aqui se não há outras crianças na familia)

74. A relação dele com irmãos ou irmãs tem melhorado.

(Marque aqui se não há irmãos ou irmãs.)

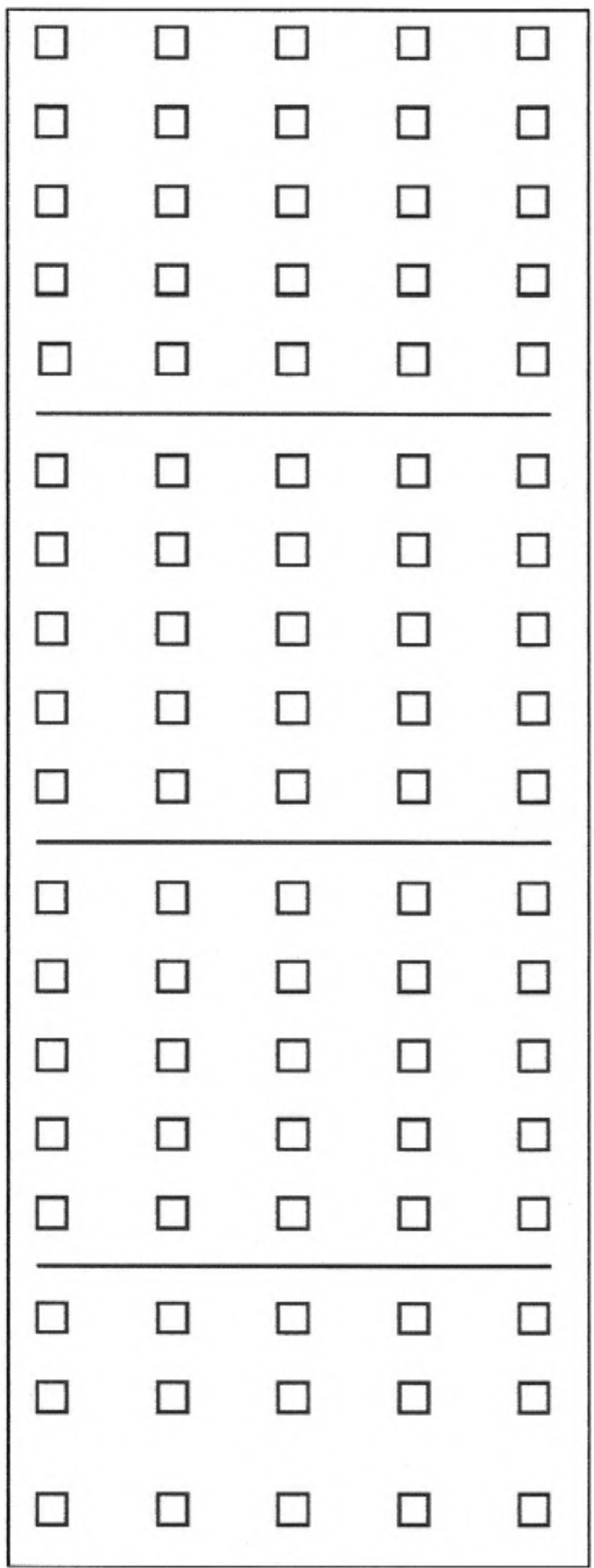




\section{Muito obrigado por preencher o questionário!}

\section{Data de nascimento da criança}

Seu nome

Sua relação com a criança

(pai, mãe, responsável pela criança etc.)

Mês e ano da cirurgia

Data de hoje

Por favor, use este espaço para fazer comentários sobre observações não abordadas neste questionário. 